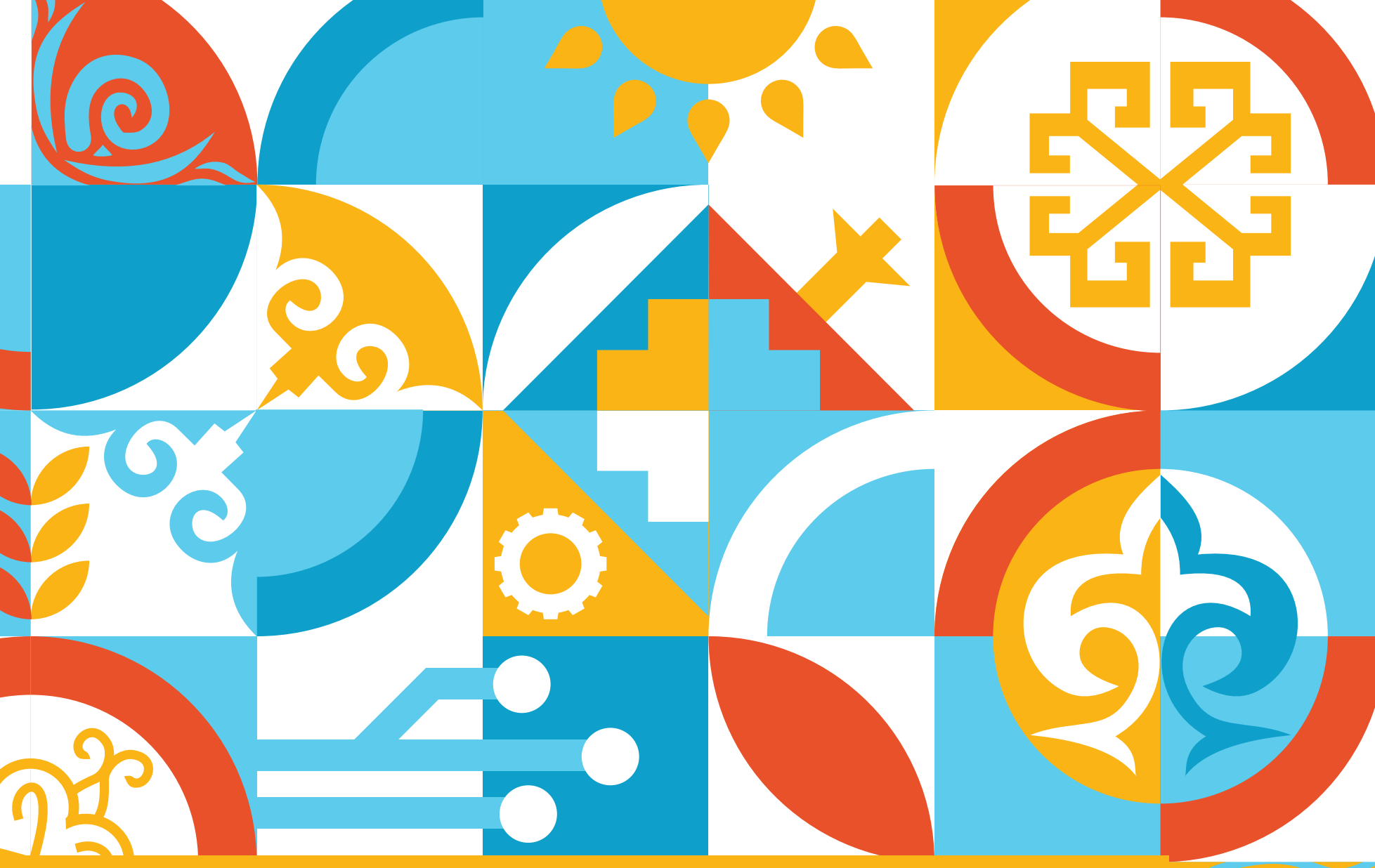

GOOD JOBS FOR INCLUSIVE GROWTH IN CENTRAL ASIA AND THE SOUTH CAUCASUS REGIONAL REPORT

Edited by Giovanni Capannelli and Ravi Kanbur

FEBRUARY 2019 



\section{GOOD JOBS FOR INCLUSIVE GROWTH IN CENTRAL ASIA AND THE SOUTH CAUCASUS REGIONAL REPORT}

Edited by Giovanni Capannelli and Ravi Kanbur

FEBRUARY 2019 
(C) 2019 Asian Development Bank

6 ADB Avenue, Mandaluyong City, 1550 Metro Manila, Philippines

Tel +632632 4444; Fax +6326362444

www.adb.org

Some rights reserved. Published in 2019.

ISBN 978-92-9261-510-9 (print), 978-92-9261-511-6 (electronic)

Publication Stock No. TCS190016-2

DOI: http://dx.doi.org/10.22617/TCS190016-2

The views expressed in this publication are those of the authors and do not necessarily reflect the views and policies of the Asian Development Bank (ADB) or its Board of Governors or the governments they represent.

ADB does not guarantee the accuracy of the data included in this publication and accepts no responsibility for any consequence of their use. The mention of specific companies or products of manufacturers does not imply that they are endorsed or recommended by ADB in preference to others of a similar nature that are not mentioned.

By making any designation of or reference to a particular territory or geographic area, or by using the term "country" in this document, $A D B$ does not intend to make any judgments as to the legal or other status of any territory or area.

This work is available under the Creative Commons Attribution 3.0 IGO license (CC BY 3.0 IGO)

https://creativecommons.org/licenses/by/3.0/igo/. By using the content of this publication, you agree to be bound by the terms of this license. For attribution, translations, adaptations, and permissions, please read the provisions and terms of use at https://www.adb.org/terms-use\#openaccess.

This CC license does not apply to non-ADB copyright materials in this publication. If the material is attributed to another source, please contact the copyright owner or publisher of that source for permission to reproduce it. $\mathrm{ADB}$ cannot be held liable for any claims that arise as a result of your use of the material.

Please contact pubsmarketing@adb.org if you have questions or comments with respect to content, or if you wish to obtain copyright permission for your intended use that does not fall within these terms, or for permission to use the ADB logo.

Corrigenda to ADB publications may be found at http://www.adb.org/publications/corrigenda.

Notes:

In this publication, “\$” refers to United States dollars.

ADB recognizes "China” as the People's Republic of China.

Cover design by Rocilyn Locsin Laccay. 


\section{CONTENTS}

TABLES, FIGURES, AND BOXES

ACKNOWLEDGMENTS $\quad \mathrm{xi}$

ABBREVIATIONS Xiii

EXECUTIVE SUMMARY Xiv

1 INTRODUCTION AND OVERVIEW 1

by Giovanni Capannelli and Ravi Kanbur

1.1 Diversity and Commonality 1

1.2 Regional Features $\quad 6$

1.3 Analytical Framework $\quad 6$

1.4 The Experience of Central Asia and the South Caucasus 8

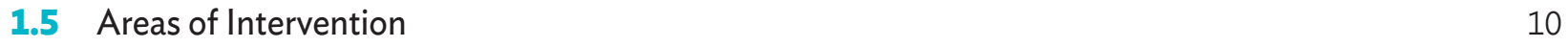

$\begin{array}{lr}\text { Demand-Side Policies } & 10\end{array}$

$\begin{array}{lr}\text { Supply-Side Policies } & 10\end{array}$

Governance and Institutions $\quad 11$

1.6 A Role for Development Partners 13

2 ECONOMIC PERFORMANCE AND PROSPECTS 14 by Bahodir Ganiev

2.1 Growth since Independence $\quad 14$

2.2 Drivers of Growth, 2001-2015 16

Foreign Direct Investment Inflows 17

$\begin{array}{ll}\text { Terms of Trade and Exports } & 17\end{array}$

Remittance Inflows 18

$\begin{array}{ll}\text { Public Investment } & 19\end{array}$

2.3 Progress on Economic and Institutional Reforms 19 
2.4 External Shocks, 2014-2016 22

Policy Responses to External Shocks $\quad 24$

2.5 Growth Prospects in Central Asia and the South Caucasus 26

Challenges and Opportunities $\quad 26$

Policy Scenarios and Growth Implications 28

3 GROWTH AND INCLUSIVENESS 30

by Ravi Kanbur and Juzhong Zhuang

3.1 Inclusive Growth: An Analytical Framework 30

Assets, Returns and Transfers $\quad 31$

Income Growth at the Country Level 32

Sectoral Disaggregation $\quad 33$

3.2 Growth, Poverty, and Inequality in Central Asia and the South Caucasus 34

Growth, Poverty, and Inequality $\quad 34$

Decomposing Income Inequality 39

3.3 Transfers and Social Protection 46

$\begin{array}{lll}3.4 & \text { Summary } & 49\end{array}$

4 GOOD JOBS AND THE LABOR MARKET 50

by Duncan Campbell and Per Ronnås

4.1 Economic Structure and Employment Trends 50

Informal Jobs and the Labor Market $\quad 54$

4.2 Demand Side: Structural Change and Labor Productivity 57

Decomposing Labor Productivity Growth 58

4.3 Good Jobs and Small and Medium-Sized Enterprises 60

4.4 Supply Side: Employment and Skills Development 63

Technical and Vocational Education and Training $\quad 64$

4.5 Labor Market Institutions $\quad 65$

$\begin{array}{ll}\text { Employment-Friendliness } & 66\end{array}$

Inclusiveness $\quad 66$

Labor Mobility $\quad 66$

$\begin{array}{ll}\text { Funding Mechanisms } & 67\end{array}$

$\begin{array}{ll}\text { Flexicurity } & 67\end{array}$

$\begin{array}{lll}\text { 4.6 Structural Reforms } & 67\end{array}$

$\begin{array}{ll}\text { Active Labor Market Policies } & 68\end{array}$

Inclusive Social Benefits and Protection $\quad 68$

$\begin{array}{ll}\text { Information Systems } & 69\end{array}$ 
5 POLICY OPTIONS

by Duncan Campbell, Giovanni Capannelli, Ravi Kanbur, Alessandro Pio, and Per Ronnås

5.1 Policy Framework

5.2 Demand-Side Policies

Economic Diversification

Private Sector Development

Regional Economic Cooperation

5.3 Supply-Side Policies

Human Capital Development

Flexible Contractual Arrangements

Social Protection Schemes

5.4 Institutions and Governance

Labor Market Intermediation

Governance and Corruption

Reducing Informality

6 A ROLE FOR DEVELOPMENT INSTITUTIONS

by Alessandro Pio

6.1 Applying the Study Framework to International Development Assistance

6.2 Responding to the Region's Distinctive Features

6.3 Sharpening Tools

Analytical and Knowledge Base

Country Strategy Preparation and Sector Selection

6.4 Choice and Design in Projects and Interventions 


\section{TABLES, FIGURES, AND BOXES}

\section{TABLES}

2.1 Selected Indicators of Foreign Direct Investment Inflows to Central Asia and the South Caucasus, 2001-2014

2.2 Average Annual Growth Rates of Merchandise Exports of Central Asia and the South Caucasus, 2001-2013

2.3 Remittance Inflows to Central Asia and the South Caucasus, Selected Years

2.4 Projected Average Annual Growth Rate of Real Gross Domestic Product, 2016-2030

3.1 Per Capita GDP and GDP Growth, Central Asia and the South Caucasus and Other Developing Asia, 2001-2015

3.2 Change in Poverty Headcount Ratio for Central Asia and the South Caucasus, from Early 2000s to Mid-2010s

3.3 Income and Consumption-Expenditure-Based Gini Indexes for Selected Countries in Central Asia and the South Caucasus

3.4 Spatial Diversity in Per Capita Income

3.5 Gender Inequality Index for Six Countries in Central Asia and the South Caucasus

3.6 Share of Social Protection Expenditures to Gross Domestic Product, 2012

3.7 Social Protection Indicator by Program, 2012

4.1 Share of Agriculture in Gross Domestic Product and Employment in Central Asia and the South Caucasus

4.2 Informality in the Central Asian and South Caucasus Economies 55

4.3 Costs and Benefits of Labor Market Informality in Central Asia 57 and the South Caucasus

4.4 Economic Sectors' Shares in Central Asia and the South Caucasus 57

4.5 Labor Productivity by Sector in Central Asia and the South Caucasus 58

5.1 Challenges and Opportunities for Good Jobs for Inclusive Growth 70 in Central Asia and the South Caucasus

5.2 Good Jobs for Inclusive Growth in Central Asia and the South Caucasus: 72 A Scheme for Policy Classification

5.3 Raising Factor Productivity: Policy Diagnostic Framework 73

5.4 Addressing Small and Poorly Diversified Domestic Markets: 74 Policy Diagnostic Framework 
A1 Growth Equation Estimation Results for Countries in Central Asia and the South Caucasus, 2016-2030

A2 Key Assumptions Underlying Growth Scenarios

\section{FIGURES}

2.1 Economic Growth in Central Asia and the South Caucasus, 1991-2016 15

2.2 Indices of World Prices for Primary Commodities, 2013-2016 22

2.3 Selected Economic Indicators for the Russian Federation, 2006-2016 23

3.1 Consumption-Based Inequality in Selected Developing Asian Countries, Mid-2010s 36

3.2 Per Capita Gross Domestic Product and Gini Index in Selected Countries, 201037

3.3 Trends in Consumption-Based Gini Index, Selected Countries in Central Asia 38 and the South Caucasus

3.4 Share of Income Inequality Explained by Educational Attainment of Household Head 40

3.5 Share of Income Inequality Explained by Urban-Rural Divide 42

3.6 Decomposition of Income Inequality by Income Source in Selected Central Asian 45 and South Caucasus Countries

3.7 Social Protection Indicator in Selected Countries in Central Asia and the South Caucasus 47 by Poverty Status, 2012

4.1 Evolution of Employment in Central Asia and the South Caucasus by Sector 52

4.2 Evolution of the Service Sector in Central Asia and the South Caucasus 53

4.3 Unemployment in Central Asia and the South Caucasus, 2010 and 2015

4.4 Labor Force Participation Rate in Central Asia and the South Caucasus, 2000 and 2015

4.5 Tax Wedge in Central Asia and the South Caucasus 55

4.6 Wage versus Self-Employment in Central Asia and the South Caucasus, 2014

4.7 Decomposition of Productivity Growth in Central Asia and the South Caucasus 59

6.1 Multilateral Development Assistance Flows to Central Asia and the South Caucasus 93

6.2 Composition of ADB's Portfolio in Central Asia and the South Caucasus 97

6.3 Evolution of ADB's Regional Cooperation Projects in CAREC Countries 101

6.4 Linking a Region: Expansion of CAREC Transport Corridors 102

\section{BOXES}

1 Demographic Snapshot of Central Asia and the South Caucasus 2

1.2 Insight into Labor Migrants from Central Asia and the South Caucasus 4

1.3 Governance, Institutions, and Labor Markets 12 
2.1 Reforms and the Development of Tourism in Georgia 21

2.2 Key Reform Measures in Response to External Shocks 25

3.1 Unequal Returns to Schooling in Georgia 41

3.2 Measuring Spatial Disparity in Uzbekistan 43

4.1 Small and Medium-Sized Enterprise Development 60 and Women's Entrepreneurship in Armenia

4.2 Credit Scoring of Small and Medium-Sized Enterprises 62 and Hometown Investment Trust Funds

4.3 Increasing Gender-Sensitivity in Technical and Vocational Education 64 and Training in Tajikistan

5.1 Promoting Agricultural Development and Inclusive Growth in Kazakhstan 76

5.2 Produce in Georgia: Promoting Good Jobs through Entrepreneurship 77

5.3 State Support for Creating Good Jobs in Small and Medium-Sized Enterprises 78 in Turkmenistan

5.4 Corporate Social Responsibility Development in the Kyrgyz Republic 80

5.5 Technical and Vocational Education and Training in Uzbekistan 82

5.6 Active Labor Market Policies in Armenia 84

5.7 Reintegration Policies for Labor Migrants in Tajikistan 86

5.8 Azerbaijan's System to Improve Government Effectiveness 90

6.1 Using Results-Based Lending to Strengthen National Systems 100 


\title{
FOREWORD
}

\begin{abstract}
$\Lambda \mathrm{s}$ the countries in Central Asia and the South Caucasus (CASC) ${ }^{1}$ transitioned from central planning to Imarket economies in the wake of independence from the Soviet Union in 1991, they first entered a decade of recession and hardship, only to enjoy strong economic performance during 2000-2014. Large inflows of foreign direct investment into natural resources and a related expansion in commodity exports helped the resource-rich countries such as Azerbaijan, Kazakhstan, and Turkmenistan. Remittances from migrant workers boosted resource-poor countries such as Armenia, the Kyrgyz Republic, and Tajikistan.
\end{abstract}

Since then, however, a sharp drop in international commodity prices in 2014 and significantly slower economic growth in the CASC countries' key trading partners - the Russian Federation, Europe, and the People's Republic of China-has set off a structural change in the economic growth models followed across the region. As prices of oil, gas, and other international commodities rapidly declined, CASC countries' balance of payments worsened, as did economic growth. Net export revenues were slashed in resource-rich and remittance-dependent countries alike, although the negative impact was relatively contained in countries such as Georgia and Uzbekistan, which had diversified economic structures to a degree.

All of the CASC countries have since adopted new strategies for economic diversification and renewed efforts to strengthen institutions and governance, promote the private sector, and reduce emerging inequalities. The latter refers especially to spatial inequalities between primary and secondary cities, and urban and rural areas, with the aim to increase resilience and ensure growth that is sustainable in the long term and inclusive.

This study, a joint effort of Asian Development Bank (ADB) staff, international and regional experts, and think tanks from CASC countries, explores prospects for inclusive growth in the region and highlights the central role played by good jobs in achieving this objective. The Central and West Asia Department of ADB focused on the promotion of good jobs and inclusive growth in recognition that labor is the most important earning asset for the vast majority of people in the region.

The study reviews economic performance in the CASC region and discusses prospects through 2030, introducing two growth scenarios related to the adoption of structural reforms for creating good jobs and inclusive growth, and highlighting the importance of adopting a full policy reform scenario.

The picture revealed in the study is mixed. Poverty declined rapidly across the region amid strong growth through 2014, yet the data point to still-high poverty at national poverty lines in four CASC countries. Moreover, reducing income inequality is a key issue for all of the CASC governments if they want to promote inclusive growth, as suggested by the results of an econometric model. Serious questions, meanwhile, surround the sustainability of ongoing social transfer systems, which have, until now, helped keep inequality trends under control.

1 The CASC region includes Armenia, Azerbaijan, Georgia, Kazakhstan, the Kyrgyz Republic, Tajikistan, Turkmenistan, and Uzbekistan. 
Importantly, this study suggests that to promote good jobs for inclusive growth, governments in CASC countries should formulate policies that focus at the same time on the supply and demand sides of the labor market, and strengthen the institutions that can help match supply with demand. Supply-side policies aim to develop human capital, promote flexible contractual arrangements, and ensure social protection. Demand-side policies promote, among other things, economic diversification and private sector development. Policies on institutions and governance help foster inclusive labor market intermediation, formalize employment conditions, and reduce corruption.

Usefully, the study also identifies a role for ADB and other development institutions in promoting good jobs for inclusive growth. It suggests how they can help governments in the region build a solid knowledge foundation and carefully plan their country partnership programs, design and implement projects, and leverage private sector resources. They can also promote regional cooperation.

I hope policy makers and practitioners find this work useful. My deepest gratitude goes to the many experts, scholars, and dedicated ADB staff and consultants who contributed to it. In particular, I would like to thank the editors of this regional report: Giovanni Capannelli, ADB's Kazakhstan Resident Mission country director, who conceived the study and led the ADB team, and Ravi Kanbur, Cornell University professor, who served as the lead scholar for the study.

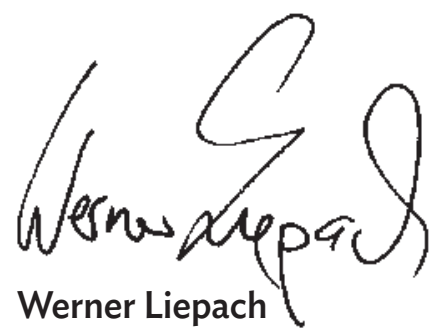

Director General

Central and West Asia Department

Asian Development Bank 


\section{ACKNOWLEDGMENTS}

This regional report was prepared by a dedicated team of Asian Development Bank (ADB) staff and
international consultants as part of ADB's Regional Technical Assistance "Strengthening Knowledge Management in Central and West Asia." The work benefited from a large body of background country and thematic papers, policy briefs, databases, and other materials commissioned to international experts as well as think tanks and scholars from the eight countries of Central Asia and the South Caucasus (CASC): Armenia, Azerbaijan, Georgia, Kazakhstan, the Kyrgyz Republic, Tajikistan, Turkmenistan, and Uzbekistan.

The team of international consultants who helped finalize the regional report was led by Ravi Kanbur, professor, Cornell University (United States). It comprised (in alphabetical order) Duncan Campbell, professor, Cornell University (United States); Bahodir Ganiev, senior advisor, Center for Economic Development, Tashkent (Uzbekistan); Alessandro Pio, scientific advisor, Istituto per gli Studi di Politica Internazionale (Italy); and Per Ronnås, associate professor, Stockholm School of Economics (Sweden). The ADB team was led by Giovanni Capannelli, country director, Kazakhstan Resident Mission, and included several staff from the Central and West Asia Department. These were coordinated under the work of Lyaziza Sabyrova, principal regional economist, and Irene de Roma, associate programs officer, Regional Cooperation and Operations Coordination Division; the Economic Research and Regional Cooperation Department, including main contributions from Juzhong Zhuang, senior economic advisor (former deputy chief economist); the Sustainable Development and Climate Change Department, including main contributions from Sri Wening Handayani, principal social development specialist; and the ADB Institute, including contributions from Peter Morgan, senior consulting economist.

The study benefited from extensive consultations, workshops, and conferences in the eight CASC countries in 2016. Background country papers and policy briefs were reviewed by CASC governments and the regional report by a team of well-known international experts, including Bakhodur Eshonov, international policy consultant, Food and Agriculture Organization of the United Nations Subregional Office for Central Asia (Turkey); Shigeo Katsu, president, Nazarbayev University (Kazakhstan); Safdar Parvez, director, Regional Cooperation and Operations Coordination Division, Central and West Asia Department, ADB; Richard Pomfret, professor, Adelaide University (Australia); Ivan Safranchuk, professor, Moscow State Institute of International Relations (Russian Federation); Mamuka Tsereteli, research director, Central Asia-Caucasus Institute and Silk Road Studies Program, Johns Hopkins University School of Advanced International Studies (United States); Rong Ying, vice-president, China Institute of International Studies (People's Republic of China); and Naoyuki Yoshino, dean, ADB Institute (Japan). 
The think tanks that participated in the study prepared country background papers and policy briefs include (i) American University of Armenia (Armenia), led by Vahram Ghushchyan; (ii) Center for Strategic Studies (Azerbaijan), led by Vusal Gasimli; (iii) International School of Economics at Tbilisi State University (Georgia), led by Lasha Labadze; (iv) Economic Research Institute (Kazakhstan), led by Sara Alpysbayeva; (v) Center for Strategic Research (Tajikistan), led by Farida Muminova; (vi) Institute of Strategic Planning and Economic Development (Turkmenistan), led by Muhammetgeldi Atayev; and (vii) Westminster International University in Tashkent (Uzbekistan), led by Muzaffarjon Ahunov. The background papers on the Kyrgyz Republic were prepared by Roman Mogilevskiy of the University of Central Asia in Bishkek. Several international scholars contributed thematic background papers, including Shanny Campbell (ADB); Megan Counahan (ADB); Elizabeth Duban (ADB consultant); Rufat Efendiyev (Azerbaijan National Academy of Sciences); Sirin Elci (Middle East Technical University, Turkey); Joao Pedro Farina (ADB); Ruth Francisco (ADB consultant); Michael Fuenfzig (International School of Economics at Tbilisi State University); Giap Minh Bui (ADB); George Gotsadze (Curatio International Foundation); Aleksandr Grigoryan (American University of Armenia); Denzel Hankinson (DH Infrastructure); Kiseok Hong (Ewha Womans University); Sevak Hovhanissyan (EV Consulting); Farrukh Irnazarov (Central Asian Development Institute, Uzbekistan); Satoru Kumagai (Institue of Developing Economies, Japan External Trade Organization, Japan); David Lewis (Exeter University); Cristina Martinez (ADB); Inmaculada Martinez (ADB); Keiju Mitsuhashi (ADB); Pundarik Mukhopadhaya (Macquarie University); Antonio Quilloy (University of the Philippines); Akmal Siddiq (ADB); Jacques Silber (Bar-Ilan University, Israel); Guntur Sugiyarto (ADB); Adrian Torres (ADB); Roman Vakulchuk (Central Asian Development Institute, Kazakhstan); Tamara Weyman (ADB consultant); and Guanghua Wan (ADB Institute). The detailed list of papers and respective authors is shown at the end of the report.

Peter Howie, professor, and Zhanna Kapsalyamova, assistant professor, Nazarbayev University (Kazakhstan), prepared the text boxes and commentaries on the regional report and background papers. A team of consultants assisted ADB staff with the study's preparation, including Julius Irving Santos (statistician), Malika Shazagatova (principal coordinator), Turdakun Tashbolotov (coordinator), Damaris Yarcia (lead econometrician), and Marlene Tablante (knowledge management coordinator). Eric Van Zant was the report's economics editor. ADB's Department of Communications, supervised by Anna K. Sherwood, senior communications specialist (Publishing), assisted with editorial and printing work through a team of experts including Ma. Theresa Arago (copy editor), Alvin Tubio (layout and composition artist), Layla Yasmin Amar (proofreader), Ma. Cecilia Abellar (page proof checker), and Ross Laccay (graphic designer). 


\section{ABBREVIATIONS}

ADB Asian Development Bank

ALMP active labor market policy

CAREC Central Asia Regional Economic Cooperation

CASC Central Asia and the South Caucasus

FDI foreign direct investment

GDP gross domestic product

GNI gross national income

IFI international financial institution

ILO International Labour Organization

IMF International Monetary Fund

OECD Organisation for Economic Co-operation and Development

SMEs small and medium-sized enterprises

SOE state-owned enterprise

SPI Social Protection Index

TVET technical and vocational education and training

UNDP United Nations Development Programme 


\section{EXECUTIVE SUMMARY}

The eight countries in Central Asia and the South Caucasus (CASC) have seen their ups and downs in
the past quarter century. Armenia, Azerbaijan, Georgia, Kazakhstan, the Kyrgyz Republic, Tajikistan, Turkmenistan, and Uzbekistan, all members of the Asian Development Bank and part of the former Soviet Union until 1991, went through a first decade of independence amid great uncertainty and hardship. The second decade brought, however, healthy recovery shored up by strong commodity prices. But as the CASC countries enter the second quarter century as independent states, external and internal challenges threaten sustained rapid and inclusive economic growth.

This study explores their prospects for inclusive growth and highlights the central role that "good" jobs can play. It identifies the key issues, illustrates the study's findings, and sets out a region-wide policy framework for CASC governments. It also identifies a possible role for the Asian Development Bank and other international financial institutions (IFIs) in promoting a good jobs for inclusive growth agenda in the region. Inclusive growth refers to rapid and sustainable economic growth whose fruits are broadly shared, without leaving individuals or groups behind on well-being, measured in both income and non-income dimensions. Good jobs are well-paid, and, because highly productive, they are secure.

\section{Analytical Framework: Diversity and Commonality in Central Asia and the South Caucasus}

The CASC region is diverse but also strongly shares certain features. CASC countries have a common legacy as former Soviet Union republics, in their relatively high dependence on the Russian Federation's economy, and trade and migration links strengthened by widespread knowledge of the Russian language. They also bear the marks of transition from planned to market economies. Since CASC countries face the challenge of further developing entrepreneurship and the private sector, they need to continue diversifying their productive structures and promoting structural economic reforms, albeit to varying degrees. Five further common features stand out, with great relevance for shaping policies that promote the creation of good jobs for inclusive growth. CASC countries have a relatively

(i) high share of low-productivity agriculture sector in the economy;

(ii) high rate of low-productivity self-employment and informality;

(iii) high rate of cross-border labor migration, especially to the Russian Federation;

(iv) high degree of spatial disparity within internal regions; and

(v) small market for non-resource production. 
In the current global environment, an economic system generating good jobs for inclusive growth is one that mitigates the adverse effects on employment and wages caused by short-term shocks to the demand for labor, and medium-term technological shifts away from demand for basic labor.

For the majority of the CASC countries' populations-certainly for the lower-income groups-income from employment is the main source of livelihood and economic opportunity. Thus, the distribution of human capital and the different rates of return that it generates according to skill level, sector of employment, location, gender, and age determine the inclusivity of economic growth. Public transfers can help mitigate inequality, provided they are sustainable-but the crucial factors remain employment and wages.

Global forces of technological change are conducive to long-run productivity enhancement but are also a challenge to inclusive growth since they shift labor demand away from basic to skilled labor, putting downward pressure on wages and employment of unskilled labor. The inclusiveness of growth is further impacted by segmentation along different dimensions. Inequality between regions keeps lagging areas from the benefits of growth; while inequality across sectors traps labor in low-productivity agriculture, and gender segmentation discriminates against women in the labor market.

\section{Policy Formulation}

The identification of policy recommendations promoting good jobs for inclusive growth in the CASC region is based on empirical observations: even though during 2001-2015, overall income inequality has decreased, spatial inequality remains structurally high within countries. Youth and gender inequality also tend to be relatively high. Policy options are formulated considering that the key features of CASC economies present both challenges and opportunities: (i) the pool of labor trapped in low-productivity agriculture can be transferred to higher-productivity manufacturing jobs if there is demand for output; (ii) informal employment is a resource waiting to be transferred into higher-productivity, formal employment, generating tax revenues; (iii) regional labor migration can provide additional resources through remittances and skills development; (iv) lowering spatial disparities through regional development and connectivity can spur domestic demand for labor; and ( $v$ ) the low penetration of global markets for nontraditional exports provides opportunities for rapid expansion into non-commodity exports.

Demand-side strategies would strengthen private sector development and economic diversification into nontraditional sectors for which demand exists internally and externally. Promoting private sector development requires policies to improve the business climate by reducing red tape or fostering the development of small and medium-sized enterprises through better access to finance and stronger managerial and technical skills. Economic diversification policies include expanding production of high value-added, nontraditional exports, and strengthening infrastructure and connectivity to raise productivity and increase the size of national and regional markets. 
Supply-side strategies would identify and build up skills in high demand and promote job security within a frame of labor market flexibility. Policy options addressing the supply side are largely related to developing human capital, promoting flexicurity, and ensuring social protection. Human capital development policies include improving the quality of technical and vocational education and training and reducing inequality of access to them. Flexicurity includes reform of social benefits to promote labor market participation and flexibility, introducing active labor market policies and enhancing information systems. Finally, social protection schemes need reform to ensure sustainability, and be designed to mitigate, not increase, inequality.

Institutional strengthening strategies would reinforce labor market intermediation and, more generally, improve governance and reduce corruption. Policies would also foster job matching and reduce labor market segmentation. However, the institutions governing labor markets are only one part of an overall system of interrelated and interacting institutions which come under the collective title of "governance." The success of any policy depends on a well-functioning governance system. In this context, corruption is certainly one of the most intractable challenges across the CASC region. Weak institutional coordination is another major challenge.

\section{A Role for Development Institutions}

IFIs and other development agencies have actively provided financial and technical support to the CASC countries since the early 1990s. In reaction to the external shock that hit the region in 2014, development partners have increasingly targeted assistance to promoting job creation and inclusive growth, especially through analytical work and policy advisory services. These institutions are also helping CASC countries reach economic development goals by catalyzing external and domestic resources.

IFls, the study concludes, are important in shaping the good jobs agenda, bringing to the table the benefits of international best practice, analytical tools, financing, meticulous project design and implementation, and the power to support economic transformation. 


\title{
CHAPTER
}

\section{INTRODUCTION AND OVERVIEW}

by Giovanni Capannelli and Ravi Kanbur

\begin{abstract}
II eight Asian Development Bank (ADB) member countries in Central Asia and the South Caucasus (CASC) have traversed an eventful quarter century since the 1991 breakdown of the Soviet Union, of which they were all part. After an initial decade of collapse, the second decade brought recovery and healthy growth buoyed by strong commodity prices. But, today, as the eight countries-Kazakhstan, the Kyrgyz Republic, Tajikistan, Turkmenistan, and Uzbekistan in Central Asia, and Armenia, Azerbaijan, and Georgia in the South Caucasus - enter their second quarter century of independence, they face external and internal challenges to rapid and inclusive economic growth.
\end{abstract}

This study explores prospects for inclusive growth in CASC countries and highlights the central role "good" jobs play in achieving this objective. Many definitions of inclusive growth and good jobs exist. For this work, however, a broad conceptualization is more useful than narrow technical definitions, which may more directly apply to specific cases. Inclusive growth is defined as rapid and sustainable economic growth whose fruits are broadly shared so that development does not leave individuals or groups behind on well-being in income and non-income dimensions. Jobs are "good" when they are well paid and secure because of their high productivity, thus contributing to inclusive growth.

The study commissioned several country and thematic background papers as the basis for its analysis and information. The report also benefited from extensive consultations and knowledge events in CASC countries in 2016 and 2017, involving think tanks and international peer reviewers. The report identifies the study's key issues, presents its findings, and sets out a policy framework for CASC governments useful to foster job creation and promote inclusiveness. The study also identifies a possible role for development institutions, such as ADB, in promoting an agenda for "good jobs for inclusive growth" in the region. ${ }^{1}$

Importantly, the report offers a perspective for the CASC region as a whole. Country-specific policy recommendations are included in the background country papers prepared for the study.

\section{1 | Diversity and Commonality}

The CASC region is simultaneously diverse and similar. In 2015, per capita incomes ranged from a low of $\$ 1,080$ for Tajikistan, through $\$ 4,020$ for Armenia, to $\$ 11,850$ for Kazakhstan. Poverty headcount ratios also vary, from $2.9 \%$ in Kazakhstan to $32.0 \%$ in Armenia. Countries differ in their natural resource bases, with Azerbaijan, Kazakhstan, Turkmenistan, and Uzbekistan exporters of oil and gas, and the others net

1 The full set of background papers, presentations, datasets, and other materials prepared for the study is available at https://www.adb.org/ projects/49045-001/main\#project-documents. 
energy importers. While Kazakhstan is a source of international migrants' remittances, other CASC countries such as Armenia, the Kyrgyz Republic, and Tajikistan rely heavily on remittance inflows, mostly from the Russian Federation. Political and institutional frameworks are also diverse, as are the countries' cultural and ethnic compositions. Box 1.1 offers a glimpse at CASC demographics.

The eight CASC countries also have many things in common. Most obvious and important is that they share the legacy of the Soviet Union, which brings with it the complications of transition from a planned to a market economic system and relatively high dependence on the Russian economy. Besides a pronounced intraregional labor mobility facilitated by the widespread knowledge of the Russian language, the CASC economies are also considerably linked in trade and remittances, due to their shared past and geographical proximity to each other and the Russian Federation.

\section{Box 1.1: Demographic Snapshot of Central Asia and the South Caucasus}

The countries in Central Asia and the South Caucasus (CASC) differ significantly on demographic indicators, size, economic structure, gross domestic product growth, and labor force. The table below presents core demographic indicators across all CASC countries.

\section{Core Demographic Indicators in Central Asia and the South Caucasus}

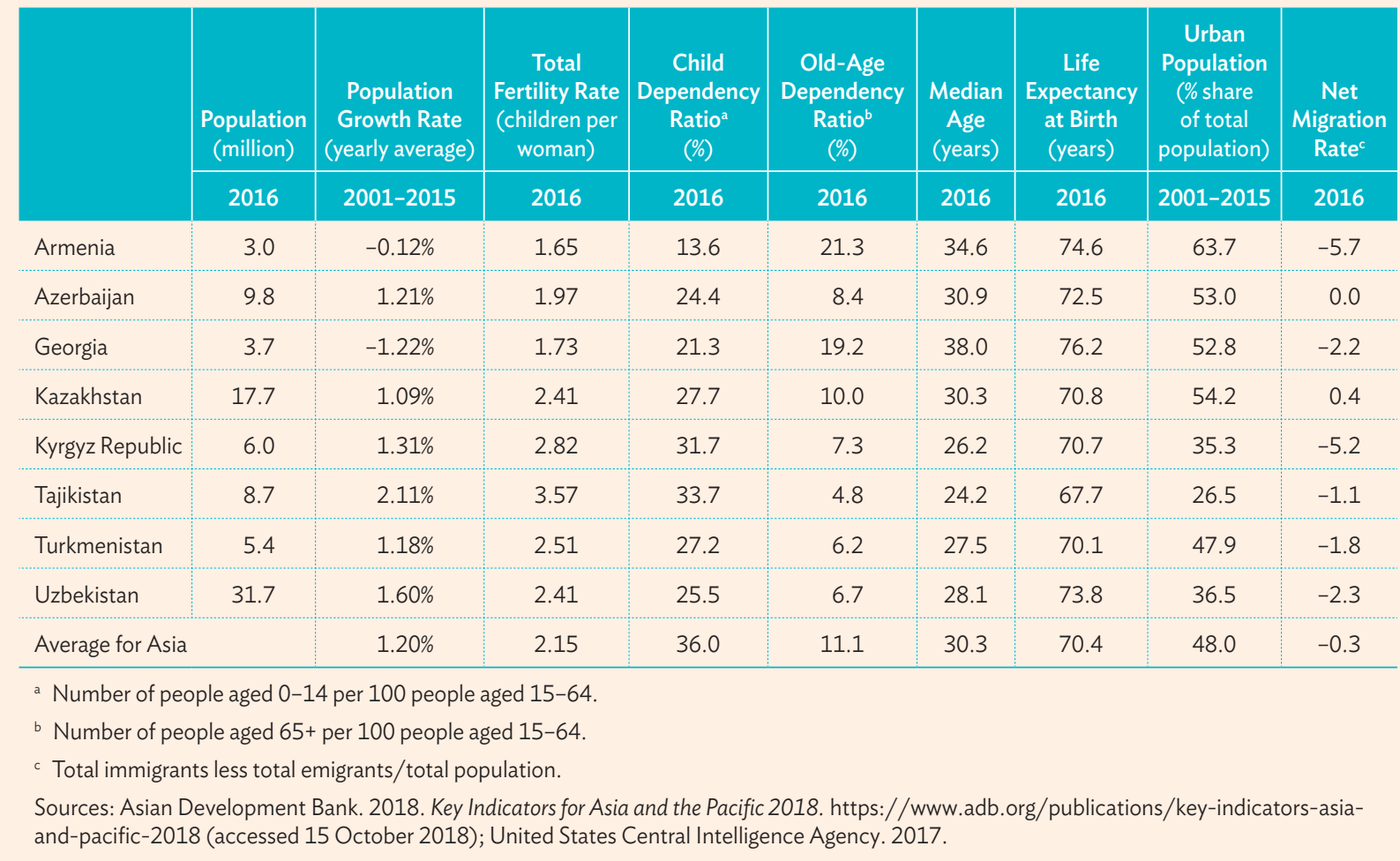


The CASC countries have relatively small populations and domestic markets and are landlocked, with vast mountain areas and deserts hindering connectivity. Private sector development is relatively limited, economic structure is largely undiversified, and self- and informal employment are significant. Another legacy from the Soviet Union is that CASC countries tend to adopt relatively generous social protection schemes, which help mitigate market inequality. However, the sustainability of these programs remains in doubt, especially since the realignment of international commodity prices started in 2014, with large implications for fiscal sustainability. Also hampering progress toward inclusive growth are a generalized and pronounced inequality between regions within countries, as well as gender and youth inequality.

Another hangover from the Soviet Union era is that a significant share of domestic output was allocated to serve the needs of other republics of the union, with relatively high agricultural specialization and a manufacturing production often concentrated in large factories. The latter, in some cases, formed "mono-cities" with high clustering of people, skills, and related services in limited geographical spaces.

\section{Box 1.1: Continued}

Demographic data provide evidence for the effectiveness of government policies. Research shows that a country's demographics can significantly affect its gross domestic product growth (through increases or decreases in working-age population growth), female economic activity rates (as small family size indicates women's potential for activity in the labor force), and productivity growth. The above figures allow generalized cross-country comparisons for CASC countries based on core demographic indicators.

- In 2016, the population of CASC countries ranged from 3.0 million (Armenia) to 31.7 million (Uzbekistan). The population growth rate in 2001-2015 ranged from $-1.2 \%$ per year (Georgia) to 2.1\% (Tajikistan). The average annual growth rate for Asia for 2000-2015 is estimated at 1.2\%.

- Life expectancy at birth during 2001-2015 is estimated from 67.7 years in Tajikistan to 76.2 years in Georgia. Life expectancies at birth for Tajikistan and Turkmenistan are below the Asian average (70.4).

- All the South Caucasus countries have total fertility rates lower than the replacement rate of 2.1 children per woman. Fertility for CASC countries ranged from 1.65 in Armenia to 3.57 in Tajikistan, compared with an estimated 2.15 for all of Asia in 2010-2015.

- Median age ranges from 24.2 years in Tajikistan to 38.0 years in Georgia. The three South Caucasus countries have median ages greater than the Asian average (30.3 in 2015), while all Central Asian countries have median ages lower than the Asian average.

- All CASC countries had a lower youth dependency ratio than the Asian average in 2015 (36\%).

- In 2015, old-age dependency ratios in Armenia and Georgia were much higher than the Asian average (11.1\%). High old-age dependency ratios for these two countries indicate the considerable burden that the economically active population and the overall economy face to support and provide the social services needed by old people, who are often economically dependent on the rest of the population.

- The data also show how migration patterns differ across CASC countries. In Kazakhstan, immigration has been light since 2001, while emigration has quite significantly slowed population growth in Armenia and the Kyrgyz Republic.

- Urbanization varies significantly across countries: for the Kyrgyz Republic, Tajikistan, and Uzbekistan, it was lower than the Asian average for 2000-2015 (48\%).

Source: Authors. 
Production planning was supported by a fairly sound system for economic data collection and by actively promoted labor migration-also aimed at facilitating cultural and ethnic integration among the diverse populations of the Soviet Union. Moreover, communism was decidedly equal by design in terms of income and economic opportunity, including free education, health, and other public social services. In addition, concepts of private entrepreneurship and private property were alien.

As the CASC countries emerged as independent states in 1991 with market economies, many of these features started to change. Income inequality rose considerably, especially during the 1990s, although it improved across the region amid poverty reduction and better income distribution. The fragmentation of the economy of the Soviet Union, and its large, centralized demand for goods and services, implied the emergence of relatively small domestic markets with new trade and investment barriers created among them, while cross-border labor migration remained relatively fluid (Box 1.2). Virtually all of the large manufacturing plants and mono-cities fell apart, with marked dispersion of labor skills and qualifications. CASC countries developed different business models and new approaches to social protection, also based on the availability of revenue from the exploitation of natural resources and ability to develop the private sector and entrepreneurship.

\section{Box 1.2: Insight into Labor Migrants from Central Asia and the South Caucasus}

Since the early 1990s, migration from many of the countries in Central Asia and the South Caucasus (CASC) to the Russian Federation and, to a lesser extent, to Ukraine and Kazakhstan, has increased dramatically. As the figure shows, remittances from migrant workers have become an important source of household incomes in Armenia, Georgia, the Kyrgyz Republic, Tajikistan, and Uzbekistan.

Remittances from the Russian Federation (\$ million, cumulative flows, 2011-2017)

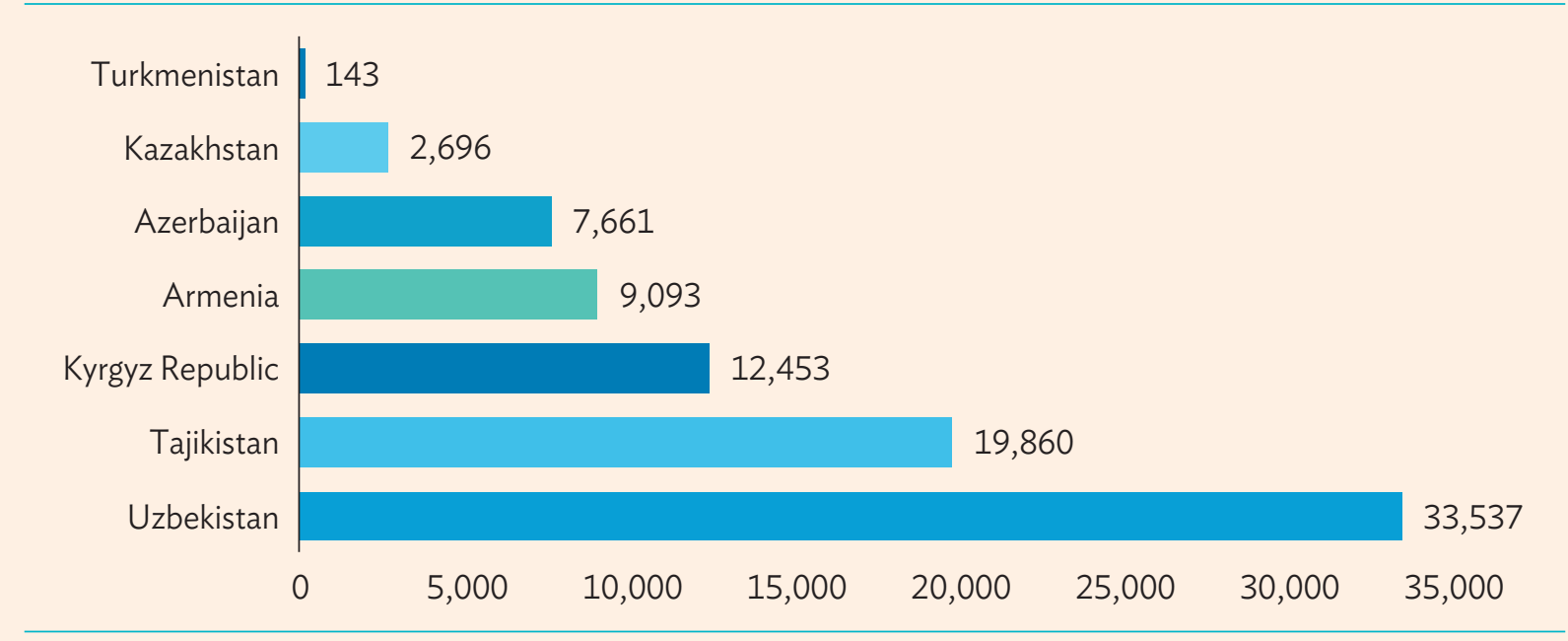

Source: Central Bank of the Russian Federation. 2018. www.cbr.ru/eng/search/?text=remittances. 


\section{Box 1.2: Continued}

At the macroeconomic level, remittances have sustained demand for goods and services, contributing to economic growth and lowering poverty. The table summarizes key features of the region's migrants.

\section{Profile of Central Asian and South Caucasus Labor Migrants}

\begin{tabular}{|l|c|c|c|c|c|c|c}
\hline & Armenia & Azerbaijan & Georgia & Kyrgyz Republic & Tajikistan & Uzbekistan \\
\hline Age range & $15-64$ & $25-44$ & $17-49$ & $17-59$ & $17-59$ & $17-59$ \\
\hline Predominant gender & Female & Male & Male & Male & Male & Male \\
\hline Major occupations & $\begin{array}{c}\text { Crafts; } \\
\text { professional } \\
\text { services }\end{array}$ & $\begin{array}{c}\text { Crafts; } \\
\text { professional } \\
\text { services }\end{array}$ & $\begin{array}{c}\text { Construction; } \\
\text { individual care }\end{array}$ & $\begin{array}{c}\text { Trade; other } \\
\text { services }\end{array}$ & $\begin{array}{c}\text { Construction; } \\
\text { extractive } \\
\text { industries }\end{array}$ & $\begin{array}{c}\text { Construction; } \\
\text { extractive } \\
\text { industries }\end{array}$ \\
\hline Nature of migration & $\begin{array}{c}\text { Long term } \\
\text { Long term and } \\
\text { seasonal }\end{array}$ & $\begin{array}{c}\text { Long term and } \\
\text { seasonal }\end{array}$ & Seasonal & Seasonal & Seasonal \\
\hline Migrant origin & $\begin{array}{c}\text { Rural and } \\
\text { urban areas }\end{array}$ & Rural areas & $\begin{array}{c}\text { Rural and } \\
\text { urban areas }\end{array}$ & $\begin{array}{c}\text { Rural and } \\
\text { urban areas }\end{array}$ & Rural areas & Rural areas \\
\hline
\end{tabular}

Source: F. Irnazarov. 2017. Key Trends and Issues of Labor Migration in Central and West Asia. Paper prepared for this report. https://www.adb.org/projects/49045-001/main\#project-documents.

Research shows that wages and employment differentials between sending and receiving countries are usually among the main motivating factors for migrant workers. In aggregate, differences in earnings, unemployment rates, cost of living, and public transfers are all important determinants. Younger people are more likely to migrate, encouraged by the time to achieve return on investment, lower social cost of separation from family and friends, and lower cost for information search. ${ }^{\mathrm{a}}$

Important gender differences exist. ${ }^{b}$ Most labor migrants from CASC countries are male (with the notable exception of Armenia). Women tend to be segregated into occupations such as domestic work or garment manufacturing; and while migrant men also experience occupational concentration, evidence shows that women have a smaller range of choices in jobs. ${ }^{c}$

Furthermore, labor migration from CASC countries is both long term and seasonal. Data indicate that while most migrants originate from rural areas-except Armenia and Georgia, where they also come from urban areasin Central Asia, migration tends to be more seasonal than in the South Caucasus.

a A. Zaiceva and K. F. Zimmerman. 2016. Migration and the Demographic Shift. In John Piggott and Alan Woodland, eds. Handbook of the Economics of Population Aging 1A. pp. 119-177. Amsterdam, The Netherlands: Elsevier.

b E. M. Grieco and M. Boyd. 2003. Women and Migration: Incorporating Gender into International Migration Theory. Migration Policy Institute. 1 March. https://www.migrationpolicy.org/article/women-and-migration-incorporating-genderinternational-migration-theory.

c S. Pedraza. 1991. Women and Migration: The Social Consequences of Gender. Annual Review of Sociology 17 (1). pp. 303-325.

Source: F. Irnazarov. 2017. Key Trends and Issues of Labor Migration in Central and West Asia. Paper prepared for this report. https://www.adb.org/projects/49045-001/main\#project-documents. 


\section{2 | Regional Features}

Based on its analysis and background papers, this study has identified five features common to all CASC economies with relevance for policies for good job creation and inclusive growth, relative to other regions:

(i) high share of low-productivity agriculture;

(ii) considerable low-productivity self-employment and informality;

(iii) high cross-border labor migration, especially toward the Russian Federation;

(iv) high spatial disparity within countries;

(v) small market size for non-resource production within each country.

All CASC countries also face the common challenges of medium- to long-term global trends in technology and short- to medium-term volatility in commodity prices and other international economic variables.

Technological changes are displacing basic, unskilled labor with skilled labor and capital while increasing overall factor productivity, a global phenomenon. All countries that open up to absorb global technology and investment, and increase labor productivity, will naturally face the challenge of a low employment intensity of economic growth. Without focused policies addressing both the demand and supply sides of the job market, these trends will increase unemployment of basic labor and push up the wage premium for skilled labor, jeopardizing inclusive growth.

The volatility of commodity price cycles, especially affecting hydrocarbons and natural resources, is the second common cloud in the horizon. The severe downturn in oil and gas prices, which began in early 2014, has been undermining economic activity and fiscal balances not only in the energy-rich countries, but in the other countries as well, which tend to be largely reliant on remittance earnings.

\section{3 | Analytical Framework}

A basic analytical framework that combines global forces with the local features of CASC countries would focus on assets, returns to assets, and nonmarket transfers as generating income for households and individuals. In such a framework, the inclusiveness of growth depends on the (in)equality of asset distribution, (in)equality in returns to these assets, and (in)equality in public transfers. Assets include land, and physical, financial, and human capital.

But for the majority of people in CASC countries-and certainly for lower-income groups-income from employment is the main source of livelihood and economic opportunity. The inclusivity of economic growth is, therefore, determined by the distribution of human capital and the different rates of return based on skill level, sector of employment, location, gender, and age. Public transfers can help mitigate inequality and improve inclusiveness, provided they are sustainable, but the crucial factors remain employment and wages (i.e., jobs and the returns to jobs). 
Once employment and jobs are identified as central to inclusive growth, the analytical framework can be developed by considering demand-side and supply-side factors that determine employment and wages. In addition, labor markets and their flexibility and ability to match demand with supply, constitute the basic transmission mechanisms between employment opportunities and income for households and individuals.

In this framework, the supply side of the labor market includes the human capital invested in labor, and its productivity, disaggregated by salient socioeconomic categories such as gender and youth. It also includes mobility of labor across sectors, regions, and national borders. On the supply side, investments in education and skills training are needed to match rising demand for skilled labor as technologies change. At the same time, the resulting rise in inequality because skilled labor is paid a premium needs to be kept under control. A second prong of this supply-side economic policy is investment in infrastructure and in better delivery of public services such as education and health, to address the non-income dimensions of inequality.

The supply-side approach is particularly congenial to international financial institutions (IFIs), since it typically leads to financing of investment projects in the physical or human capital that are crucial in promoting rapid and inclusive economic growth. However, supplying the skilled labor and infrastructure that can improve labor mobility will not deliver inclusive growth without demand for that labor. In particular, to the extent that global and local forces keep demand for basic labor low, policies focused on improving only the supply side of the labor market will simply make growth less inclusive. The demand side of labor must also be addressed.

In the current global environment, an economic system generating "good jobs for inclusive growth" is one that mitigates the adverse impact on employment and wages caused by short-term shocks to the demand for labor, and medium-term technological shifts away from demand for basic labor. The weak level and structure of labor demand-caused partly by demographic, geographic, and historical factors, as well as economic policies-is a major reason for unemployment, underemployment, and informal arrangements within and outside the labor market. Failure to address these issues will limit the impact on inclusiveness of supply-oriented labor market and economic development policies.

Most CASC countries obviously lack economic diversification, especially the resource-rich ones. As this study documents, while the natural resource sector has delivered growth, it has not been employmentintensive and growth itself remains vulnerable to falling commodity prices, as in 2014 . However, especially in hydrocarbon-abundant countries, sectors which can tap into global demand through exports of non-commodity goods and services are inadequately developed. In all CASC countries, private sector development is poor, especially of the small and medium-sized enterprises (SMEs) crucial to employmentintensive growth. On the other hand, a pool of labor is readily available in the pervasive informal sector, which could be pulled into higher value-added agriculture, manufacturing, and services, promoting nontraditional exports. Inclusive growth policy must focus equally on demand-pull mechanisms.

Finally, labor market institutions that enable or inhibit the matching of supply with demand-and that determine the extent and shape of informality in employment-are present. Their nature, clearly affecting prospects for inclusive economic growth in CASC countries, is determined by regulatory frameworks and policies. Institutional aspects are often classified on the supply side, although they affect the demand 
side as well. But labor market institutions do not exist in a vacuum: they are part of an ecosystem which constitutes the governance structure of the economy and society in any country. The extent and nature of corruption is thus a key determinant not just of the efficacy of labor market institutions but also of the inclusivity of growth itself.

\section{4 | The Experience of Central Asia and the South Caucasus}

As a large body of economic literature shows, labor productivity growth is the long-term determinant of economic growth and well-being. But as productivity growth displaces labor, whenever economic growth is not accompanied by a commensurate increase in jobs, it is not inclusive. And this is what the eight CASC countries have generally shown since the turn of the century: rapid but not inclusive growth, but with an employment intensity (to growth) which has been quite low compared to international standards. ${ }^{2}$

Overcoming this conundrum is crucial for CASC countries to enter a new phase of inclusive and sustainable economic growth: policy makers need to use available instruments to simultaneously increase labor force skills and other supply-side factors while increasing total demand for labor, domestically and for exports. Moreover, when private firms and public entities can create jobs that are also "good" - well paid and securethe impact on inclusive growth is multiplied.

One important positive impact on domestic economies of the CASC region's internationalization model is its support for induced domestic demand generated through oil, gas, and other mineral revenues, as well as migrants' remittances. Out-migration is also important to relieve labor-supply pressure domestically: it taps external demand by exporting workers rather than goods or services. However, non-resource export markets are largely untapped, missing a significant opportunity to expand production and employment. Their still limited regional and global integration, and sometimes unfriendly business environments, largely limit foreign capital inflows beyond the extractive sector, thus missing out on the competitive discipline and efficiency improvements associated with international exposure. Although some countries have made recent progress in these areas, much still needs to be done: the unexploited potential for creating good jobs remains very large.

The cyclical component of macroeconomic policies has typically the most impact on demand, whereas the structural component is more relevant for supply. CASC countries have-to the extent compatible with budget constraints - supported demand directly through public transfers, wage increases, and provision of free or low-cost public services (health, education, utilities) that create space for alternative uses of monetary income. Moreover, the supply-side impact appears often to have been suboptimal: some of the public investment has not been channeled into productive infrastructure; basic pensions and income transfers,

Notably, most CASC countries experienced productivity-driven growth during the 1990s, as is usually observed when employment is largely supply-driven in periods of economic recovery following dramatic contractions. 
even if at fairly low levels, may have discouraged formal labor market participation; provision of credit has often taken place at preferential rates and/or to selected customers; and the generally overvalued exchange rates maintained until relatively recent years in some CASC countries have discouraged expansion of noncommodity exports. In short, from a structural and supply-side perspective, the CASC experience suggests that macroeconomic policies have been hampering, not promoting, inclusive economic growth. More can be done in the policy area.

When it comes to assessing CASC countries' factor endowments, the quality of land as well as labor could be improved substantially by strengthening regulatory frameworks and expanding investment in basic infrastructure, health, education, and skills development. For physical and financial capital, still significant unmet needs could be partly addressed by sector and geographic redistribution and stronger prioritization. Taking advantage of socioeconomic regional bonds dating to the Soviet union era, labor mobility tends to be higher across, rather than within, countries. This apparent paradox is due not only to migrants' proficiency in the Russian language, but also to the pronounced inequality between capital cities, secondary cities, and other parts of those countries.

Finally, labor supply conditions can be enhanced by governance and institutional improvements for more consistent application of the rule of law to reduce uncertainty and transaction costs for investors, removal of various constraints to internal labor mobility, and freer competition to boost productivity through the elimination of rent positions.

Improvements in institutional factors are equally important to bolster the demand side. Widely used, reputable data sources, such as the World Bank's Worldwide Governance Indicators, suggest that CASC countries still have significant need for structural reforms, even in comparison with other countries at similar levels of per capita gross domestic product. Scholars have highlighted poor governance and corruption as major problems across the region. Policies promoting good governance and reducing corruption have been repeatedly identified as a priority for economic development in all CASC countries.

If sound institutions and governance were to be well established in CASC countries, together with stronger rule of law and fairer competition than is commonly observed, private sector activity would not be crowded out by special interests, or by state-owned enterprises. As a result, aggregate demand and the related demand for labor would be stronger. A large body of literature also shows that if the legal and regulatory frameworks are uncertain and if contracts are not properly enforced in a timely manner, companies tend to underinvest and under-employ workers. This trend is also observed when selected firms receive preferential treatment in access to production factors such as capital (credit) and land. The timely introduction of far-reaching privatization and commercialization strategies for state-owned enterprises, with proper scheduling plans and monitoring mechanisms for their implementation, has also proven of utmost importance to favorable conditions on the demand side of the labor market. 


\section{5 | Areas of Intervention}

The broad structure of policy options promoting good jobs for inclusive growth flows from the analytical framework adopted for this study. Causal factors were classified as demand side, supply side, or institutions which govern labor market ability to balance demand and supply. Thus, it will be useful to think of policy instruments and interventions as primarily on the demand or supply side, or institutional. In practice, however, these categories overlap and interact.

\section{Demand-Side Policies}

Given CASC countries' relatively small populations, expanding internal markets for existing production ultimately faces severe limitations as a growth strategy. While much can be done by improving infrastructure and internal connectivity, the major thrust of demand-side policies has to be diversifying individual countries' economies and expanding existing businesses to export markets of goods and services. The background papers prepared for the study reveal large potential for diversifying the structure of domestic economies, for example, in agribusiness, manufacturing production related to natural resources, logistics, tourism, and other services.

Demand-side diversification policies can be classified into instruments aiming to provide incentives in general, not specific to any sector of production, or those to support specific sectors or types of labor. Private sector and SME development strategies generally fall into the first category. Those improving the business climate would include initiatives such as reducing red tape, simplifying administrative procedures, controlling corruption, and introducing effective dispute settlement mechanisms. ${ }^{3}$

\section{Supply-Side Policies}

Supply-side policies fall under the broad rubric of interventions to boost human capital and reduce inequality in its distribution across individuals and prominent groups. Human capital-enhancing policies focus considerably on education and skills development, incorporating a range of interventions from general improvements of the educational system to specific actions to strengthen technical and vocational education and training systems.

Supply-side policy priorities are threefold. First, improving policymaking and implementation practices, including integration of policies for education, skills, and human capital development with those in support of entrepreneurship, SME development, research, and innovation. Efforts can be facilitated by establishing multilevel governance and coordination mechanisms between ministries, public bodies, and local stakeholders for enhancing policy formulation and implementation. Second, expanding and better targeting investments in education, including increasing the number of teachers and technical and vocational education and training

3 Some of these policies, such as controlling corruption, fall under the institutional heading (see Governance and Institutions). 
instructors, and their qualifications, or creating mechanisms for effective public-private partnerships-while carefully adopting modalities for these to finance education and skills development. Third, focusing on improving education and skills development for employability and job creation, ensuring that 21 st century skills are integrated into all programs offered at schools and universities, and increasing tertiary enrollment rates-particularly for students in science and engineering.

Enhancing labor mobility in its many dimensions-across jobs, occupations, sectors, and borders-is a key supply-side policy. The challenges labor markets are facing in CASC countries provide a strong argument for embracing "flexicurity," that is, a system that combines flexible contractual arrangements with income and social security for the individual, and a strong role for active labor market policies. Such policies are designed to support individuals with (re)training, job-matching, and similar instruments, while helping create an efficient and flexible labor market at the aggregate level. Underpinning this approach is a shift in the burden of financing job security from the employer to the public purse and from protecting jobs to protecting workers. A gradual transformation of job market institutions and policies in this direction would require reforms and particular attention to three interrelated areas: (i) enhancing mechanisms for funding social benefits, (ii) introducing active labor market policies, and (iii) creating strong systems for labor market information and analysis.

In demand-side and supply-side interventions, governments should pay special attention to targeting gender, youth, and spatial dimensions of inequities in human capital formation. However, equity dimensions can go well beyond these considerations. For example, all CASC countries have extensive social protection systems in place, which have quite effectively controlled inequality. However, as new systems and policies are introduced, policy makers should use appropriate mechanisms for targeting affected groups while ensuring the long-term sustainability of their social protection systems.

\section{Governance and Institutions}

The institutions governing labor markets are only one part of a system of interrelated and interacting institutions which might come under the collective title of "governance." Policy options depend on an overall well-functioning governance system in each country.

Most CASC countries rank in the lower quartile of the Transparency International Corruption Perceptions Index (2015). Recently, however, innovative policy ideas have had some positive impact in the region. For example, various models of "one-stop shops" or "customer service points" provide convenient ways to access public services, avoiding the multiple and opaque transactions that often give rise to corruption, helping to solve weaknesses in institutional coordination. Box 1.3 provides insights into governance and institutions in CASC labor markets. 


\section{Box 1.3: Governance, Institutions, and Labor Markets}

Good governance and effective institutions remain central to improving the inclusivity of growth and the capacity of any economy to generate good jobs. While countries in Central Asia and the South Caucasus (CASC) have so far followed various paths to economic development and institutional reforms, growth strategies everywhere in the region will require a new emphasis on improving the quality of governance systems and economic institutions, transparency, accountability, and the rule of law.

Since independence from the Soviet Union, the CASC countries have made significant progress on improving legal environments and formal institutions that govern economic activity. However, informal institutions still play a significant role in the region. Research shows that to maximize inclusivity and economic efficiency, the regulatory environment that governs business and labor activity needs to be clear and transparent. In practice, however, the high level of informality governing interactions between state, business, and society, and large informal labor markets, where workers often lack adequate rights, are associated with limited income, undermining inclusive growth.

Three different types of informal institutions-transactional, accessional, and distributional-impact the nature of economic growth.

Several CASC countries have shown significant improvement on transactional institutions, typically limiting the extent of everyday corruption, such as payment of small bribes to get documents and business licenses, or to facilitate customs procedures. A shift to electronic payments, tax, and customs filing in several countries has also helped diminish corrupt payments to state officials. The Azerbaijan Service and Assessment Network (Box 5.8) is one public service offering innovative delivery, which aims to reduce everyday corruption by using online payments for public services. In Kazakhstan, a "single-window" investors' service center was launched in 2016, offering a single agency for access to a large number of different state services such as issuance of licenses and land permits.

For large businesses, however, accessional institutions-agencies which can win state procurement tenders or profit in certain business sectors-are more important. Here, governments should boost strategies that discourage monopolistic practices and explore initiatives to raise public procurement rules to international standards. Although in the CASC region it is often difficult for small and medium-sized enterprises to grow into large businesses, recent reforms and new e-government initiatives have led to improvements. For example, the introduction of e-procurement in Georgia's State Procurement Agency is credited with increasing competition, improving transparency, and reducing bureaucracy and corruption.

Distributional institutions govern how welfare and other types of budgetary spending are distributed to the population. Inclusivity implies an equal distribution of growth proceeds to different regions and social groups. Given the expanding spatial disparities in CASC countries, many peripheral regions face specific development challenges and require additional government support. In this regard, introducing participatory mechanisms in forming budgets, including public hearings and better public information campaigns, is an effective way to improve responsiveness to public needs. Enhanced mechanisms for accountability of parliaments and auditors is also important to improve transparency of welfare payments. Civil society, too, has an important role to play in improving such processes.

Source: D. Lewis. 2017. Evolution of Economic Institutions and Governance in Central Asia and South Caucasus. Paper prepared for this report. https://www.adb.org/projects/49045-001/main\#project-documents. 


\section{6 | A Role for Development Partners}

The above framework of policy recommendations has specific implications for international financial institutions (IFIs) such as ADB and other development partners that help countries in the region achieve long-term economic development targets.

IFls typically operate through a variety of instruments including (i) loans and grants aimed at financing specific investment projects or supporting policy reforms; (ii) technical assistance for the preparation of feasibility studies of potential projects, or capacity building of institutions and individuals; (iii) analytical and knowledge work, also in collaboration with local agencies; and (iv) direct interventions in support of specific sectors, businesses, and firms. The selection of sectors of intervention, project design, and financing modality of investments are important in determining the impact of IFls' operations on the labor market and the inclusiveness of economic growth.

Policy approaches and investment requirements must be adapted and transformed into country-specific implementable action plans through processes that lead to the definition of country strategies and the design of specific operations. In some cases, consideration should be given to pilot approaches through projects that include a rigorous impact evaluation framework to determine whether they should be replicated nationally or subnationally.

Overall, ADB and other IFIs have an important role to play in financing infrastructure projects and the provision of social services. They typically support the development of SMEs and the private sector, and help provide knowledge solutions, including through the design and implementation of structural reforms. These institutions can also assist CASC governments, think tanks, and local civil society in analyzing, diagnosing, and monitoring policies given each country's specific context.

Because they are multilateral, IFIs are well suited to promote regional approaches and strategies, in addition to national ones. Specific operations promoting regional cooperation include creation of transport, power, water, telecommunication, and other infrastructure networks, and corresponding "soft components" that make integration successful by allowing smooth flow of people, goods, and services across borders. Typically, these financial institutions are also well positioned to play the role of "honest brokers," helping countries forge mutually beneficial agreements. 


\title{
CHAPTER
}

\section{ECONOMIC PERFORMANCE AND PROSPECTS}

\author{
by Bahodir Ganiev
}

Eollowing drastic contraction and partial economic recovery in the first decade after independence from the Soviet Union in 1991, countries in Central Asia and the South Caucasus (CASC) enjoyed overall strong economic performance until 2014. They were then hit by a decline in international commodity prices and a slowdown in major economic partners. A combination of factors drove the period of buoyant economic growth, such as foreign direct investment (FDI) into the resource sector, expansion of commodity exports, and rising remittances from migrant workers. But most of the countries failed to introduce structural reforms and improve governance and institutional systems, which would have allowed economic diversification and, thus, less dependency on export of commodities and/or inflows of remittances. While the policy response to external shocks has varied across the CASC countries, they all need to broaden and deepen economic and institutional reforms to ensure long-term sustainable and inclusive growth.

This chapter reviews CASC growth performance and progress on economic and institutional reforms during 1991-2016, offering a medium-term outlook for the external environment. It also highlights the challenges and opportunities these countries face in creating good jobs for inclusive growth. The discussion of economic prospects up to 2030 is based on an econometric exercise that introduces two alternative growth scenarios, with limited and full policy actions in structural reforms as measures to create good jobs and stimulate economic growth. The results suggest that per capita gross domestic product (GDP) in all CASC countries will grow significantly faster under a full-action scenario.

\section{1 | Growth since Independence}

In 1992, the World Bank classified all CASC countries, which embarked on the transition from a centrally planned to a market-based economic system, as lower middle-income economies. During the first several years of independence, overall economic activity contracted drastically in the region for several reasons, including the breakdown of trade and payment links among the former Soviet Union republics, high inflation, closure of many inefficient state-owned enterprises (SOEs) and, in some cases, armed conflicts. The transition recession ${ }^{4}$ lasted longer or was more severe in the CASC countries than in most transition countries outside of the former Soviet Union because of relatively unfavorable initial conditions.

4 The transition recession refers to the economic contraction typically of former socialist countries at the early stage of transition from planned to market economies. 
The cumulative decline in real GDP in the early 1990s across the region was particularly severe in Armenia (75.4\%), Georgia (72.5\%), and Tajikistan (68.3\%) due to armed conflicts (Figure 2.1). It was fairly mild in Uzbekistan (18.9\%), thanks to the mitigating effect of sustained cotton production, self-sufficiency in the energy sector, and low initial industrialization (Zettelmeyer 1998).

Figure 2.1: Economic Growth in Central Asia and the South Caucasus, 1991-2016

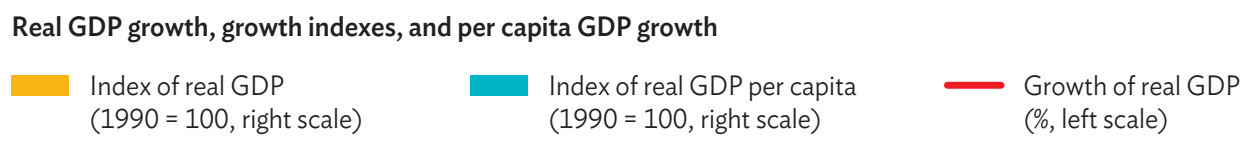

Index of real GDP

$(1990=100$, right scale $)$

Index of real GDP per capita $(1990=100$, right scale $)$

Growth of real GDP
(\%, left scale)
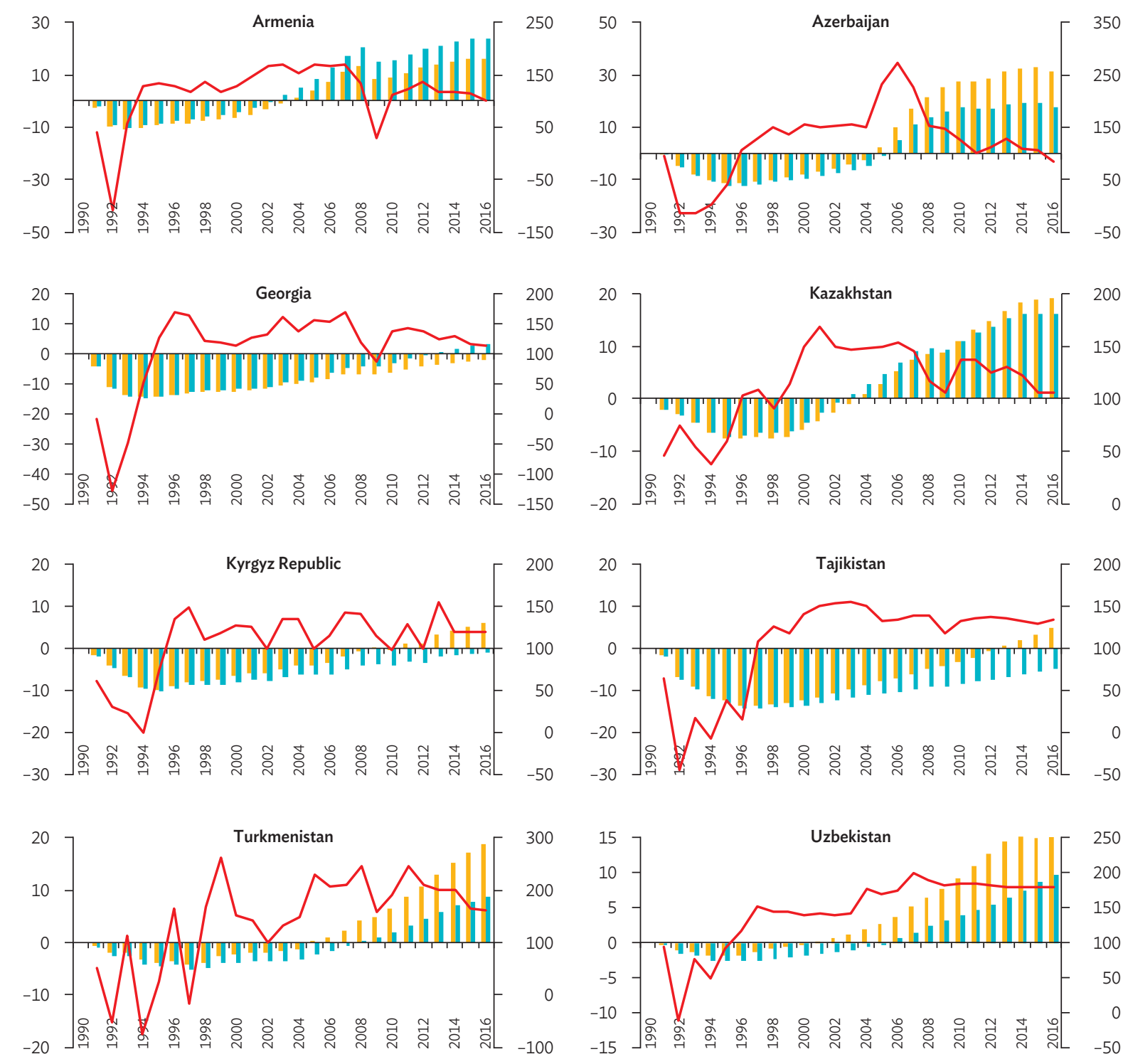

GDP = gross domestic product.

Sources: World Bank. World Development Indicators database (accessed 30 August 2017); International Monetary Fund. World Economic Outlook database (accessed 30 August 2017); and authors' computations. 
The CASC countries began to recover in 1993-1997, as their economies began, at least partially, to restore trade and payment links with each other and the rest of former Soviet Union republics. During this period, CASC countries also started to diversify trade patterns away from former republics of the Soviet Union and to curb inflation. Armed conflicts ended, or were suspended, and the private sector started to expand rapidlyalbeit from a very low level. Strong FDI inflows in the energy sector contributed to a rapid economic recovery in Azerbaijan, Kazakhstan, and Turkmenistan. Turkmenistan, nevertheless, suffered a triple-recession during 1991-1997, partly due to fluctuations in natural gas exports.

The Russian financial crisis of 1998 slowed or interrupted recovery in most CASC countries and, in 2000, real GDP per capita was still well below its 1990 level. ${ }^{5}$ By mid-2000, the World Bank continued to classify all CASC countries, except Kazakhstan, as low-income economies.

In contrast to the severe economic turbulence of the first decade of independence, CASC countries have grown fairly strongly since the turn of the century. Average annual growth of real GDP in 2001-2015 ranged from $4.3 \%$ in the Kyrgyz Republic ${ }^{6}$ to $10.6 \%$ in Azerbaijan, which enjoyed an oil boom in the mid-2000s. By comparison, annual world GDP growth averaged $2.8 \%$ during the same period.

The global financial crisis of 2008-2009 caused a recession or an economic slowdown region-wide. ${ }^{7}$ But its impact was limited in most CASC countries, except Armenia, because of (i) considerable fiscal buffers, which allowed sizable fiscal stimulus; (ii) fairly large international reserves, which enabled some countries to limit currency devaluation; (iii) emergency assistance from the international financial institutions; and (iv) relatively quick recovery in global commodity prices. In Armenia, the crisis caused a sharp decline in aggregate output by abruptly ending a construction boom fueled by strong remittance inflows.

Due to the generally strong economic growth during 2001-2015, most CASC countries reached substantially higher real GDP per capita than in 1991. By mid-2015, the World Bank reclassified Armenia, Georgia, the Kyrgyz Republic, Tajikistan, and Uzbekistan as lower middle-income, and Azerbaijan, Kazakhstan, and Turkmenistan as upper middle-income economies.

\section{2 | Drivers of Growth, 2001-2015}

Four major factors propelled economic growth of CASC countries in this period: (i) FDI inflows, mostly into energy and/or mining; (ii) improvement of terms of trade and/or export growth (mainly of primary commodities); (iii) large increases in remittance inflows from international migrants; and (iv) public investments largely financed from natural resource revenue and/or external borrowing (ADB 2016c).

Less than half of its 1990 level in Georgia and Tajikistan.

Although growth was hurt by two revolutions, civil unrest in the south, and accidents in a major gold mine.

In Georgia, the global economic crisis coincided with the aftermath of the 2008 war with the Russian Federation. 


\section{Foreign Direct Investment Inflows}

FDI inflows varied considerably over time and across CASC countries (Table 2.1). While FDI to Armenia, Georgia, Kazakhstan, and Turkmenistan were fairly strong during most of 2001-2014, inflows to Uzbekistan remained relatively weak over the same years. Average annual net FDI inflows ranged from $\$ 168.7$ million in Tajikistan to $\$ 8.4$ billion in Kazakhstan, while the ratio of net FDI inflows to GDP ranged from $1.8 \%$ in Uzbekistan to 8.9\% in Azerbaijan. Net inflows to Azerbaijan, the Kyrgyz Republic, and Tajikistan fluctuated substantially, in part because investments in these countries were concentrated in a limited number of largescale projects. Most FDI inflows went to the energy and mining sectors, although FDI shares in countries, such as Georgia, were largest in sectors such as finance, transport, and communication.

\section{Table 2.1: Selected Indicators of Foreign Direct Investment Inflows} to Central Asia and the South Caucasus, 2001-2014

\begin{tabular}{|c|c|c|c|}
\hline & $\begin{array}{l}\text { Average Annual } \\
\text { Net Inflows } \\
(\$ \text { million })\end{array}$ & $\begin{array}{c}\text { Average Annual Ratio of } \\
\text { Net FDI Inflows to GDP } \\
(\%)\end{array}$ & $\begin{array}{c}\text { Years when Ratio of } \\
\text { Net FDI Inflows to GDP > 5\% }\end{array}$ \\
\hline Armenia & 426.2 & 5.6 & 2004-2011 \\
\hline Azerbaijan & $1,170.7$ & 8.9 & 2002-2005, 2014 \\
\hline Georgia & 835.3 & 8.4 & $2003-2014$ \\
\hline Kazakhstan & $8,375.1$ & 8.2 & 2001-2004, 2006-2012 \\
\hline Kyrgyz Republic & 249.3 & 5.1 & 2004, 2007-2008, 2010-2011, 2013 \\
\hline Tajikistan & 168.7 & 4.2 & $2004,2006-2008$ \\
\hline Turkmenistan & $1,803.8$ & 8.5 & $2002,2004-2014$ \\
\hline Uzbekistan & 593.1 & 1.8 & None \\
\hline
\end{tabular}

FDI = foreign direct investment, GDP = gross domestic product.

Sources: United Nations Conference on Trade and Development; World Bank. World Development Indicators; and authors' computations.

\section{Terms of Trade and Exports}

The terms of trade of the CASC countries, except Tajikistan, improved during 2000-2012 as world commodity prices rose, with commodities a large share of exports. The terms of trade of Azerbaijan, Kazakhstan, Turkmenistan, and Uzbekistan, all major exporters of oil and/or natural gas, improved significantly, largely because of a considerable rise in world energy prices. Mostly for the same reason, the terms of trade of Tajikistan, a net importer of energy products, worsened during the period. 
During 2001-2013, merchandise export volume in Armenia, Azerbaijan, Georgia, Kazakhstan, the Kyrgyz Republic, and Tajikistan grew rapidly because of strong external demand and inflows of FDI into exportoriented sectors such as energy and mining. The value of merchandise exports of CASC countries, except Tajikistan, increased considerably due to growth in export volumes and rising export prices. Expanding exports of primary commodities, such as metals, crude oil, and natural gas, largely drove the merchandise export growth in Armenia, Azerbaijan, Kazakhstan, Turkmenistan, and Uzbekistan (Table 2.2).

\section{Table 2.2: Average Annual Growth Rates of Merchandise Exports} of Central Asia and the South Caucasus, 2001-2013 (\%)

\begin{tabular}{l|c|c|c} 
& Exports Volume & Exports Value & Value of Exports of Primary Commodities $^{\text {a }}$ \\
\hline Armenia & 7.1 & 13.2 & 16.3 \\
\hline Azerbaijan & 12.8 & 25.0 & 22.6 \\
\hline Georgia & 6.9 & 18.4 & 3.8 \\
\hline Kazakhstan & 11.5 & 19.0 & 20.6 \\
\hline Kyrgyz Republic & 7.0 & 10.2 & 3.1 \\
\hline Tajikistan & 10.3 & 3.1 & $\ldots$ \\
\hline Turkmenistan & 2.3 & 15.9 & $\ldots$ \\
\hline Uzbekistan & 0.7 & 12.2 & $\ldots$ \\
\hline ... data not available. & & & \\
a Includes exports of agricultural raw materials, fuels, ores, and metals. \\
Sources: International Monetary Fund. World Economic Outlook; World Bank. World Development Indicators; and \\
World Integrated Trade Solutions (authors' computations).
\end{tabular}

Consequently, exports from these countries became highly concentrated in primary commodities, with crude oil accounting for the bulk of merchandise exports from Azerbaijan and Kazakhstan; natural gas making up a large proportion of exports of goods from Azerbaijan, Turkmenistan, and Uzbekistan; metals accounting for a sizable portion of merchandise exports from Armenia, Kazakhstan, the Kyrgyz Republic, Tajikistan, and Uzbekistan; and cotton accounting for a substantial share of exports from Tajikistan and Uzbekistan. Although the share of primary commodities in Georgia's merchandise exports decreased between 2000 and 2013, it remained a substantial portion of total exports (around 20\%) in subsequent years, showing how CASC countries have been highly vulnerable to the ups and downs in commodities prices.

\section{Remittance Inflows}

Strong remittance inflows stimulated economic growth in Armenia, Georgia, the Kyrgyz Republic, Tajikistan, Uzbekistan and, to a lesser extent, Azerbaijan, by boosting recipient households' consumption and investment expenditure, and through the multiplier effect on the rest of the economy (Table 2.3). For example, Ganiev (2017) assesses the impact of remittances on consumption and investment expenditures of recipient households in CASC countries. Karpestam (2012) analyzes the multiplier effect of remittance inflows. 
Table 2.3: Remittance Inflows to Central Asia and the South Caucasus, Selected Years

\begin{tabular}{l|c|c|c|c|c|c} 
& \multicolumn{3}{|c|}{$\$$ million } & \multicolumn{3}{c}{$\%$ of GDP } \\
\cline { 2 - 7 } & 2000 & 2006 & 2013 & 2000 & 2006 & 2013 \\
\hline Armenia & 87.5 & $1,169.2$ & $2,192.2$ & 4.6 & 18.3 & 19.7 \\
\hline Azerbaijan & 57.1 & 790.2 & $1,733.2$ & 1.1 & 3.8 & 2.4 \\
\hline Georgia & 209.5 & 627.3 & $1,945.3$ & 6.9 & 8.1 & 12.1 \\
\hline Kazakhstan & 121.8 & 83.6 & 207.2 & 0.7 & 0.1 & 0.1 \\
\hline Kyrgyz Republic & 8.8 & 473.1 & $2,278.0$ & 0.6 & 16.7 & 31.1 \\
\hline Tajikistan & $\ldots$ & $1,018.8$ & $4,218.8$ & $\ldots$ & 36.0 & 49.6 \\
\hline Turkmenistan & $\ldots$ & 14.0 & 40.0 & $\ldots$ & 0.1 & 0.1 \\
\hline Uzbekistan & $\ldots$ & 866.0 & $6,633.0$ & $\ldots$ & 5.1 & 11.7 \\
\hline
\end{tabular}

... = data not available, GDP = gross domestic product.

Sources: World Bank. World Development Indicators database (accessed 30 August 2017); and authors' computations.

Remittances also fostered growth by promoting financial sector development in receiving countries. ${ }^{8}$ At the same time, the high concentration of remittances from a few commodity-exporting source countries, such as the Russian Federation and Kazakhstan, made Armenia, Georgia, the Kyrgyz Republic, Tajikistan, and Uzbekistan indirectly highly vulnerable to changes in world commodity prices. ${ }^{9}$

\section{Public Investment}

In response to the global financial crisis of 2008-2009, all CASC countries considerably increased public investment as part of efforts to mitigate adverse economic impacts. The ratio of public investment to GDP remained at elevated levels in most CASC countries for several years in the crisis aftermath: it averaged as high as 14.8\% in Azerbaijan during 2008-2014 and 11.6\% in Tajikistan during 2008-2013. CASC countries financed substantial portions of public investment programs through natural resource revenue and/or external borrowing.

\section{3 | Progress on Economic and Institutional Reforms}

During the 1990s, progress on market-oriented economic reforms varied significantly, in areas of reform and by country. Armenia, Azerbaijan, Georgia, Kazakhstan, the Kyrgyz Republic, and Tajikistan advanced relatively well on the so-called "first-generation" market-oriented reforms-privatization of small SOEs and liberalization of prices, trade, and the foreign exchange system. But they made limited headway on 
second-generation reforms-restructuring and privatization of medium-sized and large SOEs, improving corporate governance, and strengthening competition. Turkmenistan and Uzbekistan, meanwhile, made only limited progress on both first- and second-generation reforms.

Overall progress on first- and second-generation reforms was fairly slow in all CASC countries during 2001-2016 compared to the first decade of independence. In 2014, the average scores of transition indicators computed by the European Bank for Reconstruction and Development for both generation of reforms were generally lower than those for the Baltic countries and Mongolia. Even the most advanced reformers among CASC countries (Armenia, Georgia, and the Kyrgyz Republic) lagged considerably behind the Baltic countries in second-generation reforms. In 2015, only Georgia was ranked a mostly "free" country according to the Heritage Foundation and the Wall Street Journal's "Index of Economic Freedom." The other CASC countries were ranked "moderately free," "mostly unfree," or even "repressed."

The explanation for such relative lack of progress in market-oriented reforms during 2001-2015 can be found in the combination of two factors. First, the rapid pace of economic growth, driven either by commodity exports or remittance inflows, did not create a sense of urgency for reforms. Second, the still-weak representation of public interests in economic policy formulation prevented civil society from articulating the interests of the middle class. Moreover, vested interests who benefited from early partial reforms opposed the adoption of further reforms fearing they could shift the bulk of benefits to other groups.

At the same time, however, some CASC countries made good progress on a few institutional reform areas, translating into improvements in public administration, stronger judicial systems and the rule of law, and streamlined business regulations. The rank of several CASC countries in Worldwide Governance Indicators and in the World Bank's Doing Business Indicators improved, especially in recent years. Georgia and, to a lesser extent, the Kyrgyz Republic were able to gain a reputation as reformist countries. Georgia, in particular, introduced a good number of structural reforms reflected in stronger governance indicators and economic performance. Box 2.1 discusses structural reforms in tourism in Georgia.

Despite such trends, the overall quality of governance and institutions in CASC countries remains fairly low, with generally weak rule of law. Several countries still have problems enforcing competition policy and anticorruption measures. Indeed, all CASC countries, except Georgia, rank low on the Transparency International Corruption Perceptions Index. ${ }^{10}$

10 Even Georgia, which made great strides in combating corruption and has virtually eliminated petty corruption, had a score of 57 on a scale from 0 (highly corrupt) to 100 (very clean) in the 2016 Corruption Perceptions Index. 


\section{Box 2.1: Reforms and the Development of Tourism in Georgia}

Georgian tourism is often regarded as a success story. International tourist arrivals increased more than tenfold within just 10 years, from a little more than half a million in 2005 to almost 6 million in 2015 (figure). In the same years, revenues from tourism increased eightfold, from $\$ 240$ million in 2005 to almost $\$ 2$ billion in 2015 .

\section{Georgia-Tourism Revenues and International Arrivals, 2000-2015}

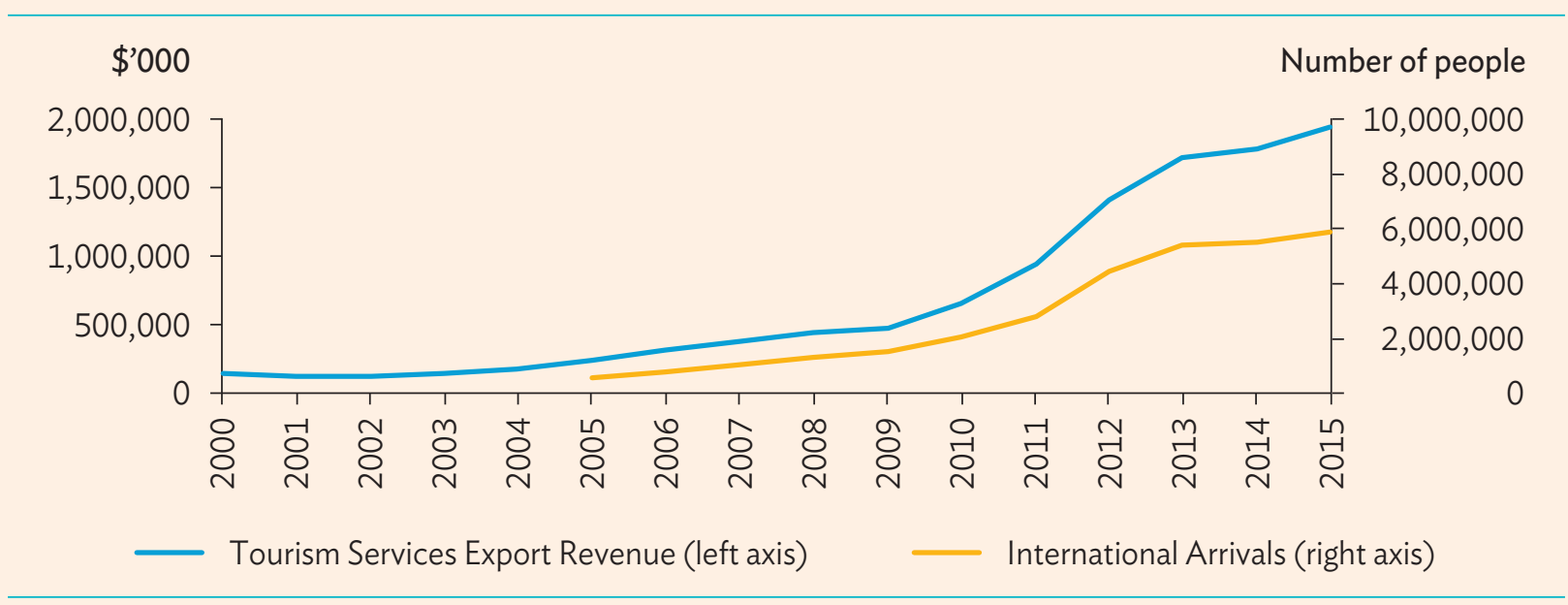

Note: Not all international arrivals are tourism-related.

Source: Georgian National Tourism Administration.

Understanding how such improvement was possible offers important lessons to policy makers. Georgia was already a major tourist destination during Soviet Union times, with more than 3 million arrivals per year in the 1980s. Tourists were attracted to its historical, cultural, and culinary heritage, and its scenery, climate, and environment.

Georgia has also introduced a wide range of policies and measures promoting tourism, which may inspire other CASC countries, including the following:

(i) Close coordination among state and non-state institutions-adopting, for example, liberal visa policies toward countries such as the Russian Federation, Iran, and Iraq despite contrasting positions initially assumed by the Ministry of Foreign Affairs and the Ministry of Internal Affairs, and the Georgian National Tourism Administration.

(ii) Public investment through the state-owned "Partnership Fund" to improve infrastructure and tourist attractions in places of interest, which were crucial for leveraging private investment in services such as hotels and restaurants.

(iii) Tax and other fiscal incentives, which helped attract foreign direct investment to hotels and casinos, including in the development of the city of Batumi.

(iv) Active engagement by the government in attracting international airlines flying to Tbilisi, with a crucial role played by the construction of a new airport in Kutaisi, aimed at attracting low-cost carriers and instituting a level-playing field among airlines.

(v) Support provided by international donors, including investment in tourism-related infrastructure and capacitybuilding programs for human resource formation.

(vi) The emergence of ecosystems of integrated tourist clusters, mitigating information externalities that would have made it difficult for entrepreneurs to reap profits from pioneering ventures.

(vii) Considerable effort by tourism-related agencies in learning, capacity building, quality upgrading, and ensuring proper maintenance of tourist facilities.

Source: M. Fuenfzig. 2017. Structural Transformation in Central and West Asia. Paper prepared for this report. https://www.adb.org/projects/49045-001/main\#project-documents; and Georgian National Tourism Administration. http://stats.gnta.ge/Default.aspx (accessed 10 February 2017). 


\section{4 | External Shocks, 2014-2016}

A series of external shocks hit the CASC economies in 2014-2016. In addition to a major and sudden fall in global primary commodity prices - the most fundamental external shock-CASC countries had problems with key economic partners, including an economic crisis in the Russian Federation, economic rebalancing and slowdown in the People's Republic of China, a political crisis in Ukraine, and currency depreciation in Turkey.

World prices for primary commodities fell substantially in the mid-2010s, amid weak demand, ample supply, and a stronger United States dollar, in which most world commodity prices are denominated. While world prices for metals fell gradually during 2013-2015 and for agricultural raw materials in 2014-2015, world energy prices (especially crude oil) dropped drastically between mid-2014 and early 2016 (Figure 2.2). Brent crude spot plummeted from $\$ 115$ per barrel on 19 June 2014 to $\$ 26$ per barrel on 20 January 2016.

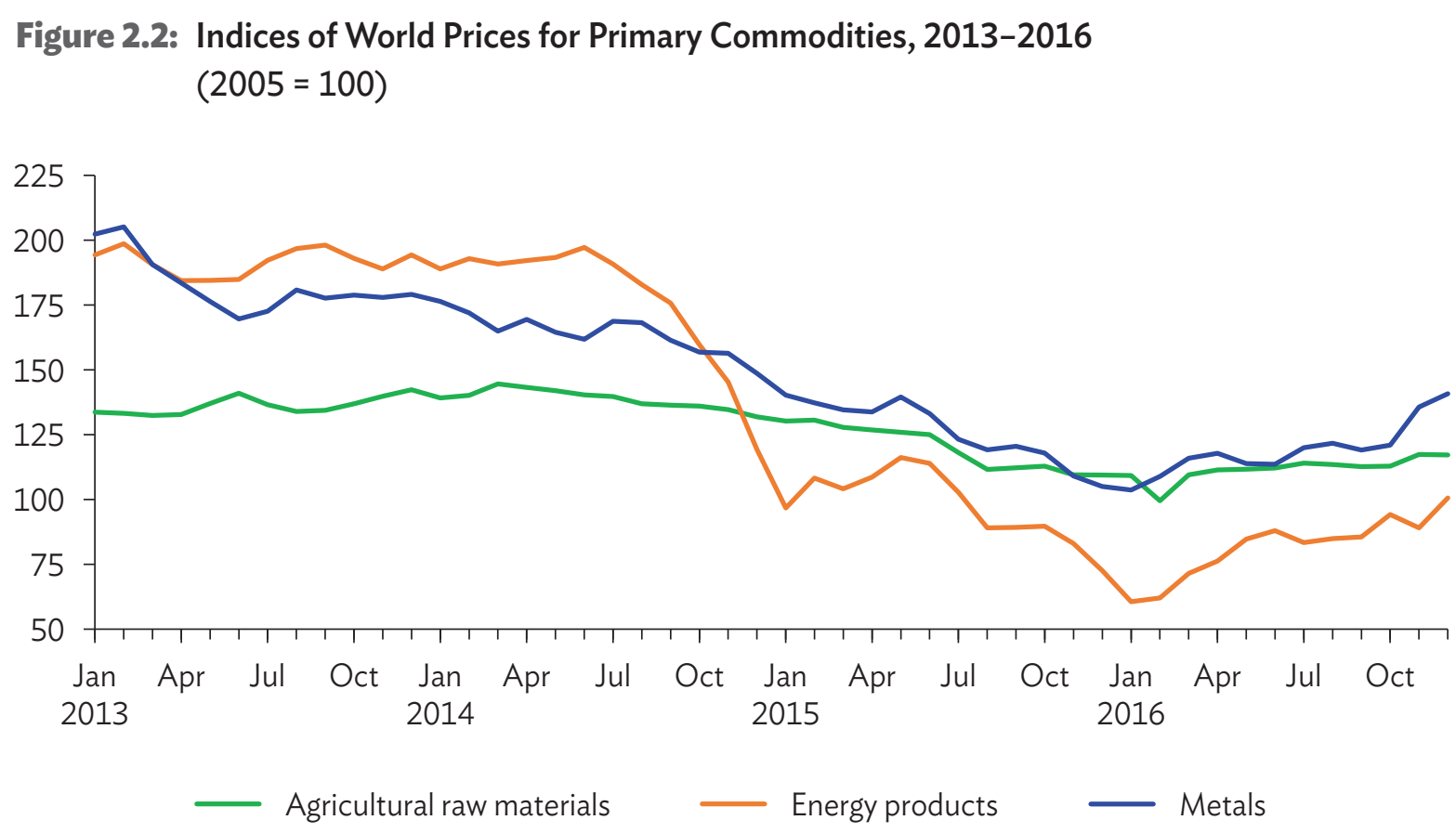

Source: International Monetary Fund. https://www.imf.org/external/np/res/commod/index.aspx.

The slump in world commodity prices had direct and indirect adverse impacts on economic growth. It had a significant direct negative effect on growth by worsening the CASC countries' terms of trade and causing slower growth of or even a decline in exports of primary commodities. Indeed, the terms of trade of Azerbaijan, Kazakhstan, the Kyrgyz Republic, Turkmenistan, and Uzbekistan worsened, and export growth of primary commodities slowed or even declined in the mid-2010s. 
The drop in commodity prices also hurt economic growth through lower aggregate demand in countries such as Azerbaijan and Kazakhstan, where dwindling budget revenues constrained public investment programs and lowered real incomes. Economic activity also contracted due to reduced FDI inflows, particularly in energy and mining. Other indirect negative effects occurred through an adverse impact on the economies of countries where exports were dominated by primary commodities and with which CASC countries have strong economic ties.

One example is the Russian Federation, a major economic partner for CASC countries, leading originator for remittances and FDI, and export market for products and services. Exacerbated by slumping world prices for its primary exports (crude oil, natural gas, metals) and economic sanctions by the European Union and the United States, the Russian economy fell into recession in 2015. In late 2014, a speculative attack against the ruble forced the Russian Federation to switch from a crawling peg to a managed float exchange rate regime ahead of a planned schedule. As capital flight intensified, the ruble depreciated drastically in late 2014 and in 2015. Merchandise imports shrank sharply in 2014-2016 amid depreciation of the ruble in 2014-2015, the economic slowdown in 2014, and the recession in 2015-2016 (Figure 2.3).

Figure 2.3: Selected Economic Indicators for the Russian Federation, 2006-2016

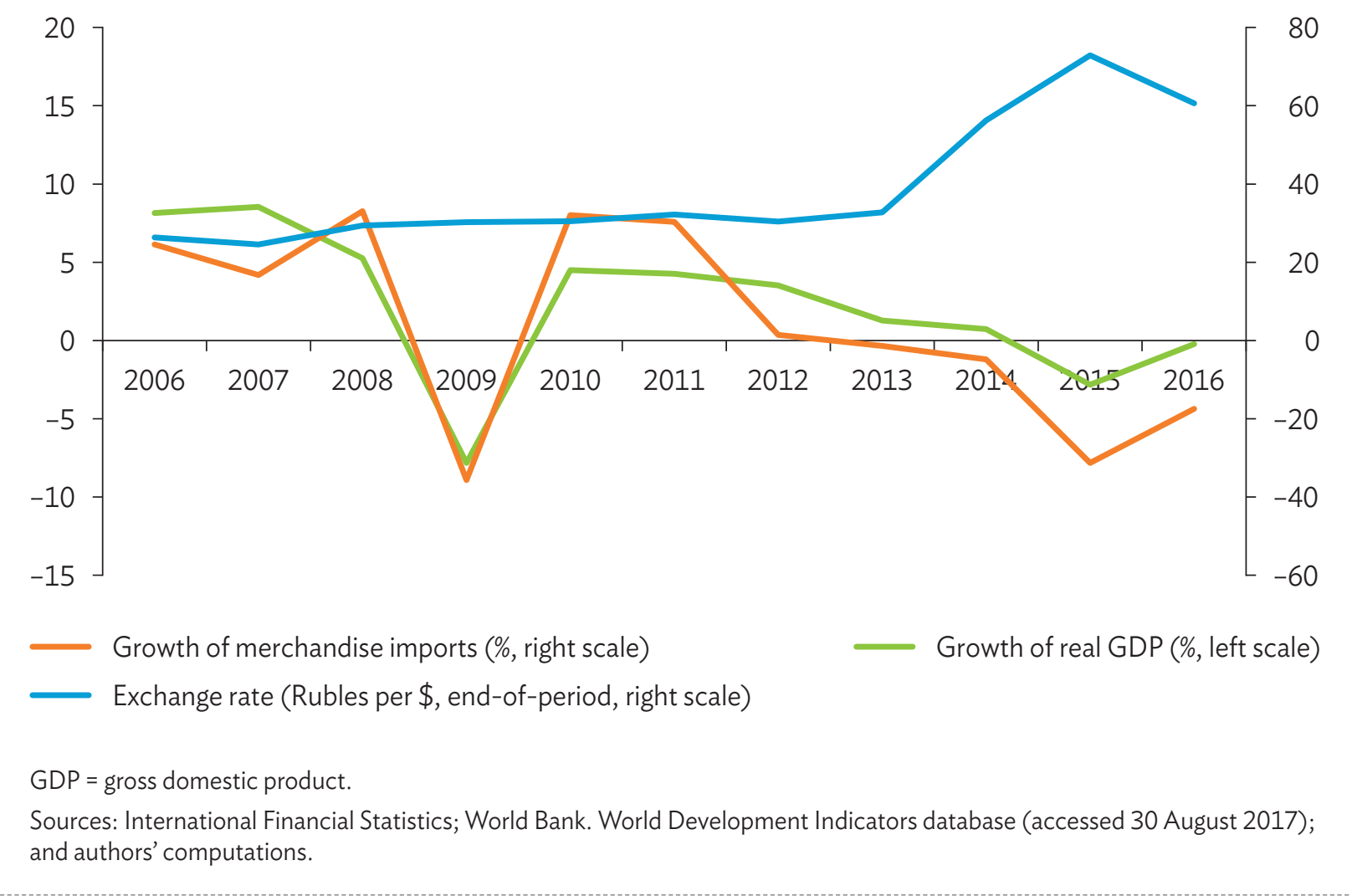


The Russian economic crisis of 2014-2016 significantly undermined economic growth in the CASC region. World Bank estimates suggest that the total yearly remittance transfers from the Russian Federation to CASC countries declined by almost half between 2013 and 2016, with particularly drastic declines in transfers to Georgia, Tajikistan, and Uzbekistan. Tighter immigration rules in the Russian Federation, introduced at the beginning of 2015, contributed to the decrease in remittance outflows.

During 2014-2016, the current account of most CASC countries worsened; the national currencies of all CASC countries depreciated or were devalued, in most cases substantially; financial sector soundness indicators deteriorated significantly in some countries, and inflation accelerated markedly in many. Despite stimulus measures introduced by some governments, economic growth decelerated in Azerbaijan, Kazakhstan, the Kyrgyz Republic, and Tajikistan in 2014, and in all CASC countries in 2015. ${ }^{11}$ Furthermore, the drivers of growth that propelled the strong performance of the previous decade weakened considerably. Economic linkages between CASC countries, while still relatively small, magnified the adverse effects of the shocks emanating from outside the region.

\section{Policy Responses to External Shocks}

CASC countries took various policy measures in response to external shocks. All of CASC countries devalued or let their currencies depreciate, often considerably. Some of them also increased their exchange rate flexibility. Kazakhstan, for instance, devalued the tenge by $20 \%$ in February 2014, moved from a crawling peg with a narrow trading corridor to a floating exchange-rate arrangement in August 2015, and let the tenge depreciate by more than $80 \%$ during August-December 2015. Similarly, Azerbaijan devalued the manat by $34 \%$ in February 2015, switched from a fixed to a floating exchange-rate regime in December 2015, and allowed the manat to depreciate by about 50\% during the same month. Armenia allowed its currency to depreciate by $19 \%$ and Georgia, by 38\%, during 2014-2015. Azerbaijan, Tajikistan, Turkmenistan, and Uzbekistan tightened foreign exchange regulations (shutting down nonbank currency exchange offices and limiting access to foreign exchange through official channels) in an attempt to reduce pressures on their currencies. ${ }^{12}$

As the devaluation/depreciation of the national currencies fueled inflation, the central banks of most CASC countries tightened monetary policy to keep inflation under control. With economic growth slowing and inflation decelerating, the central banks of Armenia, Georgia, and Kazakhstan loosened monetary policy to stimulate economic activity. The Central Bank of Armenia, for example, raised its policy rate from $6.75 \%$ a year in November 2014 to 10.5\% in February 2015, and lowered it to 6.5\% during August 2015-November 2016. The National Bank of Kazakhstan raised its policy rate from 12\% a year in September 2015 to 17\% in February 2016, and lowered it to 10.5\% during May 2016-April 2017. The central banks of Azerbaijan and Tajikistan maintained relatively tight monetary policy until the end of 2016 to curb inflation. Some countries used administrative controls over prices of some key consumption products.

11 In Azerbaijan, the continued decline in oil output, started in 2011, contributed to the deceleration of growth in 2014-2015 and the recession in 2016; in Uzbekistan, external shocks did not have significant adverse impact on economic growth in the same years. One explanation for this trend is that official statistics capture only a fraction of all informal economic activities. In turn, the informal economy depends heavily on remittance inflows, which shrank considerably in 2014-2016.

12 In September 2017, Uzbekistan devalued its official exchange rate by more than $90 \%$ and significantly liberalized access to foreign exchange through formal channels. 
Although external shocks caused a decline in government revenues in most CASC countries, fiscal policy responses varied significantly across the region. Azerbaijan, Kazakhstan, and Turkmenistan responded by curtailing budgetary expenditure (especially nonessential capital expenditure) to contain the fiscal deficit. Armenia, Georgia, and the Kyrgyz Republic cut taxes and/or increased government expenditure to mitigate the adverse impact of the shocks on economic growth and living standards. As 2015-2016 fiscal balances worsened in all CASC countries, so did the stock of public debt, with public debt-GDP ratios exceeding 50\% of GDP in Armenia and 70\% in the Kyrgyz Republic in 2016.

CASC countries also responded by implementing economic and institutional reforms - although, in many cases, reforms were planned/initiated prior to the emergence of external shocks. Box 2.2 looks at some major mitigating measures the CASC countries introduced in 2014-2015.

\section{Box 2.2: Key Reform Measures in Response to External Shocks}

Although the measures introduced in Central Asia and the South Caucasus in response to the external shocks that hit the region in 2014 were unable to create sufficient good jobs for inclusive growth, they helped mitigate adverse impacts on macroeconomic stability, growth, and living standards.

- Armenia improved tax administration, privatized a major hydropower cascade, raised capital requirement for banks, and established the Export Promotion Council tasked with providing operational and financial support to exportoriented companies in priority sectors. It also adopted the Small and Medium-Sized Enterprises (SME) Development Strategy 2016-2018 to improve the institutional, legislative, and operational environment for SME development.

- Azerbaijan strengthened its tax and customs administration, suspended inspections of businesses by government agencies, revived privatization of state-owned enterprises, began restructuring the banking system, introduced a subsidy on non-oil exports, and established the Financial Market Supervisory Chamber tasked with supervising and regulating the financial sector. It also commissioned the development of a road map for economic development until 2025.

- Georgia embarked on a reform program to reinvigorate economic growth focused on (i) liberalization of tax and customs procedures, (ii) establishment of a single window for the provision of government services to legal entities, (iii) speeding up implementation of strategic infrastructure projects, and (iv) adjusting the education system to labor demand. It also developed a debt management strategy with the assistance of international financial institutions. ${ }^{2}$

- Kazakhstan launched a major privatization program, the 100 Concrete Steps to Implement Five Institutional Reforms, introducing a broad range of economic and institutional reforms, including restructuring of the power sector, adopting a single window for customs clearance of exports and imports, and strengthening of antimonopoly policy. The reform program also envisaged deeper integration of the country's transport networks into regional systems and setting up of the Astana International Financial Centre. ${ }^{b}$

- Tajikistan embarked upon an anti-crisis program, including measures aimed at enhancing the efficiency and transparency of the public sector, improving the investment climate, promoting entrepreneurship, and strengthening social protection. Tajikistan also adopted a new “National Development Strategy 2030" - calling for greater resilience of the economy, more efficient use of natural resources, and innovation-and the medium-term development program for 2016-2020, which envisioned a shift to private investment-driven economic growth, combined with an export promotion and import substitution program.

- Uzbekistan launched a privatization program, improved the legal and regulatory framework for private sector development, and strengthened prudential regulation and supervision of banks. It also took steps to increase economic cooperation with neighboring countries and adopted a new national development strategy for 2017-2021.

Sources: ${ }^{a}$ E. Bochorishvili. 2016. Georgia's Response to External Shocks Hitting the Economy. Paper prepared for this report. https://www.adb.org/projects/49045-001/main\#project-documents.

b O. Khudaibergenov. 2016. Kazakhstan's Response to External Shocks Hitting the Economy. Paper prepared for this report. https://www.adb.org/projects/49045-001/main\#project-documents. 


\section{5 | Growth Prospects in Central Asia and the South Caucasus}

After the difficulties of 2014-2016, growth and the prospects of the CASC countries improved in 2017, thanks to partial recovery of commodity prices, a better growth outlook for the Russian economy, and rising remittance inflows. In December 2017, the CASC region's economic growth was projected to reach 3.3\% in 2017 and 3.9\% in 2018, mainly due to an improved outlook for Armenia, Georgia, Kazakhstan, and the Kyrgyz Republic. Strong growth in Kazakhstan in 2017 (4.0\%) originated mainly from extractive industries, the manufacturing sector, and trade, and it is projected to continue in 2018, thanks to countercyclical programs and stable commodity prices. In Armenia, stronger remittances and external demand accelerated growth in 2017, while Georgia benefited from higher infrastructure spending, as well as strong exports, remittance inflows, tourism earnings, and an increase in FDI. In the Kyrgyz Republic, improved gold production and remittances spurred expansion. At the same time, however, low prices for natural gas hampered growth in Turkmenistan and foreign exchange liberalization in September 2017 in Uzbekistan (ADB 2017).

As dependency on primary commodity exports and remittances from foreign workers remain basic features of the CASC economies, the region is still vulnerable to external shocks. Key external variables affecting the medium-term economic outlook include the trend of commodity prices and the pace of economic growth experienced by major trading partners and investing countries. Moreover, rapid progress in information and communication technology, artificial intelligence, and robotics is likely to continue, leading to further automation and shifting demand from unskilled to skilled labor.

\section{Challenges and Opportunities}

As the drivers that ensured overall strong growth of CASC economies during 2001-2015 are foreseeably likely to remain weak, the region needs to create new growth engines that will ensure rapid and inclusive development and generate a sufficiently large number of good jobs.

Industries such as processing of agriculture products, petrochemicals, and other natural resource-based manufacturing, transport and logistic services, information and communication technology services, and tourism have the potential to become new engines of growth and generate large numbers of good jobs in CASC countries. Such growth is based on CASC countries' comparative advantages amid conducive business environments favoring development of entrepreneurship and SMEs, with well-functioning economic institutions and governance systems.

But given that CASC domestic markets remain small, without full integration into the broader regional and world economy, it will be difficult for these industries to achieve economies of scale and generate productivity gains - a precondition to develop new growth engines and create good jobs. ${ }^{13}$ Moreover, to compete in

13 In 2016, the entire population of the CASC region was about 86.5 million (1.16\% of the world); almost 32 million of that population was in Uzbekistan (the largest CASC country by population) and only 2.9 million in Armenia (the smallest CASC country by population). In GDP at current prices, in 2016, the region produced an aggregate value of $\$ 313$ billion (or $0.41 \%$ of world GDP), of which $42 \%$ was generated in Kazakhstan (the largest CASC economy) and 2.1\% in the Kyrgyz Republic (the smallest CASC economy). By comparison, Germany, in the same year, had approximately a similar population ( 82.7 million) but accounted for more than 10 times of world GDP at current prices (4.6\% of the world total). 
international markets, CASC firms will need to keep pace with the rapidly changing modern technologies and actively participate in global value chains, improving their competitiveness.

Among the many challenges, the disadvantages arising out of landlocked geography and remoteness from major seaports increase transport costs and make transit times for international shipments long and often unpredictable (ADB 2006). At the same time, however, a young and growing population could provide demographic dividends (with the notable exception of Georgia, and partially Armenia-where populations have been declining due to high permanent outward migration). ${ }^{14}$ However, integration of youth into the labor market and creation of good jobs remain important issues.

Other key challenges include the need to develop financial markets, while ensuring soundness, as well as controlling macroeconomic indicators such as inflation, current account, fiscal deficit, and external debt.

But the CASC region also presents many opportunities to create good jobs and foster inclusive economic growth. Geography, for example, can turn into an advantage by transforming the proximity to large markets such as the People's Republic of China, India, the Russian Federation, Iran, and Turkey into concrete market opportunities and by enhancing the CASC region's role in connectivity as a major land transit route for trade between East Asia and Europe, as well as through the expected large infrastructure investment under the "Belt and Road Initiative."

Moreover, the massive real exchange rate depreciation of CASC countries' currencies, which occurred after the realignment of global commodity prices in 2014-2015, has enhanced competitiveness of the region's non-commodity exports from the tradable sector. Global advances in information and communication technology and artificial intelligence may create new opportunities for the export of services from CASC countries, such as software development, back office operations, data processing, and call centers for Russian-speaking markets.

In terms of opportunities to strengthen trade relationships and expand non-commodity exports, several CASC countries have now joined the World Trade Organization (WTO) ${ }^{15}$ and can benefit from its Trade Facilitation Agreement, which could be an important factor to considerably reduce transport costs and transit times for international shipments among WTO member countries. Moreover, members of the Eurasian Economic Union, ${ }^{16}$ which was recently established and includes three CASC countries, can benefit from reciprocal lowering of tariff and nontariff barriers to trade and movements of capital and labor.

Other trade-related opportunities include the establishment of a free trade area by Georgia and the European Union ${ }^{17}$ and the lifting of economic sanctions on Iran, which could become a major trading partner for many CASC countries.

14 From 2000 to 2016, the CASC population increased by an average 1.58\% per year, with Tajikistan having the highest (+2.25\%) and Georgia the lowest (-0.95).

15 By the end of 2017, Armenia, Georgia, Kazakhstan, the Kyrgyz Republic, and Tajikistan became members of the WTO.

16 The Eurasian Economic Union, which includes Armenia, Belarus, Kazakhstan, the Kyrgyz Republic, and the Russian Federation, was established in 2015 .

17 Georgia and the European Union established a "Deep and Comprehensive Free Trade Area” effective 1 July 2016. 


\section{Policy Scenarios and Growth Implications}

To overcome the challenges and capture the opportunities described for fostering rapid, inclusive growth, CASC countries need to carry out comprehensive structural reforms that address various aspects of the economic systems in place in the region.

The promotion of good jobs for inclusive growth requires adopting a set of reforms designed to capture the full potential of both supply of and demand for labor, removing their inadequacies, and enhancing the institutional and governance systems in place in each country. Policies are needed to improve human capital formation and create an enabling environment for the private sector to utilize capital efficiently.

To this end, with proper calibration depending on the different national economic situations, CASC countries need to improve governance and more effectively fight corruption, strengthen macroeconomic policies and public financial management, and enhance access and quality in health care and education. They also need to improve transport infrastructure and logistics services, increase regional economic cooperation, and activate a trade-investment nexus in manufacturing, supporting the development of SMEs. In so doing, the countries can learn important lessons from the relevant experiences of East Asian and Southeast Asian countries (such as Malaysia, the Republic of Korea, and Viet Nam), East European countries (such as Poland), and advanced countries with similar factor endowments (such as Australia and Canada).

The potential impact of structural reforms on the long-term economic growth of CASC countries can be assessed with an econometric exercise estimating medium-term growth rates under different scenarios. Table 2.4, which summarizes the result of the exercise, refers to the average annual growth rate of real GDP for 2016-2030 and compares "limited-action" and "full-action" scenarios. Uzbekistan is not included because of lack of data on the key economic variables used in the model to calculate the human capital index. The average growth rates for the CASC region as a whole in both scenarios were obtained using, as weights for each country, the relative share of countries' GDP on the region's total for the year 2016. The model's description and estimation results are in the Appendix. ${ }^{18}$

The results of this exercise suggest that, by introducing a limited package of structural reforms, countries in the CASC region will be able to grow at an average 3.7\% during 2016-2030. Having already introduced relatively more reforms than other CASC countries, Georgia will be able to grow at an average annual rate of 4.6\% and the Kyrgyz Republic, at 4.4\%, over 2016-2030. Azerbaijan, which shows less appetite for reforms, will be relegated to an average $2.4 \%$ per year.

18 The full econometric exercise is presented in Ganiev (2017). 
Table 2.4: Projected Average Annual Growth Rate of Real Gross Domestic Product, 2016-2030

\begin{tabular}{l|c|c|c} 
& "Limited-Action" Scenario & "Full-Action" Scenario & Difference \\
\hline Armenia & 3.0 & 7.1 & 4.1 \\
\hline Azerbaijan & 2.4 & 6.7 & 4.4 \\
\hline Georgia & 4.6 & 7.6 & 3.0 \\
\hline Kazakhstan & 3.4 & 7.4 & 4.0 \\
\hline Kyrgyz Republic & 4.4 & 8.6 & 4.2 \\
\hline Tajikistan & 3.6 & 9.2 & 5.6 \\
\hline Turkmenistan & 4.1 & 8.8 & 4.7 \\
\hline Region-wide $^{\mathrm{a}}$ & 3.4 & 7.5 & 4.1 \\
\hline
\end{tabular}

a The results for Central Asia and the South Caucasus do not include Uzbekistan due to a lack of data needed to compute the human capital index. The average growth rates for the region are obtained using, as weights for each country, the relative share of countries' gross domestic product on the region's total for the year 2016.

Sources: B. Ganiev. 2017. Growth Performance and Prospects of the Countries of Central Asia and South Caucasus. Background paper prepared for this report. https://www.adb.org/projects/49045-001/main\#project-documents; and authors' computations.

Introducing a full reform package will have a very significant impact on the speed of economic growth across the region. Adopting a "full-action" scenario will, on average, "add" 4.1 basis points to long-term annual GDP growth, with the region, as a whole, growing at an average annual rate of 7.5\%. Tajikistan will benefit most from the region's reformist approach.

The limited-action scenario refers to a situation where CASC countries decide to introduce only a limited range of measures, policies, and reforms aimed at building human capital, strengthening the labor market and social protection, promoting economic diversification, enhancing the development of the private sector, and improving governance and institutions-while maintaining macroeconomic stability. In such case, economic growth will largely be driven by an increased supply of unskilled labor and accumulation of physical capital, with only a relatively small number of good jobs being created and with relatively high unemployment, underemployment, and/or informal employment. Moreover, brain drain will increase, and inequality rise. Eventually, most CASC countries could fall into the middle-income trap.

The full-action scenario is one in which CASC countries not only maintain macroeconomic stability, but also make considerable progress in all areas of structural reforms-from building human capital to strengthening productivity, as well as improving governance and institutions. Under such scenario, growth will be mostly driven by accumulation of human capital and rising total factor productivity. Many good jobs will be created; unemployment, underemployment, informal employment, poverty, and inequality decline significantly. As a result, a few CASC countries will be able to join the high-income group by 2030. 


\title{
GROWTH AND INCLUSIVENESS
}

\author{
by Ravi Kanbur and Juzhong Zhuang
}

\begin{abstract}
mid many definitions of inclusive growth involving income and non-income dimensions, this chapter introduces an analytical framework in which income generation is based on assets (physical, financial, and human capital), return to assets, and public transfers. It focuses on the human capital embodied in labor and how skill levels affect the return to labor (wages).
\end{abstract}

The chapter discusses public transfers that are part of social protection, which can help mitigate inequality and improve inclusiveness. It analyzes the implications of the informal economy, which tends to be large in countries in Central Asia and the South Caucasus (CASC). It discusses inequality using the basic categories of space, gender, and youth, through which it can be disaggregated.

\section{1 | Inclusive Growth: An Analytical Framework}

What is inclusive growth? The literature discusses its definition extensively, and different international agencies use similar and closely related conceptualizations. The United Nations Development Programme, for example, defines economic growth as inclusive when it addresses poverty, inequality, social exclusion, and unemployment. The World Bank expands the definition to include the distributional and social impacts of policy reforms on the well-being of different groups of the population, particularly the poor and vulnerable. The International Monetary Fund defines economic growth as inclusive when lower-income earners benefit from growth equally or more than the population as a whole. The World Economic Forum refers to the pace and pattern of growth, which are interlinked and must be addressed together, for growth to be inclusive. The Organisation for Economic Co-operation and Development considers economic growth inclusive if it creates opportunity for all segments of the population and distributes the dividends of increased prosperity fairly across society, both in monetary and nonmonetary terms. ${ }^{19}$

Reducing inequalities in the region is a core operational priority of ADB's Strategy 2030, emphasizing human development and social inclusion to achieve this goal (ADB 2018b). ADB views inclusive growth as the central pillar to achieve an "Asia and Pacific region free of poverty" (ADB 2008b). ${ }^{20}$ It defines inclusive growth as "growth that creates and expands economic opportunities and ensures broader access to these opportunities."

19 United Nations Development Programme. http://www.undp.org/content/undp/en/home/sustainable-development/developmentplanning-and-inclusive-sustainable-growth/inclusive-growth--addressing-inequality-and-social-exclusion.html; World Bank (2009); World Economic Forum (2017); Kireyev and Chen (2017); and Organisation for Economic Co-operation and Development. http://www.oecd.org/inclusive-growth/.

20 The strategy's other two pillars are environmentally sustainable growth and regional integration. 
From these frameworks, specifications for identifying inclusive growth include economic growth with (Ali and Zhuang 2007)

(i) income poverty reduction,

(ii) no increase in income inequality,

(iii) reduction in income inequality,

(iv) reduction in income inequality and income poverty,

(v) reduction in income and non-income dimensions of inequality and poverty, and

(vi) economic growth coupled with equality of opportunity.

Since economic growth that neither increases nor reduces income inequality will also reduce income poverty, the inclusiveness of growth is closely associated with the evolution of inequality. A rise in inequality will threaten inclusiveness on any definition. There may be trade-offs: if faster economic growth requires a rise in inequality, policy makers face a tough choice. However, if analysis can identify win-win scenarios in which policy reforms and investments can enable growth and address inequality at the same time, these scenarios should be given high weight in policy discussions.

One objective of this study is to identify policy packages for CASC countries where higher growth and its inclusiveness go hand in hand, by generating opportunities for creation and expansion of good jobs.

\section{Assets, Returns, and Transfers}

A simple way to begin thinking about the inclusiveness of growth is to consider income $Y$ as the product of an asset $A$ and the rate of return on that asset $R$ :

$$
Y=A R
$$

The asset can be physical, financial, or human. The rate of return on a physical asset, such as a house, can be calculated based on its cost and the rental received when leased, net of taxes. The rate of return on a financial asset is easiest to grasp: for example, the interest on bank savings, or the returns from stocks and shares. But for most people, especially the poor, their most important income earning asset is simply their human capital-their labor. This study focuses on labor, as it is key to creating good jobs for inclusive growth.

Although human capital embodied in labor encompasses a range of factors, at the simplest cut, it can be classified into different skill levels ranging from basic unskilled labor to high-end skills which might be almost like capital, except that they are embodied in a human being. The return to skill is known to be positive, and increasing: there is a "skill premium" in wages relative to basic labor, and the premium rises at higher and higher levels of skill. The returns to labor, and indeed to any asset, will be determined by supply-side and demand-side factors. A relative scarcity of a particular type of skilled labor will tend to increase the return to that skill, and a relative abundance of another type of labor will tend to lower the wage for that labor or, if wages are not flexible downward, cause unemployment. 
The above discussion, on assets, returns, and income, revolves around market income. It is about the "pre-distribution" as it is sometimes known. The actual distribution of "take home" income depends also on public transfers such as pensions, unemployment benefits, and so on. At the household level, total resources would include other transfers such as child or housing benefit, or the monetary equivalent of benefits in-kind. These benefits have to be paid for by the public, of course, through taxes.

Adding $T$ as the net transfer (transfers after subtracting taxes and other payments to the state), a formula for final income can be written as

$$
Y=A R+T
$$

In the above formula, $A$ can be considered as a collection of assets and $R$ as a collection of corresponding rates of return. However, this study focuses on human assets ranging from basic labor through the skill spectrum, and the wages for different categories of labor.

When income depends on assets, returns, and net transfers, then inequality of income will depend on inequality in assets, inequality in rates of return, and inequality in net transfers. Leaving to one side some technical issues in measurement, broadly speaking, inequality will be greater, the greater the asset inequality, rate of return's inequality, and net transfers' inequality. The evolution of income inequality over time will, in turn, depend on the evolution of inequality of assets, in rates of return, and in net transfers. If these inequalities are increasing, income inequality will also increase (Kanbur 2014).

\section{Income Growth at the Country Level}

The next step is to consider income growth at the country level. Aggregate growth of income in each country will depend on aggregate growth of assets, of rates of return, and of net transfers. In the aggregate, of course, net transfers and growth of net transfers must be zero unless there are significant flows from outside the economy, or the government is building up debt. Sustainability of gross transfers is thrown into sharp relief by this aggregate perspective. The sums must add up overall.

Aggregate income growth in the medium term, thus, depends on accumulation of assets for given rates of return and on increasing the average rate of return on assets. For human capital, or labor, this means building up human capital and increasing the return to labor of different skill categories. Of course, the two variablesthe asset and its return-are related. Accumulation of skills on the supply side with no change in the demand for them will depress the rate of return to skill. Demand and supply have to be taken together. If there are sectoral rigidities such that labor is stuck in sectors with low productivity, reallocation of this labor to higher return sectors will be both growth- and equity-enhancing. 
Governments can influence the supply of human capital, and the demand for it, through a range of policies discussed in this report. But these policies operate in the shadow of global forces of technology and trade. The fundamental trend in global technology since the mid-1990s has been to increase the productivity and, thus, the demand for skilled labor (and complementary capital) relative to basic labor. These forces are being transmitted to all countries through international trade and investment. They have brought growth benefits, but have also increased inequality through displacement of basic labor and skewed distribution of return to physical capital and financial assets. The answer to this rising inequality is not, of course, to shut off the transmission mechanism of higher productivity from global trends, but to prepare the economy to absorb them and use them to enhance economic development. By adopting appropriate economic policies, countries can increase the supply of skilled labor and improve the mobility of labor from low-productivity to high-productivity sectors.

Net transfers-and social protection mechanisms more generally-have the potential to enhance the inclusivity of growth. In a purely accounting sense, the more equally distributed are net transfers, the lower will be overall inequality - with two major caveats. First, many types of transfers are not equality-enhancing. For example, government pension schemes, which focus primarily on the formal sector of the economy, tend to leave out low-income workers operating in the informal sector. Second, the detailed rules for these transfers, including the taxes needed to finance them, can create distortions and market incentives which may encourage informality and hold back the structural economic transformation needed for achieving inclusive growth.

\section{Sectoral Disaggregation}

Inclusiveness of growth applies not just across individuals but also across salient socioeconomic groups. This study highlights groups differentiated by gender, age, and location. Specifically, growth that leaves behind women, youth, and disadvantaged regions is neither equitable nor efficient. Income differences across these groups account for a significant share of overall inequality. But the differences in returns to similar human capital across the divides of gender, age, and location represent an inefficiency, the removal of which can enhance economic growth. Differences also represent, particularly for youth and lagging regions, a serious problem for social cohesion at a time when difficult policy decisions need to be made to address the many external challenges facing CASC economies.

Finally, inclusiveness and inequality are surely not restricted to the income dimension. Non-income dimensions of well-being, such as health and education, are also extremely important. These together also constitute components of human capital. Thus, not only are inequalities in health and education indicators of non-inclusiveness in well-being across individuals and across socioeconomic groups: they are also the foundations of human capital inequality and, therefore, generate income inequality. 


\section{2 | Growth, Poverty, and Inequality in Central Asia and the South Caucasus}

\section{Growth, Poverty, and Inequality}

During 2001-2015, on average, CASC countries achieved rapid economic growth. Annual average GDP growth for these countries reached 7.5\%, lower than the average growth of East Asia in the same period, but higher than that of Southeast Asia, South Asia, and the Pacific countries (Table 3.1). The annual GDP growth rate was particularly pronounced in Azerbaijan and Turkmenistan, driven by oil and gas. But growth has also been impressive in all other CASC countries, with the notable exception of the Kyrgyz Republic, which grew at $4.3 \%$ annually. This high growth also reflects recovery from low bases after the CASC countries contracted sharply in the 1990s following their separation from the Soviet Union.

\section{Table 3.1: Per Capita GDP and GDP Growth, Central Asia and the South Caucasus and Other Developing Asia, 2001-2015}

\begin{tabular}{l|c|c|c|c} 
& \multicolumn{3}{|c|}{ Per Capita GDP (constant 2010 \$) } & Average GDP \\
\cline { 2 - 4 } & 2001 & 2015 & Growth Rate (\%) & Growth Rate (\%) \\
\hline Armenia & 1,548 & 3,935 & 6.89 & 6.55 \\
\hline Azerbaijan & 1,781 & 6,117 & 9.21 & 10.58 \\
\hline Georgia & 1,517 & 3,973 & 7.12 & 5.86 \\
\hline Kazakhstan & 5,107 & 10,617 & 5.37 & 6.62 \\
\hline Kyrgyz Republic & 683 & 1,021 & 2.92 & 4.30 \\
\hline Tajikistan & 448 & 926 & 5.32 & 7.61 \\
\hline Turkmenistan & 2,459 & 6,694 & 7.42 & 8.95 \\
\hline Uzbekistan & 837 & 1,851 & 5.84 & 7.56 \\
\hline CASC & 1,933 & 4,469 & 6.06 & 7.47 \\
\hline East Asia & 2,502 & 7,297 & 8.91 & 9.50 \\
\hline South Asia & 768 & 1,604 & 5.29 & 6.89 \\
\hline Southeast Asia & 2,345 & 4,003 & 4.55 & 5.88 \\
\hline Pacific & 1,846 & 2,620 & 2.65 & 4.85 \\
\hline Developing Asia & 1,688 & 4,146 & 6.51 & 7.69 \\
\hline
\end{tabular}

CASC = Central Asia and the South Caucasus, GDP = gross domestic product.

Notes: Regional averages are weighted by population size in 2015. The Cook Islands; Nauru; and Taipei, China are not included in the regional estimates because data were not available.

Source: World Bank. World Development Indicators database (accessed 29 August 2017). 
During the 1990s, poverty increased in the CASC countries as living standards and budgetary expenditures on social protection declined sharply. Poverty incidence has decreased significantly since the early 2000s, nevertheless, thanks to strong economic growth, particularly in Azerbaijan and Kazakhstan. With the annualized poverty reduction at least twice that of neighboring countries, Azerbaijan's poverty rate at the national poverty line declined from 49\% in 2001 to 5.9\% in 2016, and Kazakhstan's from 46.7\% to 2.6\%. In other countries, poverty reduction, measured at the national poverty line, has also been significant since 2000, although the absolute level remained relatively high by the mid-2010s (Table 3.2).

Table 3.2: Change in Poverty Headcount Ratio for Central Asia and the South Caucasus, from Early 2000s to Mid-2010s

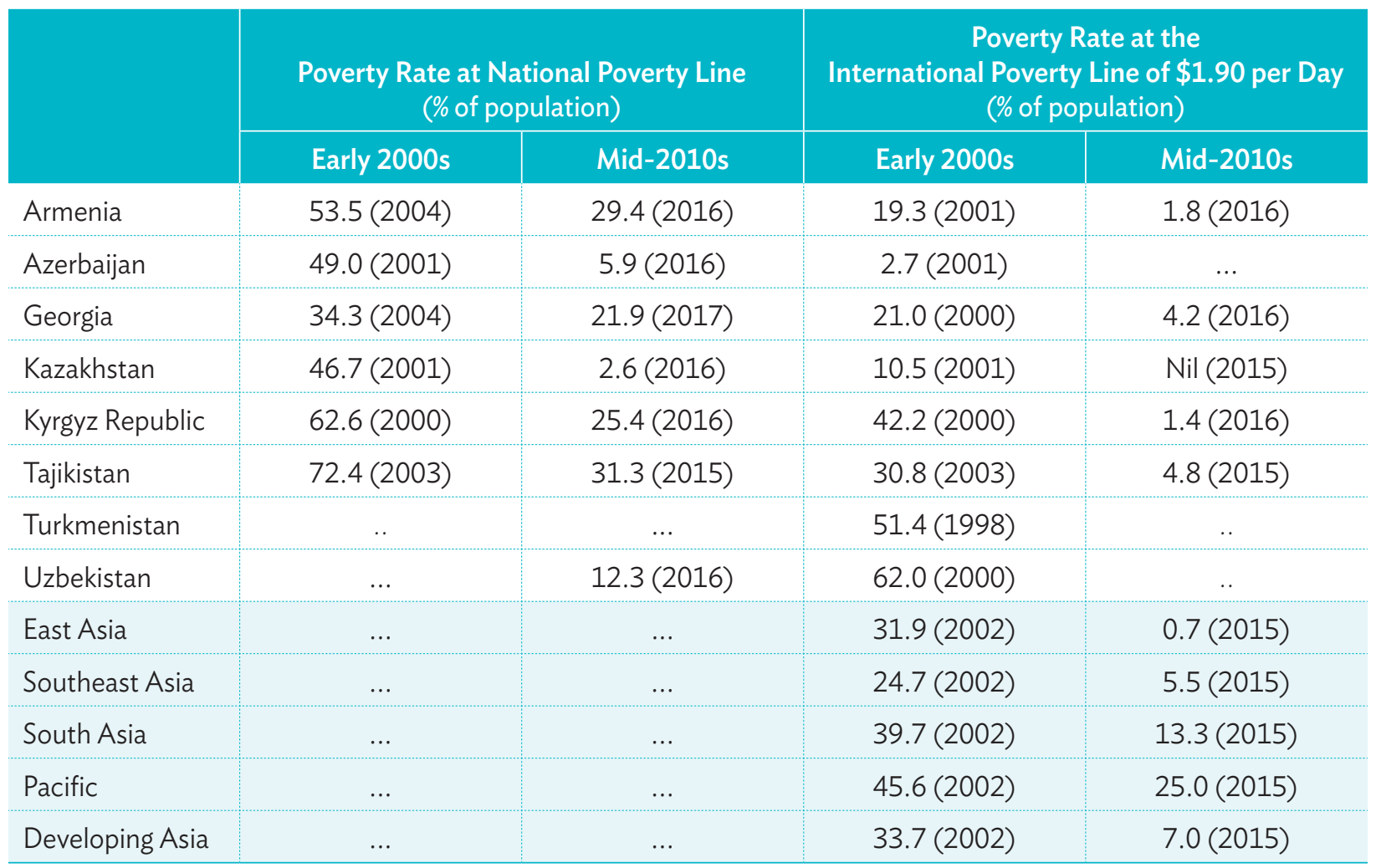

$\ldots=$ data not available.

Sources: World Bank. World Development Indicators database (accessed 30 August 2017); and Asian Development Bank estimates based on PovcalNet data (accessed 24 September 2017).

Measured at the $\$ 1.90$ per day international poverty line, extreme poverty has been eradicated in four CASC countries (Armenia, Azerbaijan, ${ }^{21}$ Kazakhstan, and the Kyrgyz Republic), and was close to being eradicated in Georgia and Tajikistan by the mid-2010s, while data are not available for Turkmenistan and Uzbekistan. CASC countries' extreme poverty, at the $\$ 1.90$ international poverty line, is also lower than most subregions of developing Asia, except for East Asia.

21 Although updated figures are not available, poverty at the $\$ 1.90$ international poverty line for Azerbaijan (at 2.7\% in 2001) was considered eradicated by the mid-2010s. 
Recent data on the Gini index, ${ }^{22}$ one of most standard measures of income inequality, shows wide diversity across CASC countries, with Georgia somewhat an outlier with higher inequality than other countries in the region, especially Kazakhstan and the Kyrgyz Republic (Figure 3.1).

\section{Figure 3.1: Consumption-Based Inequality in Selected Developing Asian Countries, Mid-2010s}

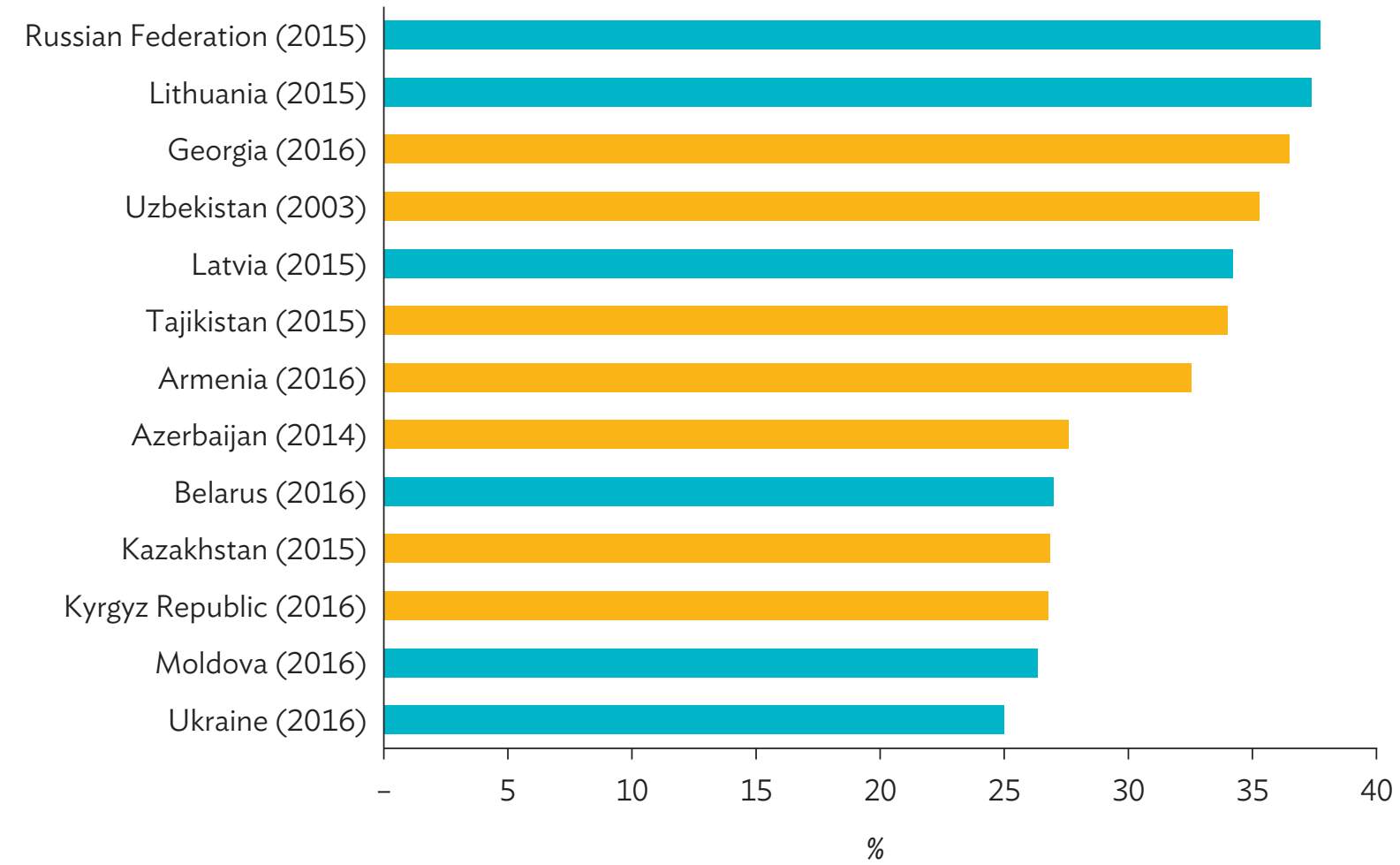

Note: All are consumption-based inequality estimates, except for Azerbaijan, Latvia, and Uzbekistan, which are income-based estimates.

Sources: Gini coefficients for Azerbaijan and Uzbekistan are from national sources reported in country papers. The rest are from PovcalNet, the online tool for poverty measurement developed by the Development Research Group of the World Bank. http://iresearch.worldbank.org/PovcalNet/home.aspx (accessed 28 August 2018).

While CASC countries tend to score favorably compared with the rest of the world, especially with countries at similar per capita GDP levels from developing Asia, they tend to be in line with the range of former Soviet Union members. For example, Kazakhstan, which had per capita income of \$10,617 and a Gini index of 26.9 in 2015, can be compared to the Russian Federation, where per capita GDP was $\$ 11,326$ and the

22 The Gini index measures the extent to which income distribution among households deviates from a perfectly equal distribution. A Gini index of 0 indicates perfect equality, while an index of 100 implies total inequality. 

Figure 3.2: Per Capita Gross Domestic Product (constant 2010 \$)
and Gini Index in Selected Countries, 2010

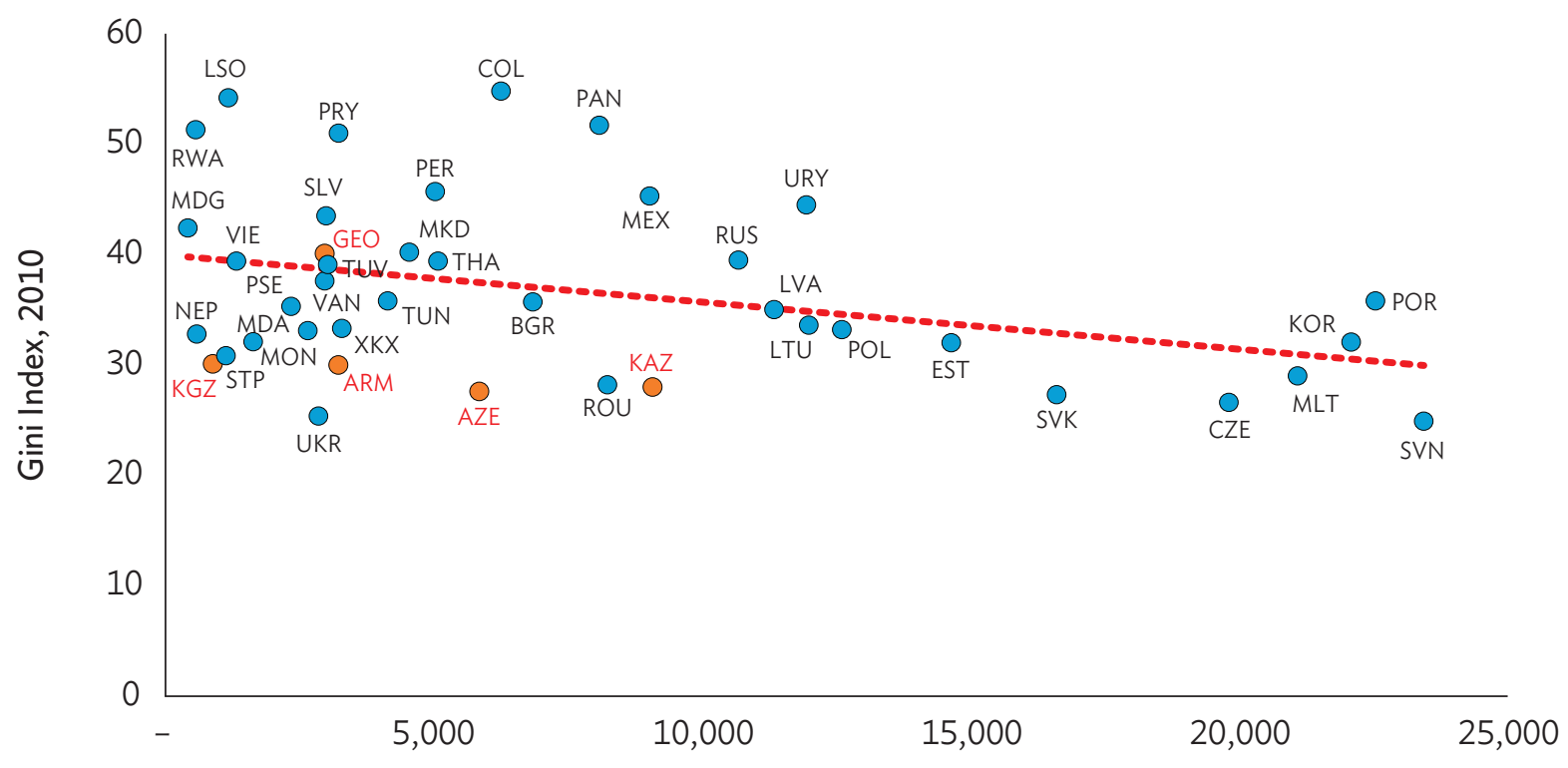

Per capita GDP (constant 2010 \$), 2010

GDP = gross domestic product.

Notes: For comparability, only countries with income levels similar to the Central Asian and South Caucasus countries were included in the chart, with Slovenia (SVN) as an upper limit. The Gini used for Azerbaijan is for 2014.

The countries are: $A R M=$ Armenia, $A Z E=$ Azerbaijan, $B G R=$ Bulgaria, $C O L=$ Colombia, $C Z E=$ Czech Republic, $\mathrm{EST}=$ Estonia, $\mathrm{GEO}=$ Georgia, KAZ = Kazakhstan, KGZ = Kyrgyz Republic, KOR = Republic of Korea, LSO = Lesotho, LTU = Lithuania, LVA = Latvia, MDA = Moldova, MDG = Madagascar, MEX = Mexico, MKD = Macedonia, MLT = Malta, $\mathrm{MON}=$ Mongolia, NEP $=$ Nepal, $\mathrm{PAN}=$ Panama, $\mathrm{PER}=$ Peru, $\mathrm{POL}=$ Poland, $\mathrm{POR}=$ Portugal, $\mathrm{PRY}=$ Paraguay, $\mathrm{PSE}=$ West Bank and Gaza, ROU = Romania, RUS = Russian Federation, RWA = Rwanda, SLV = El Salvador, STP = Sao Tome and Principe, SVK = Slovak Republic, SVN = Slovenia, THA = Thailand, TUN = Tunisia, TUV = Tuvalu, UKR = Ukraine, URY = Uruguay, VAN = Vanuatu, VIE = Viet Nam, XKX = Kosovo.

Sources: The Gini for Azerbaijan is from national sources. The rest are from PovcalNet, the online tool for poverty measurement developed by the Development Research Group of the World Bank. http://iresearch.worldbank.org/ PovcalNet/home.aspx (accessed 28 August 2017) and World Development Indicators database (accessed 28 August 2017).

Gini index was 37.7 in the same year. Figure 3.2 further illustrates this situation, showing the relatively lower Gini indexes of the CASC countries than the norm for countries at the same levels of income (shown by Gini coefficients along the broken line).

Furthermore, the consumption-based Gini indexes show an overall downward trend during 2000-2016 for most of CASC countries, with the exception of some upward movements experienced in recent years in Azerbaijan and Tajikistan (Figure 3.3). 


\section{Figure 3.3: Trends in Consumption-Based Gini Index, Selected Countries in Central Asia and the South Caucasus}

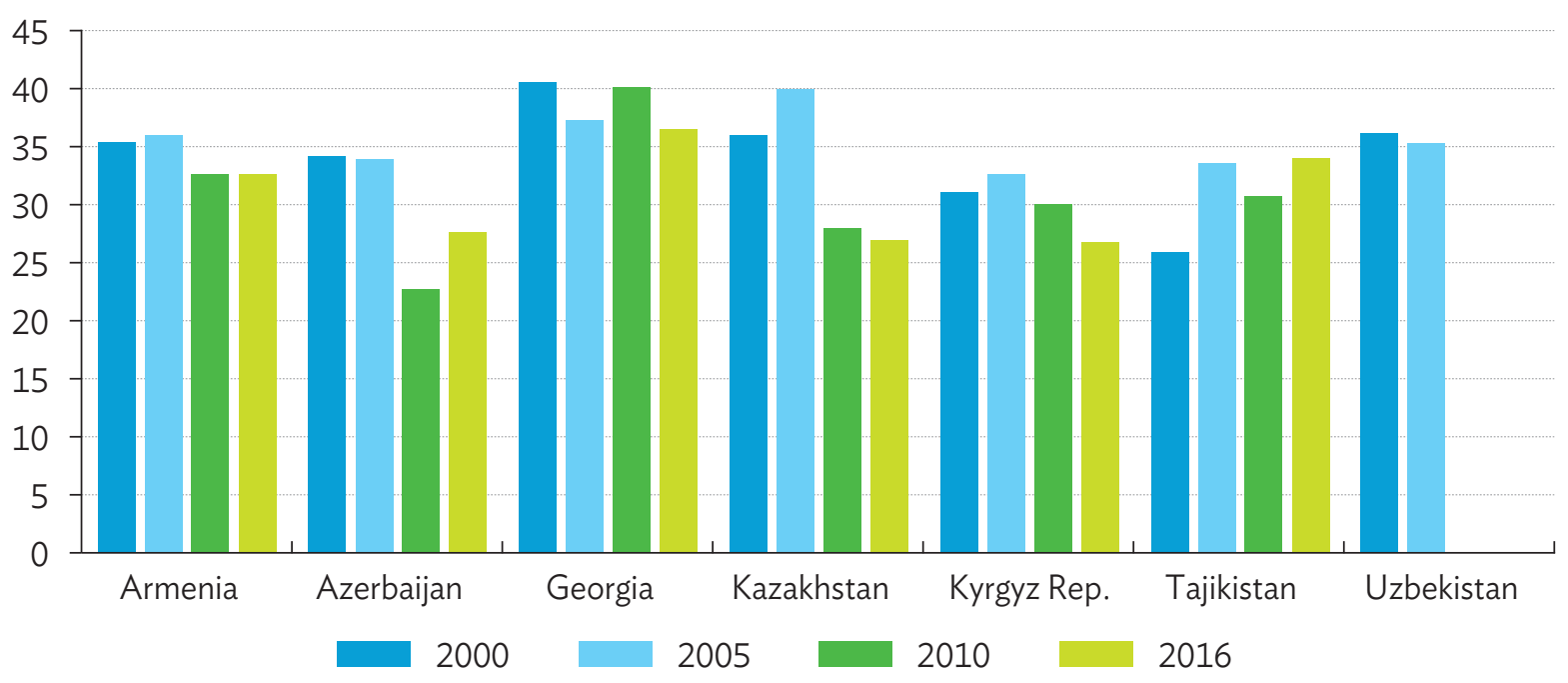

Notes: For Tajikistan, the figure in 2000 is from the year 1999, 2005 from 2004, 2010 from 2009, and 2016 from 2015; for Kazakhstan, the figure in 2000 is from 2001, and in 2016 from 2015; for Uzbekistan, the figure in 2005 is from 2003 ; and for Azerbaijan, the figure in 2000 is from 2003, in 2010 from 2011, and in 2016 from 2014. The Gini indexes are consumption-expenditure-based (at 2011 purchasing power parity in \$), except those for Azerbaijan, which are incomebased from national sources. Data are not available for Turkmenistan. Data are not available for Uzbekistan in 2010 and 2016.

Sources: Country report on Azerbaijan, PovcalNet, the online tool for poverty measurement developed by the Development Research Group of the World Bank. http://iresearch.worldbank.org/PovcalNet/home.aspx (accessed 28 August 2017).

Even though poverty in most CASC countries has been significantly reduced and income inequality in these countries compares favorably with that in many other countries in Asia and with countries at similar income levels, there is no room for complacency in pursuing inclusive growth. Extreme poverty, measured at the $\$ 1.90$ international poverty line, has been eradicated or is close to being eradicated in most CASC countries, as discussed. But the poverty rate, measured th the national poverty line, remains fairly high at $20 \%-30 \%$ in four countries, suggesting poverty reduction remains a key development challenge there. ${ }^{23}$

Moreover, although average income inequality in CASC countries is not high compared with that in the rest of Asia and other countries around the world, the Gini coefficients shown in Figure 3.3 are based on per capita household consumption expenditure data, which tend to be more equally distributed and less responsive to economic fluctuations than household income data. The overall picture presented so far may thus reflect a rather conservative estimate of the levels and trends in inequality for the region. As a consequence, the recent rise in inequality shown in Azerbaijan and Tajikistan could be more pronounced and widespread when reviewed using household income data. Table 3.3 illustrates this trend, comparing consumption expenditure-based Gini indexes with income-based Gini indexes for the four CASC countries where household survey data are available.

23 Poverty data for Turkmenistan are not available. 
Table 3.3: Income and Consumption-Expenditure-Based Gini Indexes for Selected Countries in Central Asia and the South Caucasus

\begin{tabular}{|c|c|c|c|c|c|c|c|c|c|} 
& \multicolumn{2}{|c|}{ Armenia } & \multicolumn{2}{c|}{ Georgia } & \multicolumn{2}{c|}{ Kyrgyz Republic } & \multicolumn{2}{c}{ Tajikistan } \\
\cline { 2 - 10 } & Income & Expenditure & Income & Expenditure & Income & Expenditure & Income & Expenditure \\
\hline 2004 & 38.6 & 37.5 & 43.2 & 36.3 & 44.4 & 34.8 & 44.6 & 33.6 \\
\hline 2009 & 35.3 & 28.0 & 44.6 & 38.1 & 37.1 & 29.9 & 44.4 & 30.8 \\
\hline 2015 & 38.5 & 32.4 & 40.0 & 36.4 & 36.4 & 29.0 & $\ldots$ & 34.0 \\
\hline
\end{tabular}

$\ldots$ = data not available.

Sources: Income inequality estimates: Authors' calculations using household survey data from various years; Consumption expenditure inequality estimates: World Bank. World Development Indicators database (accessed 29 August 2017).

The income-based Gini indexes are much higher than the consumption expenditure-based for all four countries, with the difference marked in the range of 4-7 points for most years. Furthermore, recent experiences from other countries around the world suggest that while forces of technological progress and globalization drive growth, they can also have significant implications for income distribution and, in many cases, lead to rising income inequality. It is, therefore, important that when governments pursue high GDP growth, efforts focus on ensuring that the benefits of growth are broadly shared.

There is consensus among economic analysts that the extremes of income distributions tend not to be well captured in household surveys, from which inequality estimates are usually derived. Sampling errors, where surveys fail to include households in extreme poverty, or nonresponse bias, where high-income earners are not responsive, tend therefore to understate inequality. Household income and expenditure surveys do not capture wealth inequality in inheritance, investments, and other nonlabor income, because of the presence of large informal economies, and the unwillingness of survey respondents to fully disclose their wealth. These factors are important in the CASC region and could help explain the widespread social perception that while the gap between the haves and the have-nots has been widening in recent years, this is not adequately captured by Gini coefficients.

\section{Decomposing Income Inequality}

Several income inequality measures can be decomposed into different parts, such as inequality between different population groups and within each population group, and inequality of various income sources. Such decomposition analysis helps understand sources of income inequality and determinants or drivers of its change, and gauge their respective contributions to overall inequality. This report applies the decomposition analysis to the four CASC countries (Armenia, Georgia, the Kyrgyz Republic, and Tajikistan) where household survey data are available.

Decomposition by subpopulation groups. One important question in examining drivers of income inequality is what role educational attainments play. Figure 3.4 presents the results of between-group and within-group decomposition analysis by household subgroups classified according to education attainment (illiterate; primary, secondary, or tertiary education) of heads of households in the survey data. The analysis focuses on income-based inequality measures. 


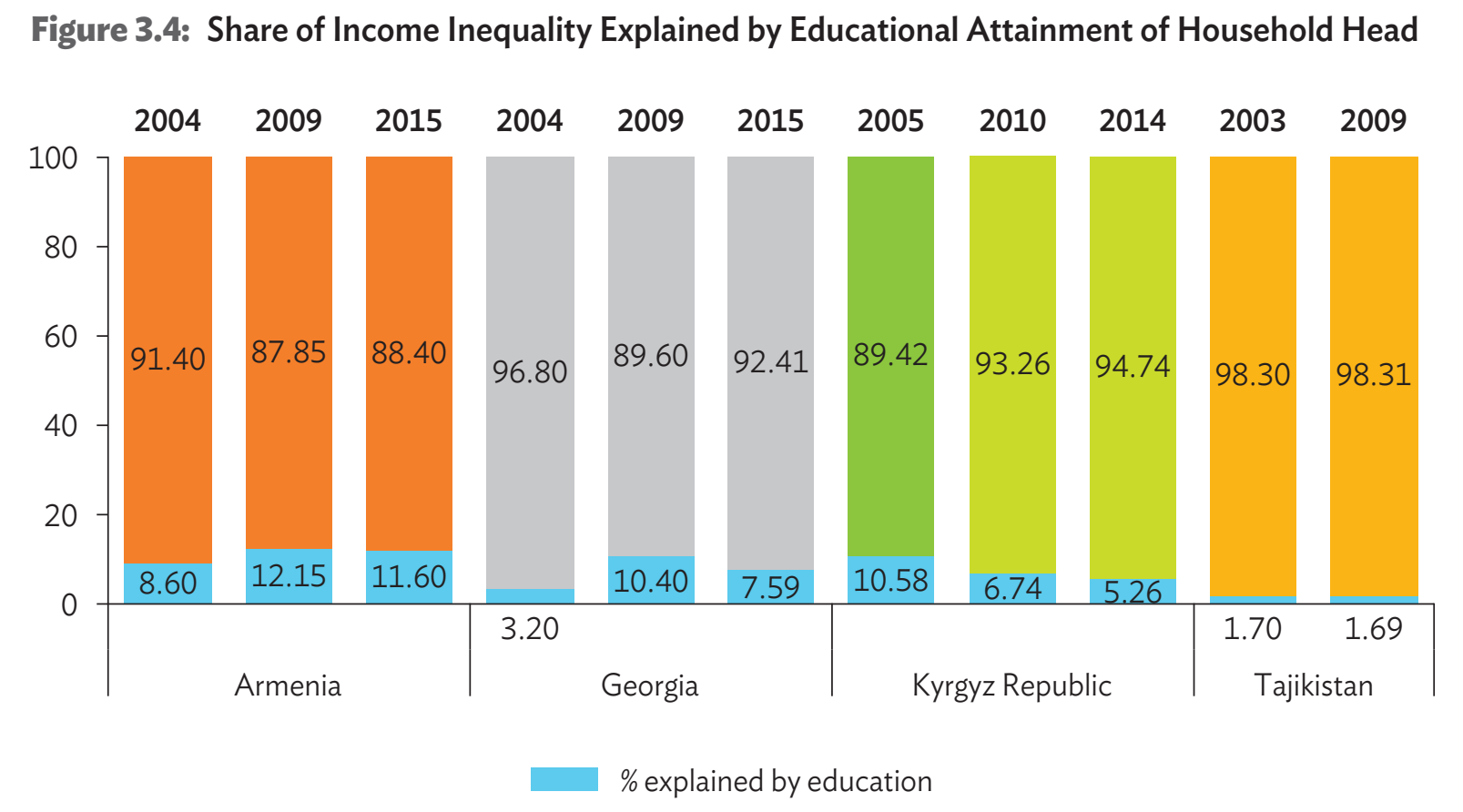

Source: Authors' estimates using household survey data from various years.

The results show that, in the latest year available (2015), educational attainments of heads of households can explain $11.60 \%$ of total income inequality in Armenia, 7.59\% in Georgia, 5.26\% in the Kyrgyz Republic, and $1.69 \%$ in Tajikistan. These figures look small compared with those in other countries in developing Asia: recent estimates show that the educational attainments can explain about $25 \%$ of total income inequality in the People's Republic of China, Indonesia, and Pakistan; 30\% in India; and 35\% in the Philippines (Zhuang, Kanbur, and Rhee 2014).

Despite a relatively low value in international comparison, the importance of education in explaining income increased in Armenia and Georgia, comparing the value in 2015 with 2004. But the explanatory power of education declined in the Kyrgyz Republic and remained unchanged in Tajikistan. The low power of education in explaining income inequality in CASC countries may be because educational attainments of heads of households may not be able to adequately measure educational attainments of an entire household, which are determined by the attainments of all the members of the household labor force.

To further examine the role of education in determining incomes, an econometric exercise was carried out using household survey data for Georgia. Mincer regression results show that the largest contributors to income inequality during 2009-2014 were, in fact, education and gender (Box 3.1). 


\section{Box 3.1: Unequal Returns to Schooling in Georgia}

The drivers of income inequality among households can be analyzed through the results of "Mincer regressions," i.e., econometric exercises which quantify the returns to additional schooling. According to recent Mincer regression run for Georgia for 2009-2014, based on survey data, the largest contributors to income inequality in this country for the observed period were education and gender (table).

\section{Returns to Schooling from Mincer Models}

\begin{tabular}{l|c|c|c|c|c|c|c} 
& 2009 & 2010 & 2011 & 2012 & 2013 & 2014 \\
\hline Professional education & 7.7 & 11.6 & 6.2 & 5.8 & 8.1 & 8.1 \\
\hline Higher education & 61.2 & 65.6 & 61.8 & 63.4 & 66.4 & 66.4 \\
\hline Age & 2.4 & 4.1 & 4.5 & 4.2 & 4.4 & 4.4 \\
\hline age squared & $(0.03)$ & $(0.05)$ & $(0.06)$ & $(0.06)$ & $(0.06)$ & $(0.06)$ \\
\hline Male & 57.6 & 44.8 & 43.5 & 43.7 & 41.8 & 41.8 \\
\hline constant & 4.53 & 4.21 & 4.21 & 4.44 & 4.46 & 4.46 \\
\hline Flipping age & 36 & 39 & 39 & 36 & 39 & 39 \\
\hline $\mathrm{R}^{2}$ & 23.4 & 19.4 & 17.9 & 20.8 & 20.2 & 17.3 \\
\hline
\end{tabular}

( ) = negative, $R^{2}=$ coefficient of determination.

Note: All variables are significant at the $5 \%$ level.

Source: C. E. Montenegro and H. A. Patrinos. 2014. Comparable Estimates of Returns to Schooling Around the World. Policy Research Working Paper; WPS 7020. Washington, DC: World Bank Group. http://documents.worldbank.org/curated/en/830831468147839247/ comprable-estimates-of -returns-to-schooling-around-the-world.

Income earners with higher education degrees, on average, were able to increase their income by more than $60 \%$ compared to households with only general education. Furthermore, the return to higher education rose from $61.2 \%$ in 2009 to $66.4 \%$ in 2014, confirming that demand for high skills has been increasing. But while higher education is an important explanation of rising income, professional education is shown to contribute relatively little, increasing wages by only $5 \%-12 \%$ over the 5 -year period.

Moreover, the results of the Mincer model show that Georgian males earned, on average, between $42 \%$ and 58\% more than females working in similar circumstances. These findings suggest that gender is an important factor in explaining income variation in Georgia. It should be noted, however, that while the gender gap remains substantial, the discrepancy has been shrinking.

Source: Authors.

A structural source of inequality in CASC countries could be geographic location, which generates spatial disparity. Figure 3.5 presents results of between-group and within-group decomposition analysis by household subgroups classified according to whether a household is urban or rural. The analysis focuses on incomebased inequality measure. The results show that, in the latest year where data are available, the urban-rural divide can explain $10.2 \%$ of total income inequality in Armenia, 6\% in Georgia, 14.3\% in the Kyrgyz Republic, and only $2.8 \%$ in Tajikistan. These figures also look low when compared with those in other Asian countries. For instance, the urban-rural divide could explain more than $40 \%$ of the total income inequality in the People's Republic of China in 2007 (Zhuang, Kanbur, and Rhee 2014). 
Figure 3.5: Share of Income Inequality Explained by Urban-Rural Divide

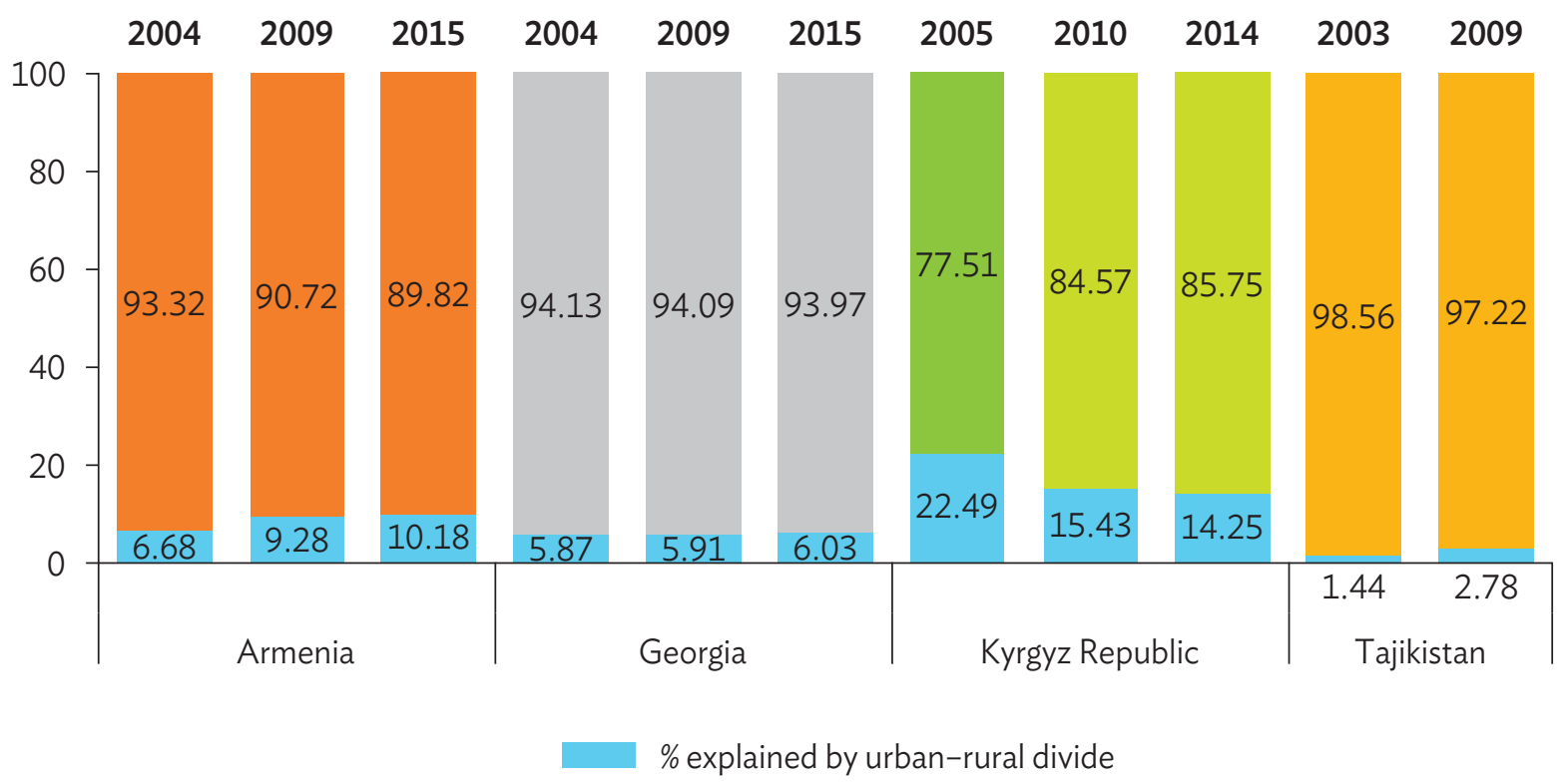

Source: Authors' estimates using household survey data from various years.

To further examine the importance of spatial inequality in contributing to total income inequality in CASC countries, Table 3.4 presents spatial diversity in per capita income among capital cities, other cities, and rural areas. The results show large differentials in per capita income among these locations, with levels much higher in capital cities than in other cities and rural areas. Over time, the income gap between capital cities and other cities declined, except in Tajikistan where the gap increased; the income gaps increased between capital cities and rural areas, except in the Kyrgyz Republic where the gap declined.

Table 3.4: Spatial Diversity in Per Capita Income (index, capital city = 100)

\begin{tabular}{l|l|l|l|l|l|l|l} 
Armenia & 2004 & 2009 & 2014 & Kyrgyz Republic & 2005 & 2010 & 2014 \\
\hline Yerevan & 1.00 & 1.00 & 1.00 & Bishkek & 1.00 & 1.00 & 1.00 \\
\hline Other cities & 0.73 & 0.76 & 0.79 & Other cities & 0.61 & 0.78 & 0.76 \\
\hline Rural areas & 0.75 & 0.75 & 0.71 & Rural areas & 0.41 & 0.60 & 0.59 \\
\hline Georgia & 2004 & 2009 & 2014 & Tajikistan & 2003 & 2009 & \\
\hline Tbilisi & 1.00 & 1.00 & 1.00 & Dushanbe & 1.00 & 1.00 & $\ldots$ \\
\hline Other cities & 0.73 & 0.80 & 0.77 & Other cities & 0.90 & 0.73 & $\ldots$ \\
\hline Rural areas & 0.99 & 0.67 & 0.68 & Rural areas & 0.90 & 0.69 & $\ldots$ \\
\hline
\end{tabular}

$\ldots=$ data not available.

Source: Authors' estimates using household survey data from various years. 
Country-specific analysis conducted for this study confirms the importance of spatial disparities. Box 3.2 shows that, in 2017, the richest region in Uzbekistan (Tashkent City) had three times the per capita income of the poorest region (Jizzak), and that regional disparities have been getting larger in recent years.

\section{Box 3.2: Measuring Spatial Disparity in Uzbekistan}

Interregional disparities in income and employment levels remain high in Central Asia and the South Caucasus. A number of reports show evidence of substantial spatial inequality across the regions of Uzbekistan, as measured by per capita gross regional product.

Data from the State Statistics Committee of Uzbekistan show that interregional variation in income levels is considerably high (figure). In 2017, per capita gross regional product in the country's poorest regions-the Karakalpak Republic, Jizzak, and Namangan-was more than three times lower than that of the capital city, Tashkent, and more than twice lower than that of the region of Navoi, which is rich in natural resources and has a low population density.

\section{Uzbekistan Per Capita Gross Income, by Region, 2017 ('000 sum)}

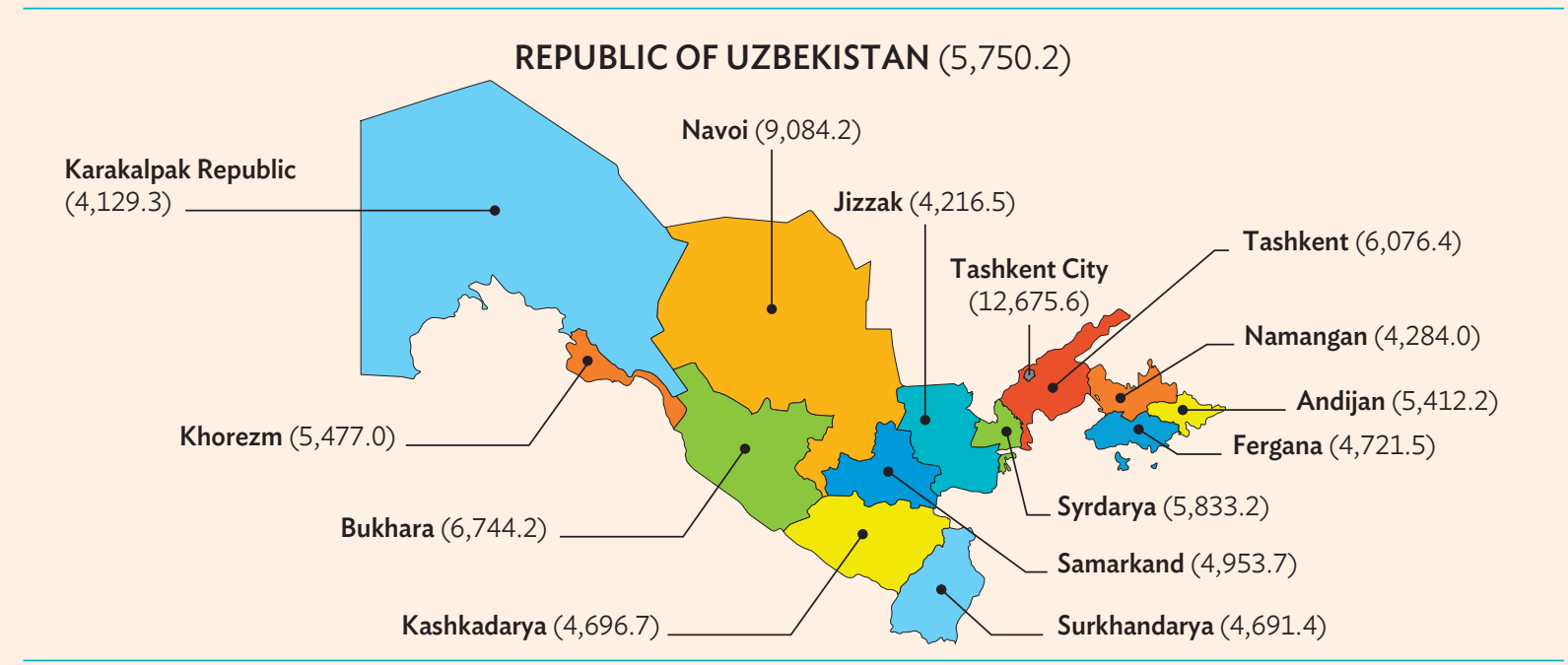

Source: State Statistics Committee of the Republic of Uzbekistan.

The figure on the right presents additional information about the degree of differentiation in per capita gross income across the regions of Uzbekistan. The vertical lines mark the lower and upper bounds of $95 \%$ confidence intervals around the national averages. Interregional disparity in income levels grew in Uzbekistan from 2010 to 2013 (as indicated by longer vertical lines).

\section{Interregional Differentiation of Per Capita Gross Income in Uzbekistan} (sum, 2010-2013)

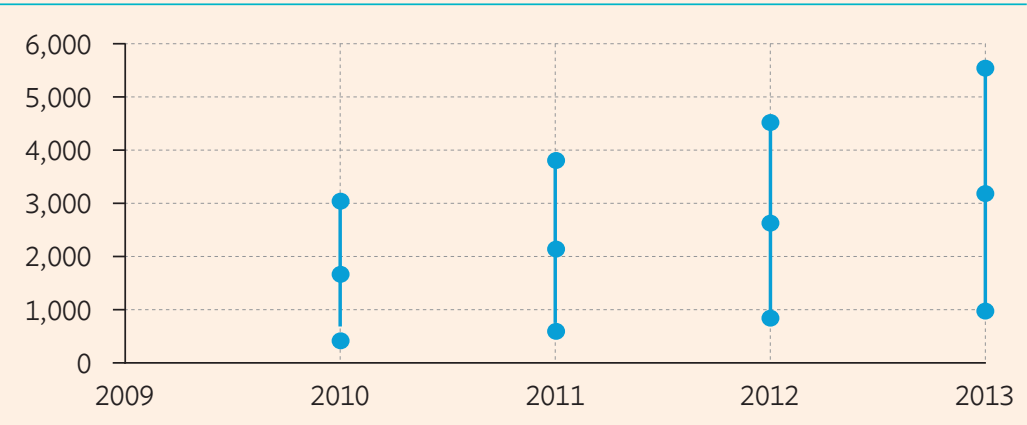

Note: The figure shows average per capita gross income +/-2 standard deviations. Source: State Statistics Committee of the Republic of Uzbekistan. 
The between-group and within-group decomposition analysis can also be applied to gauge the extent of the gender factor in causing total income inequality, which is also central to determining the inclusiveness of growth. Estimating the contribution of gender inequality to overall inequality using household survey data following this approach is, however, problematic because the data only allow comparison of households headed by men with those headed by women, which does not provide enough information about gender differentials in earnings. More focused analysis using individual-level data on earnings, as shown in the Georgian case, demonstrates the presence of a wide gender gap in earnings in favor of men.

The Gender Inequality Index, constructed using health, empowerment, and labor market indicators, helps measure the extent of gender differentials in the CASC region. Table 3.5 presents the index from 2000 to 2014 for six of the CASC countries. ${ }^{24}$ While the general trend shows an improvement in the inequality index, the level of gender inequality remains relatively high compared to other former Soviet Union republics, such as the Russian Federation and others, as well as the developed countries in Asia and Europe, which represent a major target for CASC countries to aspire to.

Table 3.5: Gender Inequality Index for Six Countries in Central Asia and the South Caucasus

\begin{tabular}{|c|c|c|c|c|c|c|c|c|}
\hline & $2000^{a}$ & $2005^{a}$ & $2008^{b}$ & $2010^{a}$ & $2011^{c}$ & $2012^{d}$ & $2013^{a}$ & $2014^{e}$ \\
\hline Azerbaijan & $\ldots$ & $\ldots$ & 0.553 & $\ldots$ & 0.314 & 0.323 & 0.340 & 0.303 \\
\hline Armenia & 0.458 & 0.392 & 0.570 & 0.337 & 0.343 & 0.340 & 0.325 & 0.318 \\
\hline Georgia & $\ldots$ & $\cdots$ & 0.597 & $\ldots$ & 0.418 & 0.438 & $\cdots$ & 0.382 \\
\hline Kazakhstan & 0.407 & 0.369 & 0.575 & 0.338 & 0.334 & 0.312 & 0.323 & 0.267 \\
\hline Kyrgyz Republic & 0.490 & 0.676 & 0.560 & 0.349 & 0.370 & 0.357 & 0.348 & 0.353 \\
\hline Tajikistan & 0.452 & 0.385 & 0.568 & 0.380 & 0.347 & 0.338 & 0.383 & 0.357 \\
\hline \multicolumn{9}{|c|}{$\begin{array}{l}\ldots=\text { data not available. } \\
\text { a United Nations Development Programme (UNDP). Human Development Report (various editions), Gender Inequality Index. } \\
\text { http://hdr.undp.org/en/content/gender-inequality-index. }\end{array}$} \\
\hline \multicolumn{9}{|c|}{ b UNDP. Human Development Report 2010, Table 4, Gender Inequality Index, pp. 156-160. } \\
\hline \multicolumn{9}{|c|}{ c UNDP. Human Development Report 2013, Table 4, Gender Inequality Index, pp. 156-159. } \\
\hline \multicolumn{9}{|c|}{ d UNDP. Human Development Report 2014, Table 4, Gender Inequality Index, pp. 172-175. } \\
\hline \multicolumn{9}{|c|}{ e UNDP. Human Development Report 2015, Table 5, Gender Inequality Index, pp. 224-227. } \\
\hline \multicolumn{9}{|c|}{ Source: Authors, based on United Nations Development Programme, Human Development Reports 2010, 2013, $2014,2015}$. \\
\hline
\end{tabular}

Decomposition by income source. Decomposition by income source reveals contributions to total income inequality by various components of household incomes. Figure 3.6 presents the results of decomposition by income source for four CASC countries in which a typical household in a CASC country receives income from various sources, including salaries, agriculture and household enterprises, private transfers, social transfers, and nonmonetary and other income.

24 Unfortunately, data are insufficient to construct a reliable Gender Inequality Index for Turkmenistan and Uzbekistan. 


\section{Figure 3.6: Decomposition of Income Inequality by Income Source in Selected Central Asian and South Caucasus Countries}

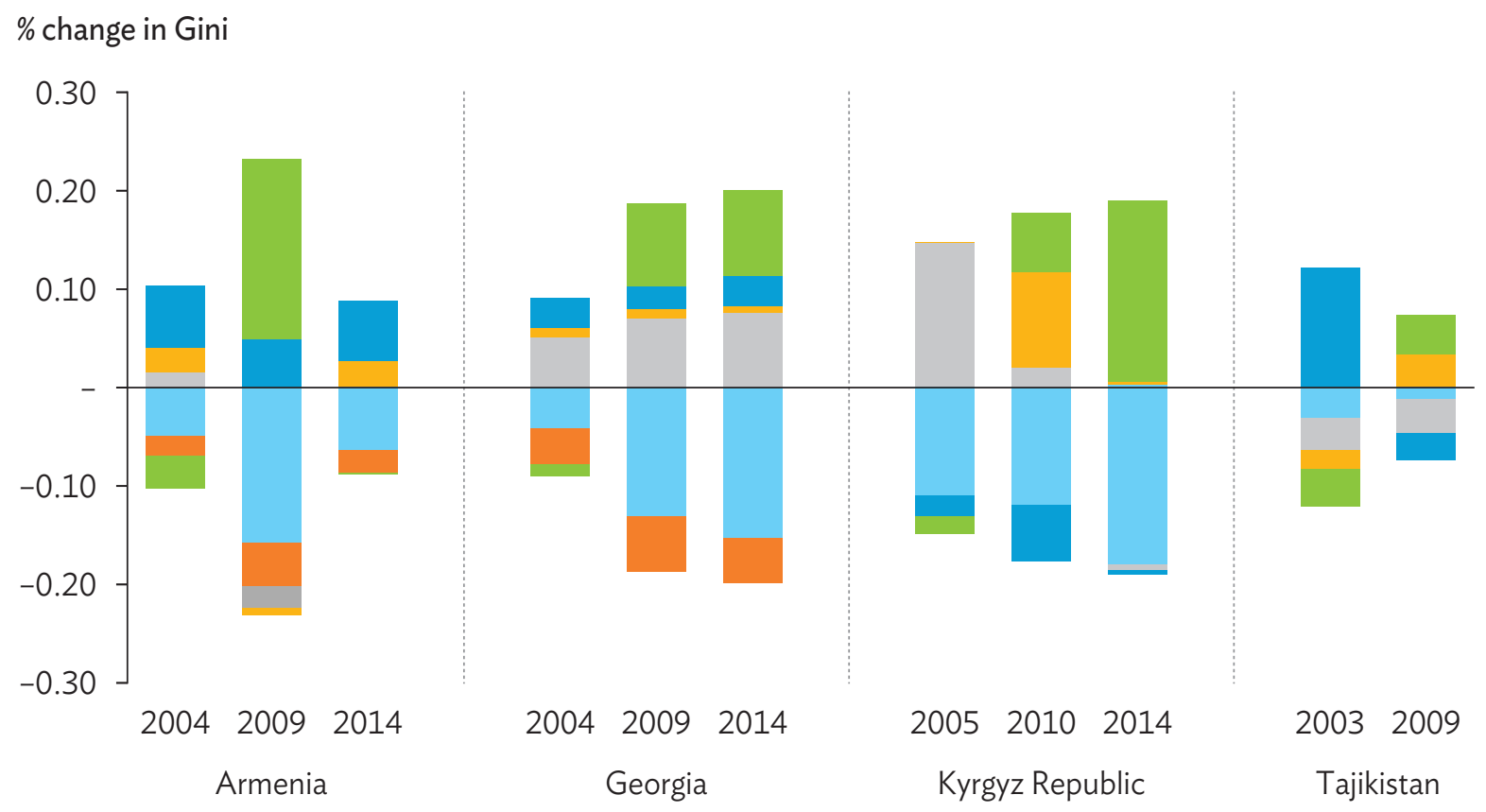
Salary
Agriculture/household enterprise
Private transfers
Other income
Nonmonetary
Social transfers

Source: Authors' estimates using household survey data from various years.

The results suggest that salaries and business income often raise inequality, while social transfers are the only income source that consistently reduces inequality across all countries and years. However, a key issue with social transfers is their sustainability in the face of pressure for rising inequality of market income. As discussed in the next section, appropriate policy can help improve the distribution of social transfers so that the same inequality reduction could be achieved with fewer resources-or the same amount of resources could generate greater reduction in inequality.

Given concerns on the sustainability of social transfers, policies should put enough focus on improving the distribution of income pre-transfer, through market forces. Given that social transfers mostly compensate for inequality caused by wages and compensation, one way to ease pressure on the social security system is to address inequalities in the labor market. The skill premium is a fundamental factor in explaining inequality in labor markets. Policy action needs to be channeled to reduce skill inequality. 


\section{3 | Transfers and Social Protection}

As set out at the start of this chapter, public transfers can be a major mechanism for transforming market incomes - the "pre-distribution" - to a more equitable outcome. Policy makers have, in fact, a broader set of instruments than just income or cash transfers.

These policy measures come under the broad rubric of "social protection" and are typically classified into three categories: (i) social insurance, or contributory schemes to help people respond to common risks such as illness, old age, and unemployment; (ii) social assistance, or unrequited transfers to groups such as the poor who cannot qualify for insurance or would receive inadequate benefits from such a source; and (iii) labor market programs, including training programs, or cash transfers, or food-for-work programs.

In 2005, ADB developed, together with a set of knowledge partners, the Social Protection Index (SPI) as an indicator for assessing social protection effectiveness within and across Asian countries. The SPI is a unitary ratio and is based first on dividing total expenditures on social protection by the total potential beneficiaries of such protection. Then, this ratio is compared with per capita GDP. The SPI can be disaggregated into the depth and breadth of coverage of social protection in each country. The depth of benefits is the average benefit received by each beneficiary of social protection (relative to per capita GDP); the breadth of coverage is the proportion of the total potential beneficiaries who are actual beneficiaries (i.e., those who actually receive social protection benefits).

The average central government social protection expenditures for Asian economies was about $5.2 \%$ of GDP (at current prices) in 2012 (Table 3.6). In the same year, the share for the CASC region (excluding Kazakhstan and Turkmenistan) averaged $6.9 \%{ }^{25}$

Table 3.6: Share of Social Protection Expenditures to Gross Domestic Product, 2012

\begin{tabular}{l|c|c}
\hline Asia & GDP $(\$$ million $)$ & $\begin{array}{c}\text { Share of Social Protection } \\
\text { Expenditures to GDP } \%)\end{array}$ \\
\hline Central Asia and the South Caucasus & 805,470 & 5.2 \\
\hline Armenia & 26,771 & 6.9 \\
\hline Azerbaijan & 9,958 & 6.5 \\
\hline Georgia & 69,680 & 6.4 \\
\hline Kyrgyz Republic & 15,847 & 6.4 \\
\hline Tajikistan & 6,605 & 11.6 \\
\hline Uzbekistan & 7,633 & 0.8 \\
\hline
\end{tabular}

GDP = gross domestic product.

Source: Asian Development Bank estimates based on Social Protection Index country reports, 2015.

25 Social protection expenditures refer to actual government expenditures excluding operating costs. The CASC regional average is calculated as a GDP-weighted average. 
The relatively higher average SPI for the CASC region, when compared with that for the rest of Asia, is largely due to the transitional nature of CASC economies, moving from a socialist system where social insurance, especially for pension schemes, was typically well developed-although not necessarily in terms of labor market programs and protection against unemployment.

How well targeted are social protection programs toward the lower end of the income distribution? Figure 3.7 illustrates the relative social protection schemes received by poor and nonpoor beneficiaries compared to the per capita GDP in the CASC region.

\section{Figure 3.7: Social Protection Indicator in Selected Countries in Central Asia and the South Caucasus by Poverty Status, 2012}

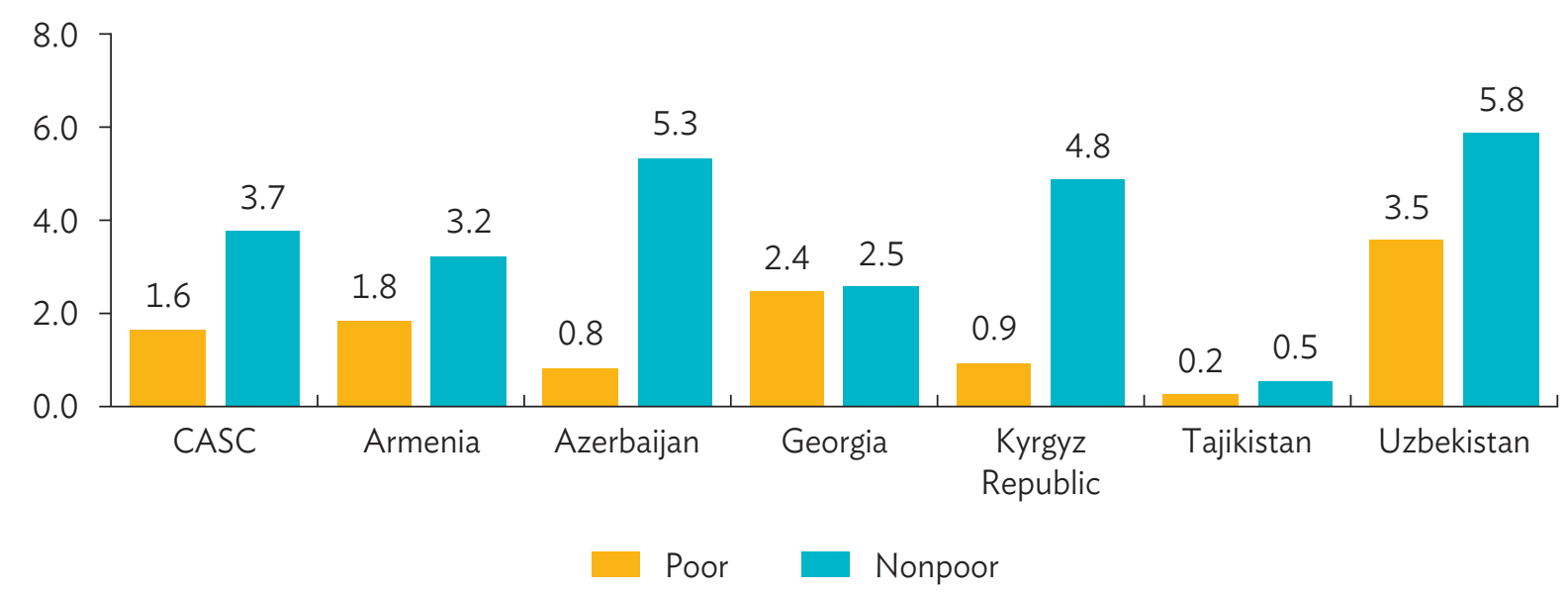

CASC $=$ Central Asia and the South Caucasus.

Source: Asian Development Bank estimates based on Social Protection Index country reports, 2015.

Table 3.7 shows that, in 2012, the SPI for the whole Asian region was 3.7\%. This value measures the average per capita government social protection expenditures as a share of per capita GDP. For the CASC region (excluding Kazakhstan and Turkmenistan), the 2012 average was 5.3\%, which is substantially higher than the Asian average, even though the average per capita GDP for the region is structurally lower than that for the whole of Asia. Only the SPI for Tajikistan, which is less than $1 \%$ of its per capita GDP, is (much) lower than the region's and Asia's average values. ${ }^{26}$

26 The very low SPI value for Tajikistan may be due to poor quality of available data. 
Table 3.7: Social Protection Indicator by Program, 2012

\begin{tabular}{l|c|c|c|c|c} 
& $\begin{array}{c}\text { Per Capita } \\
\text { GDP } \\
(\$)\end{array}$ & $\begin{array}{c}\text { SPI } \\
(\%)\end{array}$ & $\begin{array}{c}\text { Social } \\
\text { Insurance } \\
(\%)\end{array}$ & $\begin{array}{c}\text { Social } \\
\text { Assistance } \\
(\%)\end{array}$ & $\begin{array}{c}\text { Labor Market } \\
\text { Programs } \\
(\%)\end{array}$ \\
\hline Asia & 7,684 & 3.7 & 2.7 & 0.9 & 0.100 \\
\hline Central Asia and the South Caucasus & 3,036 & 5.3 & 3.8 & 1.5 & 0.010 \\
\hline Armenia & 3,293 & 4.9 & 3.4 & 1.5 & 0.010 \\
\hline Azerbaijan & 7,500 & 6.2 & 4.3 & 1.9 & 0.003 \\
\hline Georgia & 3,523 & 4.9 & 2.7 & 2.2 & $\ldots$ \\
\hline Kyrgyz Republic & 1,234 & 5.7 & 4.5 & 1.3 & 0.010 \\
\hline Tajikistan & 956 & 0.7 & 0.5 & 0.2 & 0.020 \\
\hline Uzbekistan & 1,710 & 9.3 & 7.5 & 1.8 & 0.001 \\
\hline
\end{tabular}

$\ldots$.. data not available, GDP = gross domestic product, $\mathrm{SPI}=$ social protection index .

Source: Asian Development Bank estimates based on Social Protection Index country reports, 2015.

The SPI results reveal that generally, the nonpoor received more social protection benefits than the poor. In CASC countries, excluding Kazakhstan and Turkmenistan, the average benefits for the nonpoor in 2012 was a 3.7\% share of per capita GDP-more than twice than that for the poor at $1.6 \% .{ }^{27}$ This result suggests the importance for CASC economies of social insurance, which is often tied to employment and whose beneficiaries are not considered, or classified, as poor. In Azerbaijan, for example, in 2012, social protection benefits for the poor were relatively small at less than $1 \%$ of the country's per capita GDP, while the benefits for the nonpoor were $5.3 \%$.

Looking at the gender dimension of the SPI, the benefits received by women are typically smaller than those received by men, which are both only a fraction of the per capita GDP in each of the six CASC countries, excluding Kazakhstan and Turkmenistan. For these countries, the average benefits received by females in 2012 were about 2.3\% of the per capita GDP, smaller than the 3\% attributed to male beneficiaries. Overall, women receive smaller benefits than men: women are usually more poorly represented in private sector formal employment, and therefore are likely to receive fewer social insurance benefits than men. Such discriminatory practices reveal a dimension of gender inequality, which often remains hidden and not immediately evident across the region. Apart from considerations on the sustainability of total government expenditure, these results suggest the need to restructure social protection programs in CASC countries to better contribute to the inclusiveness of growth.

27 Social protection schemes may have helped many of the poor to become nonpoor. 


\section{4 | Summary}

Economic growth in the CASC countries has been strong for most of the period since the early 2000, except in recent years, when the region was affected by the external shocks discussed in Chapter 2. On the inclusiveness of growth, the CASC countries present a mixed picture. While poverty reduction has been rapid, which has been supported by strong growth, the poverty rates measured at the national poverty lines remain high, at 20\%-30\%, in four CASC countries. Consumption-based inequality estimates suggest CASC countries compare favorably with the average levels globally and in developing Asian countries. However, income-based inequality estimates suggest that reducing income inequality is a key issue CASC governments should tackle in the years ahead to promote inclusive growth.

On the determinants of income inequality, evidence suggests that earning differentials between skilled and/or educated workers and less-skilled and/or less-educated workers have increased in some countries. It also suggests that spatial inequality (between capital cities, other cities, and rural areas) remains high; that gender inequality, while improving, also remains high, especially compared to other former Soviet Union republics and developed countries in Asia and Europe; and social transfers reduce income inequality. Given the data constraints, however, a more accurate picture of poverty and inequality in the region is yet to emerge as additional information and more adequate measurements, together with updated figures, are needed to capture the actual impact on inequality trends of the external shocks that hit the region in 2014-2015.

Policy makers in the CASC countries face a complexity of serious policy issues to place inclusive growth at the center of their objective functions. The global forces of technical change are leading to a widening of skill premiums, which needs to be addressed through equalization of human capital. Spatial disparities persist and tend to expand, while gender inequality, although improving, remains relatively high in international comparison. Serious questions are also raised about the sustainability of the social transfers which have, so far, underpinned inequality trends in consumption. 


\title{
CHAPTER
}

\section{GOOD JOBS AND \\ THE LABOR MARKET}

\author{
by Duncan Campbell and Per Ronnås
}

$T^{\text {his }}$

his chapter begins with a look at employment trends in the economic systems and the structural changes in labor productivity in countries in Central Asia and the South Caucasus (CASC). It then discusses the importance of creating demand for jobs, giving special attention to employment opportunities generated by small and medium-sized enterprises (SMEs). It analyzes how skills are being developed from the supply side of the labor market and examines the importance of labor market institutions in connecting demand with supply. The chapter concludes with a look at structural reforms introducing labor market policies that promote good jobs for inclusive growth.

\subsection{Economic Structure and Employment Trends}

The decline of the manufacturing sector as a share of gross domestic product (GDP) has been central to the evolution of CASC countries' economic structures since the 1990s. This is largely reflected in the region's employment patterns. The abrupt end of the centrally planned Soviet Union economy in 1991 also set off two other major trends: (i) a sharp fall in formal wage employment, as workers were forced into a variety of occupations in the informal sector; and (ii) a counter-secular increase in agricultural employment shares across the region. The latter reversed the pattern of structural economic transformation in which agricultural contributions to GDP and employment typically decline.

Table 4.1 describes the evolution of the agriculture sector as a share of GDP and employment in the region. As agricultural employment rose with the end of the Soviet Union economy (1991-2000), the sector buffered the absence of other income sources in most countries in the CASC region. The subsequent decline, particularly in the five Central Asian countries, corresponds to the period of fast economic growth in the 2000s (Chapter 2).

The employment share of agriculture (and of the manufacturing sector) declined beginning at the turn of the century in the CASC countries, while direct employment in mining remained low. The labor force has thus been concentrating in the service economy (Figure 4.1).

Employment in services, as emblematic of the private market economy, has grown in the CASC region, especially in wholesale and retail trade, restaurants, hotels, and construction, where employment has grown fastest. By the end of 2016, the average share of the service sector in GDP for countries in the CASC region had grown close to 60\%, against 30\% in 1991 (Figure 4.2). 
Table 4.1: Share of Agriculture in Gross Domestic Product and Employment in Central Asia and the South Caucasus

\begin{tabular}{|l|c|c|c|c|c|c|}
\hline & \multicolumn{3}{|c|}{ Agriculture Share of GDP (\%) } & \multicolumn{3}{c|}{ Agriculture Share of Employment (\%) } \\
\cline { 2 - 7 } & 1989 & $\begin{array}{c}1991-2000 \\
\text { average }\end{array}$ & $2016^{\mathrm{a}}$ & 1989 & $\begin{array}{c}1991-2000 \\
\text { average }\end{array}$ & $2016^{\mathrm{a}}$ \\
\hline Armenia & 17 & 21 & 22 & 14 & 34 & 35 \\
\hline Azerbaijan & 20 & 13 & 6 & 28 & 38 & 37 \\
\hline Georgia & 31 & 26 & 9 & 22 & 52 & 51 \\
\hline Kazakhstan & 32 & 10 & 5 & 22 & 36 & 24 \\
\hline Kyrgyz Republic & 34 & 37 & 17 & 33 & 49 & 32 \\
\hline Tajikistan & 34 & 27 & 21 & 45 & 65 & 53 \\
\hline Turkmenistan & 33 & $\ldots$ & 15 & 41 & $\ldots$ & 43 \\
\hline Uzbekistan & 33 & 34 & 20 & 39 & 34 & 27 \\
\hline
\end{tabular}

$\ldots=$ data not available, $\mathrm{GDP}=$ gross domestic product.

a Figures refer to 2016 or latest available year.

Source: Compiled by the authors based on United Nations National Accounts System and National Labour Force Surveys.

Since the 1990s, CASC unemployment rates have been considerably higher than those in the Central and Eastern European transition economies, in sharp contrast with the virtual absence of open unemployment before the collapse of the Soviet Union. While average unemployment for the CASC region declined from $11.4 \%$ in 2000 to $6.8 \%$ in 2015, unemployment remained high in Armenia, Georgia, and Tajikistan (Figure 4.3).

After 1991, labor force participation rates also abruptly declined in the region, particularly for male workers, whose jobs disproportionately disappeared with the shift away from the planned economy. ${ }^{28}$ At the same time, the region's employment shifted from wage-earning jobs to self-employment as informality in the economic system rose sharply. In 2015, the labor force participation rate was, on average, $62.7 \%$ of the active population for the CASC region (Figure 4.4), quite low compared with other world regions. Male labor force participation, in particular, declined as men became discouraged about new employment opportunities. Moreover, in 2015, a quarter of CASC households had no family member employed in the (formal) labor market (World Bank 2015, 26).

28 The labor force participation rate is the proportion of the population (aged 15-64) that is economically active. 


\section{Figure 4.1: Evolution of Employment in Central Asia and the South Caucasus by Sector}

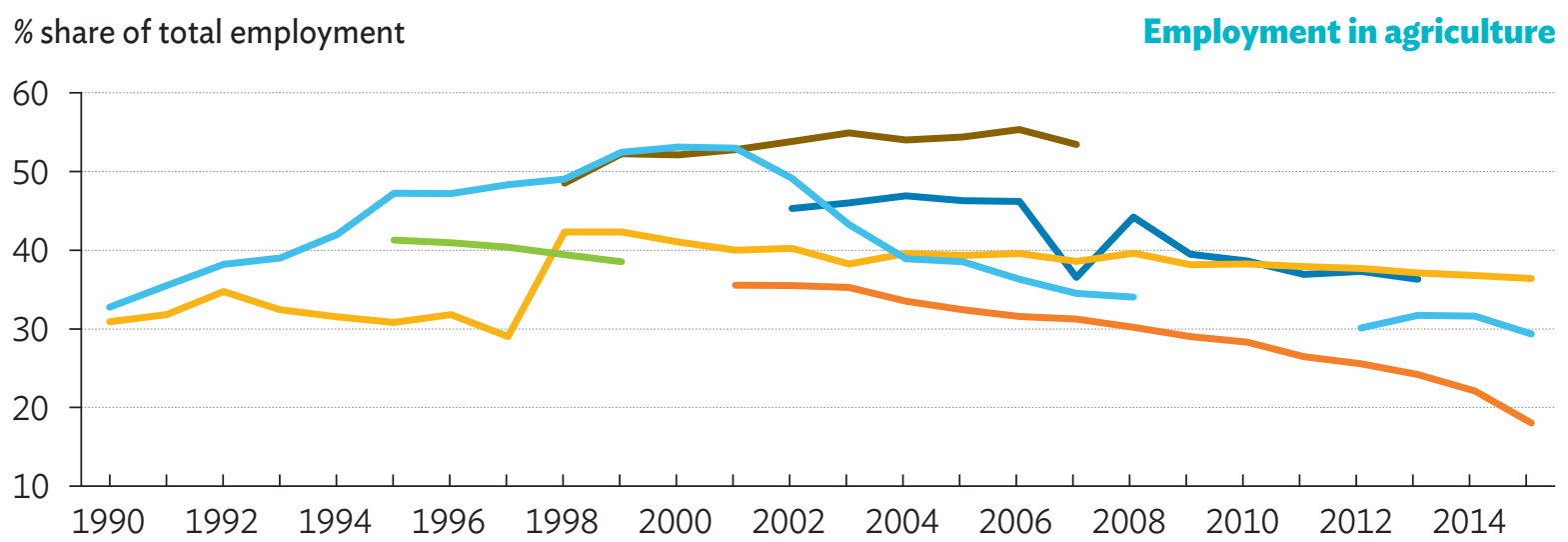

$\%$ share of total employment

Employment in industry

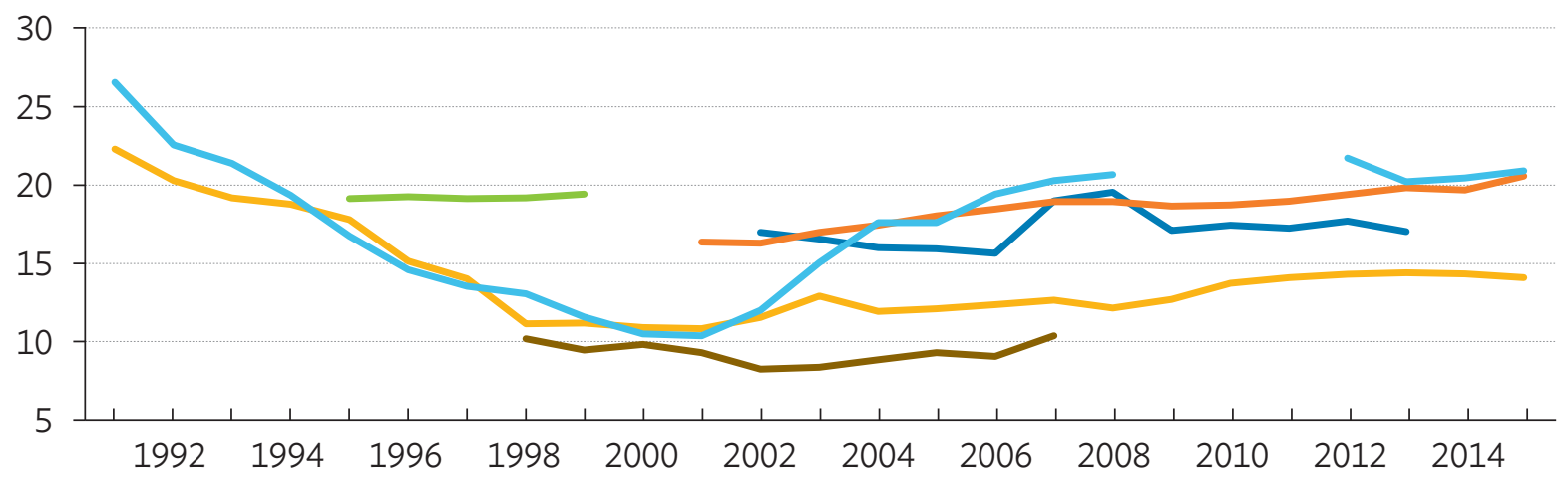

$\%$ share of total employment

Employment in services

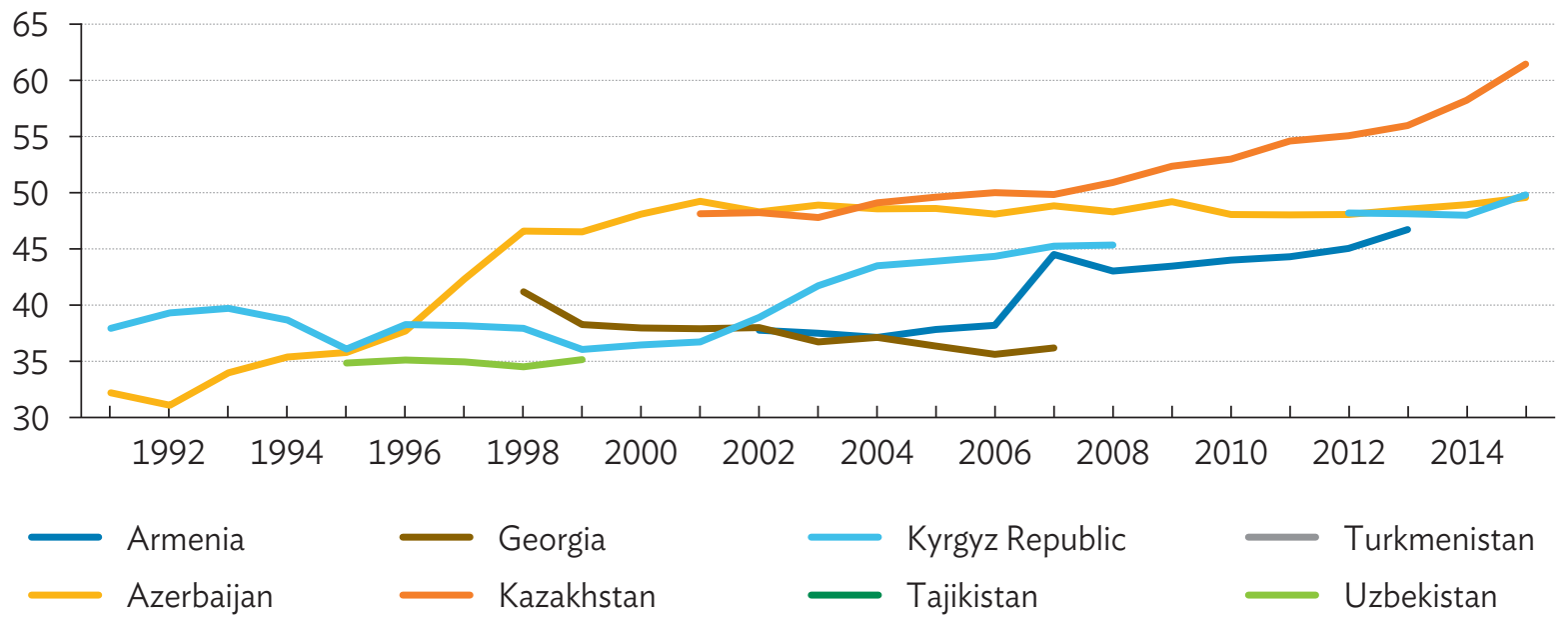

Source: International Labour Organization. Key Indicators of the Labour Market database (accessed 30 August 2017). 
Figure 4.2: Evolution of the Service Sector in Central Asia and the South Caucasus

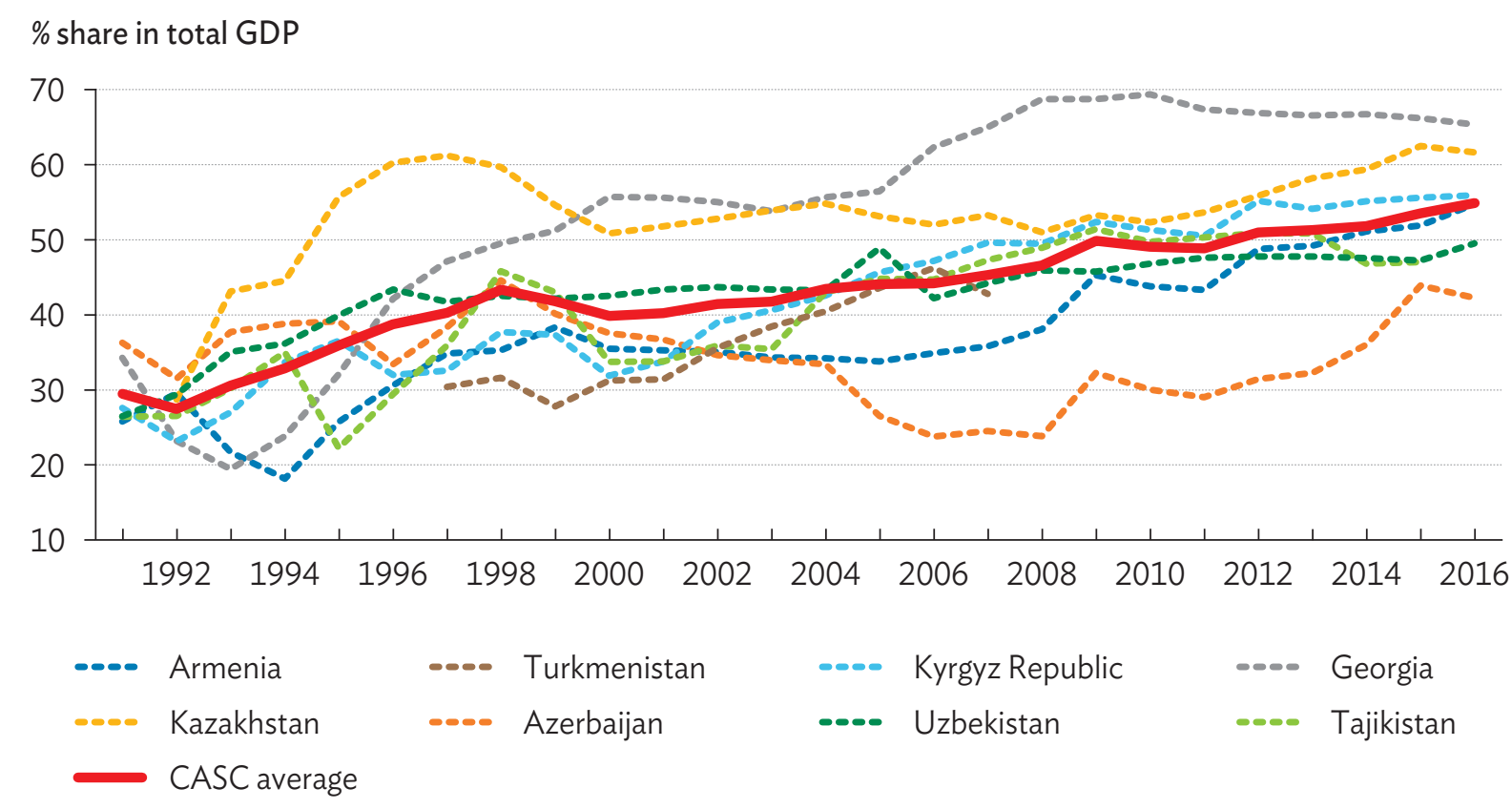

CASC = Central Asia and the South Caucasus, GDP = gross domestic product.

Source: World Bank. 2017. World Development Indicators 2017. Washington, DC: World Bank.

Figure 4.3: Unemployment in Central Asia and the South Caucasus, 2010 and 2015

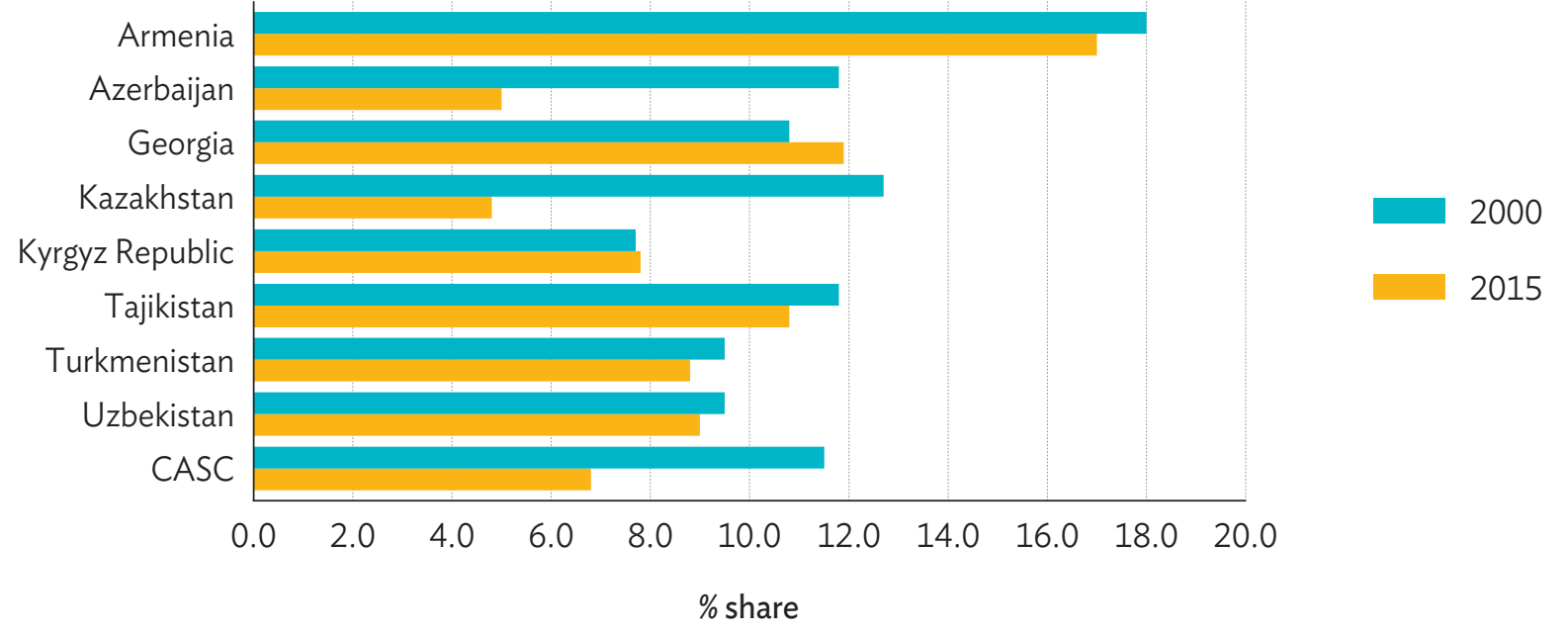

CASC $=$ Central Asia and the South Caucasus.

Note: Unemployment refers to the share of the labor force that is without work but available for and seeking employment. Source: International Labour Organization. ILOSTAT database (accessed 28 August 2017). 
Figure 4.4: Labor Force Participation Rate in Central Asia and the South Caucasus, 2000 and 2015

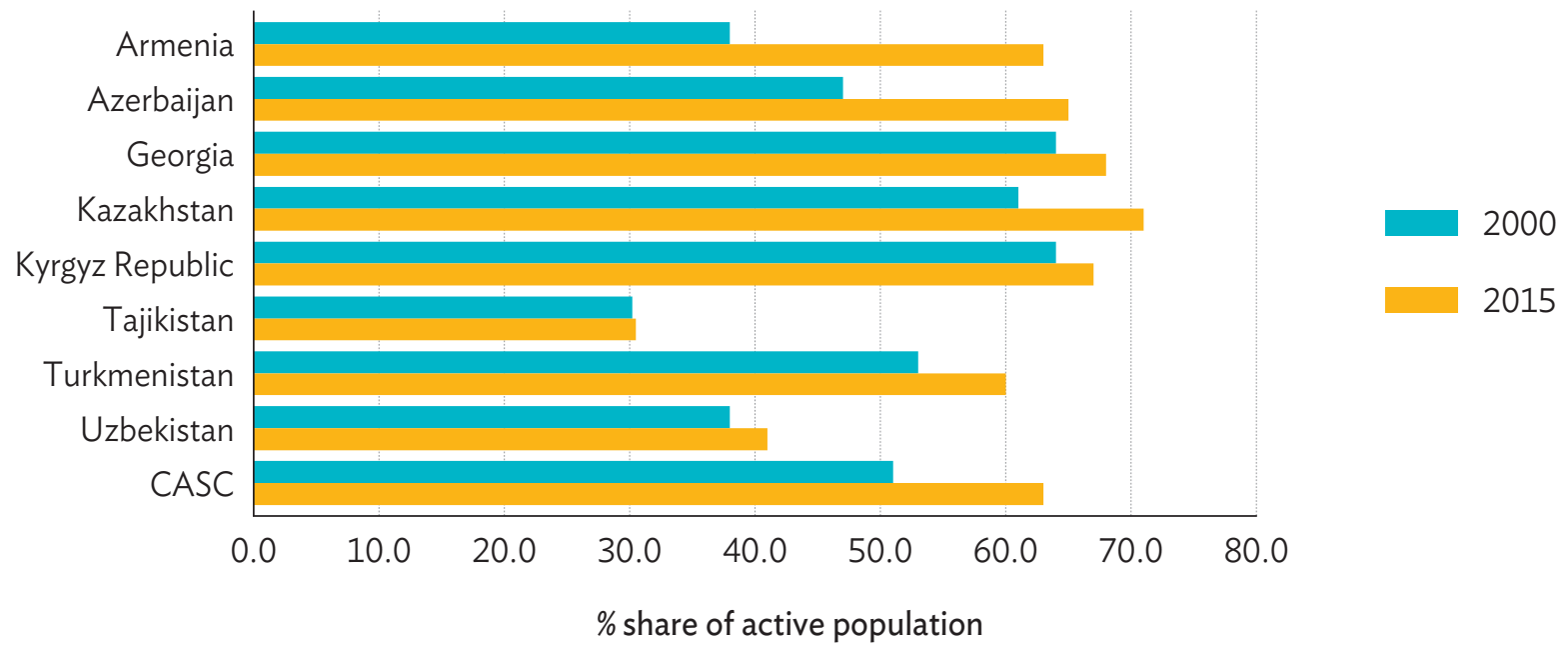

CASC $=$ Central Asia and the South Caucasus.

Note: The labor force participation rate is the proportion of the population (aged 15-64) that is economically active.

Source: International Labour Organization. ILOSTAT database (accessed 30 August 2017).

\section{Informal Jobs and the Labor Market}

What are the main factors explaining the trends in unemployment and labor force participation rates observed in CASC countries? Some have argued that large social assistance and pensions might play a role as they disincentivize an active job search. But, more plausibly, gaining access to a pension scheme results in fewer people reporting they are working, as pensions and other social transfers are often conditional upon not having any other source of income. Low labor force participation may also be explained by the fact that income payroll taxes tend to turn regressive for entry-level, low-skilled workers, as they are disproportionately high for low-skilled workers on average across the region, discouraging them from being hired.

Since in CASC countries, the income tax base is narrow and low, labor taxes tend to be high (Figure 4.5). Such dichotomy would help explain the persistence in the formal economy of low labor force participation for low-skilled workers, whose main entry into the labor force is the informal economy.

Growth in self-employment tends to correlate highly with informality. Especially during the first decade after independence from the Soviet Union, informalization in CASC countries resulted from the combined effect of a virtual collapse in formal employment and the need to earn a minimum income to subsist. Hence, informalization of employment is directly linked with the informalization of the economy: the magnitude of the estimates suggests the informal sector is sizable in all countries and has not significantly shrunk in recent years (Table 4.2). 


\section{Figure 4.5: Tax Wedge in Central Asia and the South Caucasus}

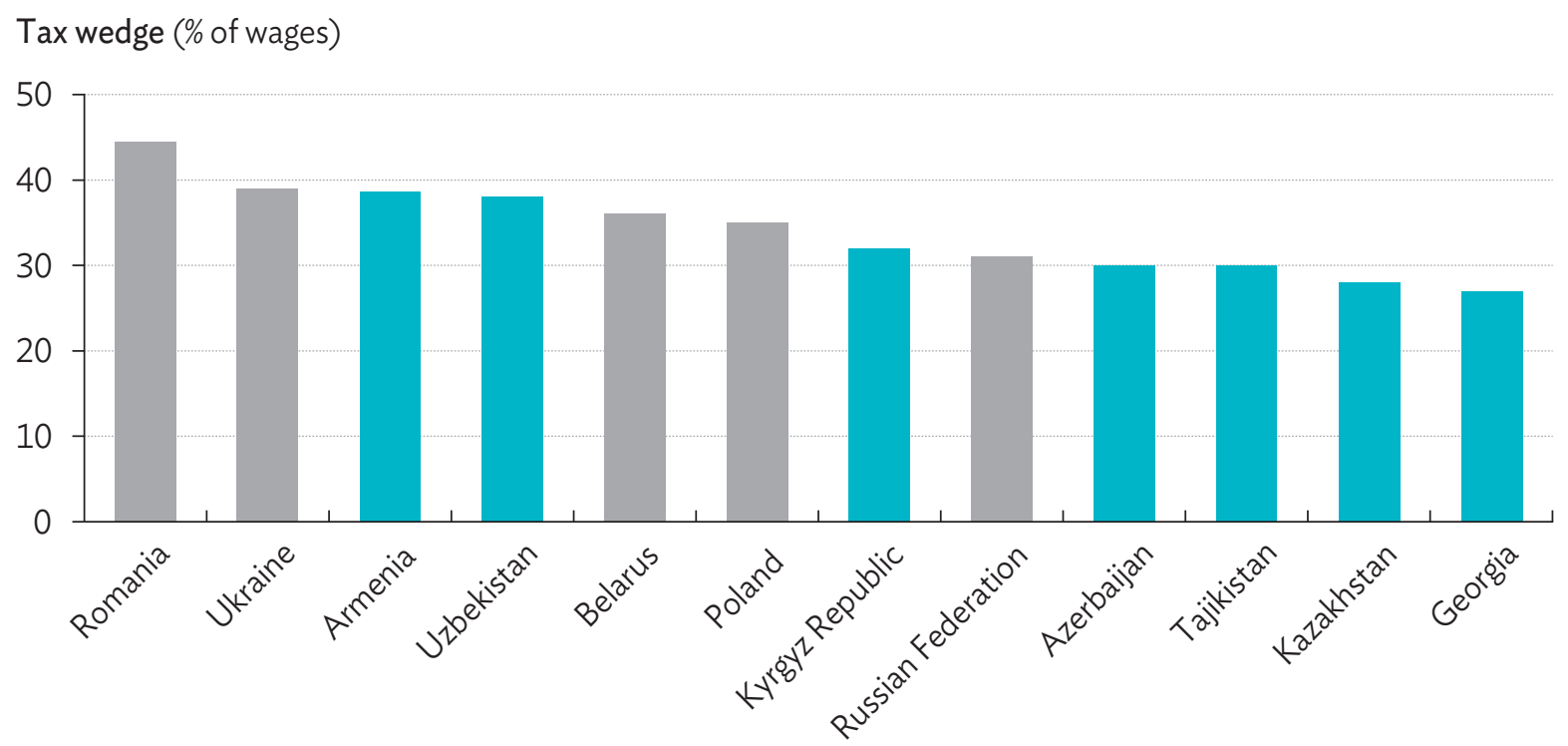

Source: World Bank. 2015. Promoting Labor Market Participation and Social Inclusion in Europe's and Central Asia's Poorest Countries. Washington, DC: World Bank.

Table 4.2: Informality in the Central Asian and South Caucasus Economies (\% of GDP)

\begin{tabular}{|c|c|c|c|c|c|}
\hline \multirow[b]{2}{*}{ Economy } & \multicolumn{5}{|c|}{ Year(s) } \\
\hline & $1990-2001^{a}$ & $1990-2001^{b}$ & $2003-2005^{c}$ & $2006^{d}$ & $2008^{e}$ \\
\hline Armenia & 51.5 & 24.0 & 28.9 & 44.0 & 35.0 \\
\hline Azerbaijan & 39.8 & 43.8 & 20.7 & 58.0 & 31.5 \\
\hline Georgia & 29.6 & 49.2 & 28.3 & 65.8 & 30.1 \\
\hline Kazakhstan & 43.2 & 24.7 & 21.6 & 41.1 & 33.0 \\
\hline Kyrgyz Republic & 46.2 & 49.5 & 17.0 & 40.4 & 26.3 \\
\hline Tajikistan & 64.8 & 54.2 & 25.0 & 42.2 & 32.8 \\
\hline Turkmenistan & 0.2 & 19.0 & 18.1 & $\ldots$ & $\ldots$ \\
\hline Uzbekistan & 32.5 & 25.8 & 29.0 & $\ldots$ & $\ldots$ \\
\hline
\end{tabular}

$\ldots=$ data not available, GDP = gross domestic product.

Note: All percent shares are computed in each study with respect to the formal and informal economy.

a E. L. Feige and I. Urban. 2008. Measuring Underground (Unobserved, Non-Observed, Unrecorded) Economies in Transition Countries: Can We Trust GDP? William Davidson Institute Working Paper No. 913. March (based on currency ratios).

b Feige and Urban (2008) (based on electricity usage).

c United Nations Development Programme (UNDP). 2008. National Human Development Report (2007/08) Education in Uzbekistan: Matching Supply and Demand. Tashkent, Uzbekistan.

d F. Schneider, A. Buehn, and C. Montenegro. 2011. Shadow Economies All Over the World: New Estimates for 162 Countries from 1999 to 2007. Handbook on the Shadow Economy. Econ Papers. Edward Elgar Publishing.

e Y. Abdih and L. Medina. 2013. Measuring the Informal Economy in the Caucasus and Central Asia. IMF Working Paper No. 13/137. 
Alongside growing informality, self-employment has grown in the CASC economies, albeit with marked differences between the Central Asian and South Caucasus countries (Figure 4.6). The rise in selfemployment, as opposed to wage employment, can be seen from three different angles. Self-employment could be (i) a subsistence response in the absence of better employment opportunities; (ii) explained by the growth in entrepreneurial culture among those willing and prepared to take advantage of new opportunities in the market; or (iii) a way to avoid regulation, taxation, and rent-seeking behavior in general.

Figure 4.6: Wage versus Self-Employment in Central Asia and the South Caucasus, 2014

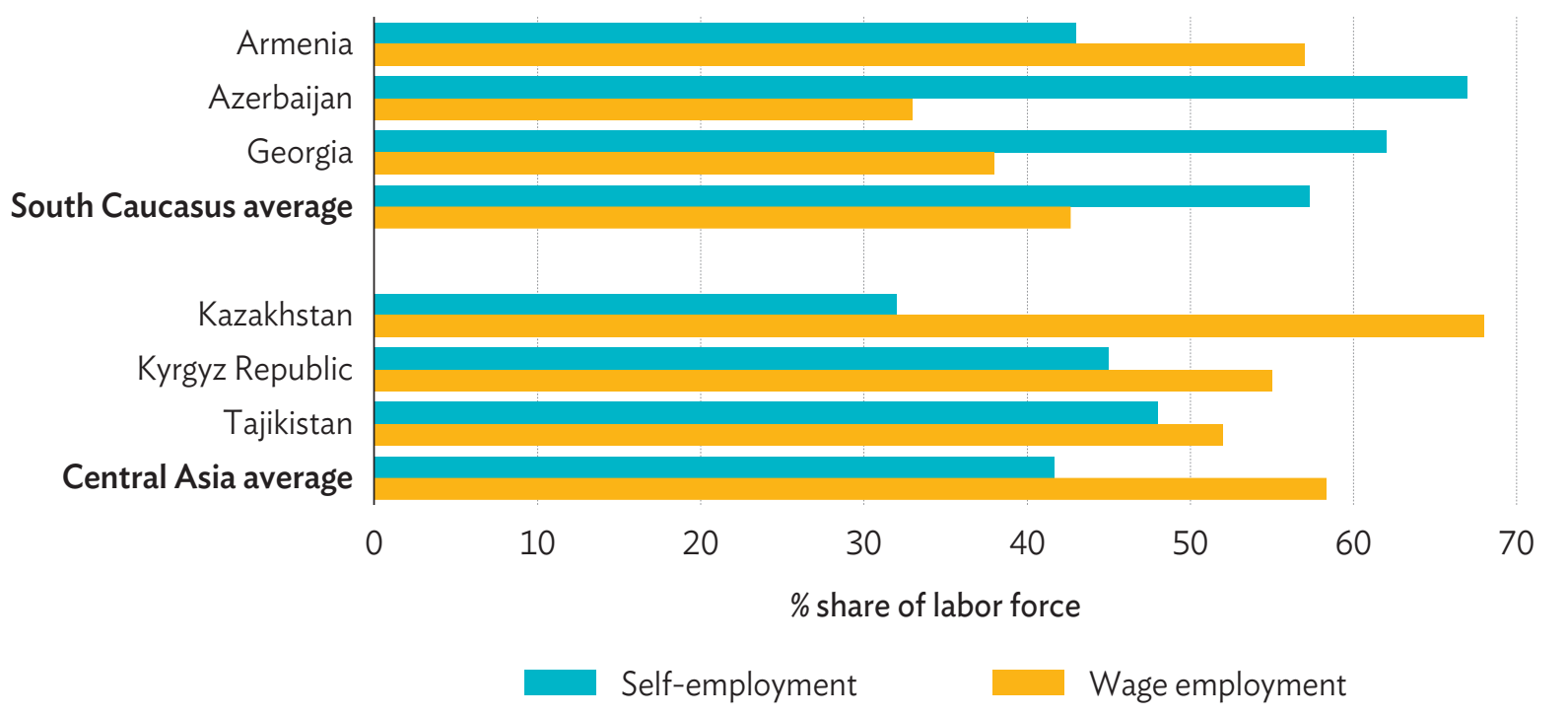

Note: The median value for self-employment is close to $50 \%$.

Source: Authors' calculation based on International Labour Organization Key Indicators of the Labour Market 2015.

Informality may, in some instances, be rational; often, it is the only alternative to a scarcity of formal jobs. And informality can be associated with certain benefits for employers, employees, consumers, and governments, related to flexibility, low transaction costs, low entry barriers, and other factors. However, working in informal economic activities produces typically inferior benefits to employment in the formal sector: it is less productive, it generates lower earnings, and it is associated with lower security and social protection (Table 4.3).

As a consequence, informal jobs cannot be considered good jobs: they are not protected by legislation that sets out enforceable employers' obligations and, as noted, tend to generate much lower salaries than formal jobs. Overall, informality can be seen as an effective survival mechanism, but not a conducive system for long-term sustainable and inclusive economic growth. The gradual formalization of the labor market is thus an important policy objective for CASC countries. 
Table 4.3: Costs and Benefits of Labor Market Informality in Central Asia and the South Caucasus

\begin{tabular}{l|l}
\multicolumn{1}{c|}{ Costs } & \multicolumn{1}{c}{ Benefits } \\
\hline Lack of worker rights' protection & Production flexibility \\
\hline Difficulties for employers in retaining skilled workers & Low transaction costs \\
\hline $\begin{array}{l}\text { Limited capacity for firms to utilize modern technologies and } \\
\text { best management practices }\end{array}$ & Low entry barriers for entrepreneurs \\
\hline Difficulties with products and processes quality certification & Lower prices of goods and services for consumers \\
\hline Less inclusive growth due to uneven taxation & Significant tax savings \\
\hline
\end{tabular}

Source: Authors.

\section{2 | Demand Side: Structural Change and Labor Productivity}

Table 4.4 provides some basic information on cross-sectoral patterns of economic activity in the CASC region. Countries with abundant natural resources-Kazakhstan, Azerbaijan, and Turkmenistan-have a relatively high share of industry in value added, as is to be expected. Moreover, agricultural employment is high in all CASC economies, especially those lacking natural resources. Levels and GDP shares of the sector are high, although they vary considerably, and are comparable to what is usually found in low- and middle-income countries in the rest of the world.

Table 4.4: Economic Sectors' Shares in Central Asia and the South Caucasus (Percent share of total GDP and employment, 2014)

\begin{tabular}{|c|c|c|c|c|c|c|c|}
\hline & \multicolumn{3}{|c|}{ Employment } & \multicolumn{3}{|c|}{ GDP } & \multirow{2}{*}{$\frac{\text { GDP-PPP }}{\text { Per Capita (\$) }}$} \\
\hline & Agriculture & Industry & Service & Agriculture & Industry & Service & \\
\hline Armenia & 36.3 & 17.0 & 46.7 & 20.8 & 28.6 & 50.6 & 8,069 \\
\hline Azerbaijan & 36.8 & 14.3 & 48.9 & 5.7 & 58.3 & 36.0 & 17,520 \\
\hline Georgia & 43.2 & 8.2 & 48.6 & 9.2 & 24.4 & 66.4 & 9,162 \\
\hline Kazakhstan & 24.2 & 19.8 & 56.0 & 4.7 & 36.0 & 59.3 & 24,227 \\
\hline Kyrgyz Republic & 31.7 & 20.2 & 48.1 & 27.4 & 26.7 & 56.0 & 3,321 \\
\hline Tajikistan $^{a}$ & 52.9 & 9.4 & 39.2 & 20.9 & 27.7 & 51.4 & 2,690 \\
\hline Turkmenistan ${ }^{b}$ & 46.6 & 14.1 & 39.3 & 14.5 & 40.3 & 45.1 & 15,473 \\
\hline Uzbekistan & 29.0 & 15.0 & 56.0 & 18.8 & 33.7 & 47.5 & 5,573 \\
\hline
\end{tabular}

GDP = gross domestic product, $\mathrm{PPP}=$ purchasing power parity.

a 2009, authors' calculation.

b 2011, value added and employment shares, authors' calculation.

Source: World Bank. 2016. World Development Indicators 2016. Washington, DC: World Bank. 
A sectoral comparison of labor productivity across CASC countries is provided in Table 4.5. That agriculture is by far the least productive sector in any country ${ }^{29}$ is consistent with the literature, as is that workers resort to subsistence agriculture as they fail to secure employment in urban areas (Gollin, Lagakos, and Waugh 2014). Like elsewhere in the world, the agriculture sector has been important to structural transformation by absorbing surplus labor from other sectors.

Table 4.5: Labor Productivity by Sector in Central Asia and the South Caucasus (\$ at constant 2005 PPP, 2013)

\begin{tabular}{|c|c|c|c|c|c|c|c|c|}
\hline & AGR & MIN & UTI & MAN & $\mathrm{CON}$ & WRT & TRA & OTH \\
\hline Armenia & 9,420 & $\ldots$ & 30,363 & $\ldots$ & 44,719 & 17,683 & 21,756 & 9,595 \\
\hline Azerbaijan & 4,305 & 211,722 & $\ldots$ & 23,832 & 54,701 & 14,628 & 51,654 & 7,925 \\
\hline Georgia & 3,257 & $\ldots$ & 35,715 & $\ldots$ & 19,249 & 12,268 & 46,880 & 24,770 \\
\hline Kazakhstan & 10,191 & 79,848 & $\ldots$ & 66,782 & 44,065 & 34,411 & 61,580 & 31,075 \\
\hline Kyrgyz Republic & 4,903 & 11,045 & $\ldots$ & 10,810 & 3,011 & 8,596 & 13,155 & 4,205 \\
\hline Tajikistan $^{a}$ & 2,719 & 11,870 & $\ldots$ & $\ldots$ & 4,465 & 13,258 & 16,504 & 6,807 \\
\hline Turkmenistan ${ }^{b}$ & 5,689 & $\ldots$ & 49,123 & $\ldots$ & 17,596 & 11,497 & 21,245 & 25,902 \\
\hline Uzbekistan & 8,658 & 10,442 & $\ldots$ & 11,202 & 4,103 & 10,402 & 26,507 & 7,975 \\
\hline
\end{tabular}

$\ldots$ = data not available, $\mathrm{AGR}=$ agriculture, $\mathrm{CON}=$ construction, $\mathrm{MAN}=$ manufacturing, $\mathrm{MIN}=$ mining, $\mathrm{OTH}=$ other activities, PPP = purchasing power parity, TRA = transport and communication, UTI = utilities, WRT = wholesale and retail trade.

a 2008.

b 2010.

Source: Authors' calculations.

\section{Decomposing Labor Productivity Growth}

The economic literature suggests that labor productivity can grow due to three effects (McMillan, Rodrik, and Verduzco-Gallo 2014; Foster-McGregor and Verspagen 2016). It can grow by reallocating labor from less to more productive sectors across periods (static effect) or during the same period of time (dynamic effect). Labor productivity can also grow due to capital accumulation, enhanced factor allocation, technological improvement, and enhanced management practices occurring within each sector (within effect).

Figure 4.7 shows the decomposition of labor productivity growth into within, static, and dynamic effects that occurred between 2003 and 2015. The fact that, in all CASC countries, the within effect dominates, suggests that most productivity growth has been taking place within, not across, sectors. In other words, structural change seems to have only modestly contributed to increasing labor productivity in the region. As productivity gains across sectors are substantial, the results indicate, at least in theory, a large potential for productivity growth driven by structural change.

29 The only exception is the construction sector in the Kyrgyz Republic, where, in 2013, labor productivity was lower than in the agriculture sector. 


\section{Figure 4.7: Decomposition of Productivity Growth in Central Asia and the South Caucasus (By region, weighted by total employment, various years)}

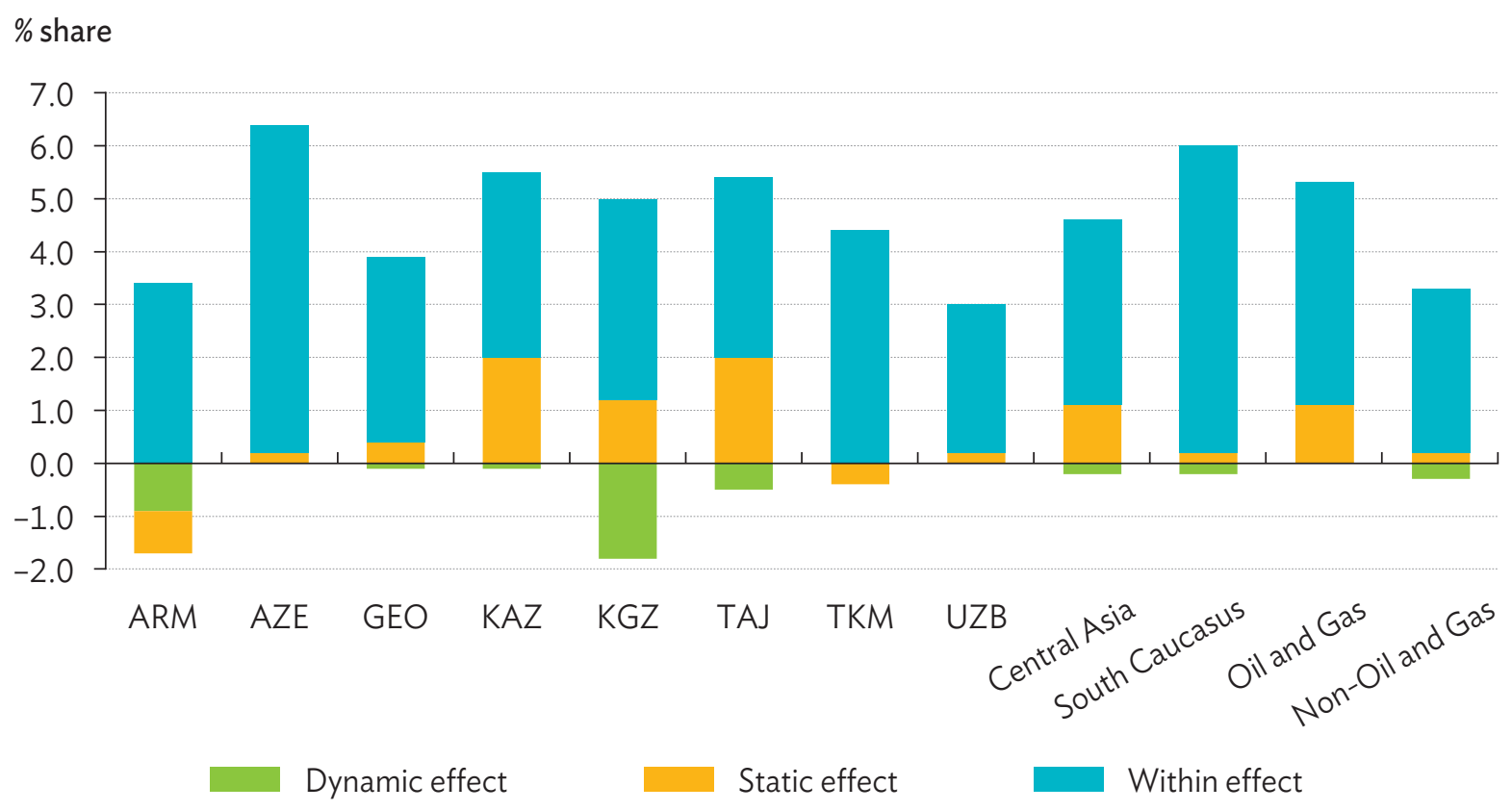

ARM = Armenia (2008-2014), AZE = Azerbaijan (2009-2015), GEO = Georgia (2009-2015), KAZ = Kazakhstan (2007-2014), KGZ = Kyrgyz Republic (2007-2014), TAJ = Tajikistan (2003, 2008), TKM = Turkmenistan (2006-2010), UZB = Uzbekistan (2009-2015).

Notes:

1. Oil and gas includes Azerbaijan, Kazakhstan, and Turkmenistan.

2. Non-oil and gas includes Armenia, Georgia, the Kyrgyz Republic, Tajikistan, and Uzbekistan. Decomposition by region weighted by total employment.

Source: Authors' calculations.

The fact that for all CASC countries the dynamic effect is negative, suggests that sectors with falling labor productivity tend to attract labor inflows (and vice versa). While apparently counterintuitive, such a result is because less labor is needed to produce a given output in sectors with increasing labor productivity, as labor inflows will reduce labor productivity through diminishing returns.

In the case of the Kyrgyz Republic, structural transformation contributed positively to labor productivity growth, as labor moved to relatively more productive sectors over time, although the positive effect has been offset by labor shed in sectors with higher labor productivity growth. In Armenia, by contrast, structural transformation has reduced labor productivity by almost $2 \%$ a year, as shown by the negative signs of the static and dynamic effects. 


\section{3 | Good Jobs and Small and Medium-Sized Enterprises}

Demand for labor and generation of good jobs are affected by the size of firms. International experience suggests two patterns in countries undergoing structural transformation: (i) larger firms tend to offer better jobs than smaller ones; and (ii) labor originating in low-productivity sectors, such as agriculture, or displaced by rapid productivity growth in other sectors, is typically absorbed by SMEs.

It is, therefore, important to observe how SMEs in CASC countries can play a role in employment creation, especially in the generation of good jobs for inclusive growth, and what constraints they face. How do agriculture workers moving into SMEs transform their skills? And how can government policy help SMEs offer jobs that are increasingly safe, inclusive, and well-paid? Box 4.1 discusses the job creation process for SMEs in Armenia and how it can promote entrepreneurship among women.

\section{Box 4.1: Small and Medium-Sized Enterprise Development and Women's Entrepreneurship in Armenia}

Should policies aiming to promote good jobs for inclusive growth favor larger over smaller enterprises? In general, the economic literature widely supports the idea that good jobs-well-paid, inclusive, and secure-are mostly created in larger firms. However, small and medium-sized enterprises (SMEs) can still play an important role in promoting good jobs for inclusive growth, as they provide an intermediate stage to the labor force for shifting from low-productivity sectors such as agriculture, to higher-productivity sectors such as manufacturing. Moreover, although labor productivity is lower in SMEs than in larger firms, SMEs still have large labor absorption capacity, especially for unskilled workers.

Countries in Central Asia and the South Caucasus can introduce targeted policies and structural reforms to strengthen the SMEs' function in generating good jobs for inclusive growth. In 2015, the Republican Union of Employers of Armenia conducted a survey among SMEs to identify the main challenges and needed reforms. Access to finance, weak macro environment, and high tax rates were reported to be the major problems during 2009-2014, as shown in the figure.

While the macro environment is independent of SME policies, Armenia has successfully introduced specific SME policies addressing issues, such as access to finance and corruption, by focusing on financial literacy, microfinance, and strengthening governance and the SME regulatory framework.

\section{Major Problems and Major Reforms Affecting SMEs} in 2009-2014 (\% of responding SMEs)

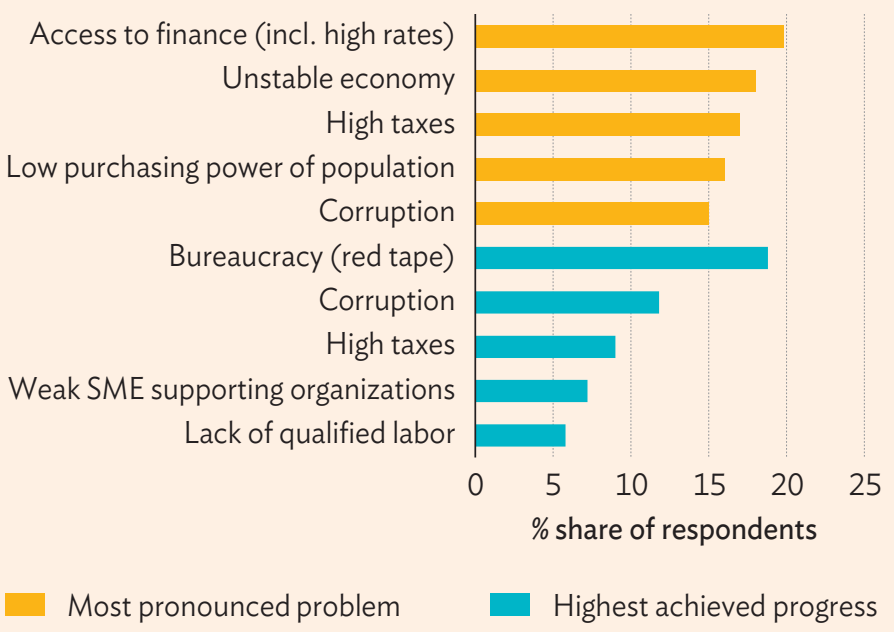

SMEs = small and medium-sized enterprises

Source: Republican Union of Employers of Armenia. 2015. The Main Business Obstacles in Armenia: SME Situational Comprehensive Survey at Macro and Micro Levels. Yerevan. http://www.employers.am/News.aspx?Newsld=60\&lang=eng. 


\section{Box 4.1: Continued}

\section{Promoting women's entrepreneurship}

Armenia has also shown how SMEs can be an effective conduit to promote women's entrepreneurship. Although there are no official statistics on the number or share of female entrepreneurs in the country, experts' estimates range from around $15 \%$ of all active SMEs (including microenterprises) to $20 \%$ of all business owners and $30 \%$ of individual and microenterprise owners combined. ${ }^{\text {a }}$

Understanding women's representation among entrepreneurs is further complicated by the fact that national statistics are generated from sex-disaggregated data on legally registered business owners. This practice inflates gender statistics in favor of women, as men commonly register their businesses in the names of female relatives to reduce their own visibility or to take advantage of donor programs that prioritize credit lines for women. Still, female engagement in SMEs in Armenia is considerably less than in Organisation for Economic Co-operation and Development (OECD) countries, in which the female self-employment rate is around half that of the male. ${ }^{b}$

To address this issue, since 2000, Armenia has proactively supported SME development and has identified the need to increase the ratio of women among entrepreneurs. Growth in women's entrepreneurship is a cross-cutting element of the national strategy on SME development, in recognition of the fact that enhancing women's roles will, ultimately, contribute to "the establishment of additional workplaces in the country and ultimately to economic growth."

Starting in 2013, under the Asian Development Bank's Armenia: Women's Entrepreneurship Support Sector Development Program, the National Agency for the Promotion of Small and Medium-sized Entrepreneurs undertook several research and assessment projects to identify the most critical gender-based obstacles to entrepreneurship that women were facing. The findings show that

(i) Women are more likely to start a business out of necessity (e.g., due to job loss) than men, whereas men more often have previous business experience which they apply to their new venture when they see opportunities. Males have more often developed business plans and are more likely to have introduced innovation to their businesses than female entrepreneurs. ${ }^{c}$

(ii) Female entrepreneurs tend to enter markets where there are low knowledge barriers, but which are also saturated and have few long-term prospects (e.g., beauty salons, catering, educational services, petty trade, etc.). The reasons for these divisions are related both to women's more limited readiness to innovate as well as gender stereotypes and patriarchal attitudes that make it difficult for women to enter sectors that are considered "unacceptable."

(iii) While female and male entrepreneurs at the start-up level express similar need for business support services and identify the same areas of interest, women not only tend to have less access to existing services, they also identify problems that men generally do not, such as a lack of opportunities for networking and making business contacts.

In response to these challenges, the Small and Medium Enterprise Development National Center adopted a new strategy on women's entrepreneurship implementing focused activities through the Women's Entrepreneurship Support Sector Development Program for female entrepreneurs of microenterprises and SMEs. Specific activities include

(i) providing start-up support training programs in which half of the participants are women,

(ii) sensitizing and training key staff of financial institutions about the specifics of women's entrepreneurship to help remove barriers faced in accessing credit,

(iii) initiating a new scheme for gender-responsive loan guarantees,

(iv) launching a mentorship and networking program between women entrepreneurs,

(v) promoting public awareness campaigns and success stories about female entrepreneurs, and

(vi) introducing capacity-building programs to develop and maintain a sex-disaggregated database and reporting system and design nonfinancial products in support of female entrepreneurs.

Sources: a E. Duban. 2015. Armenia Country Gender Assessment. Manila: Asian Development Bank.

b Organisation for Economic Co-operation and Development. Entrepreneurship at a Glance. http://www.oecd.org/std/ business-stats/entrepreneurship-at-a-glance-22266941.htm.

c A. Sarkisyan and M. Shahmenendyan. 2014. Armenia: Promoting Gender Equality and Women's Empowerment (baseline assessment). Caucasus Research Resource Center. 
The empirical literature shows that in CASC countries, as elsewhere in the world, access to finance is the most important binding constraint on SME growth. Introducing targeted policies to eliminate, or at least reduce, these constraints, is another way policy makers in CASC countries can stimulate demand for labor generated by SMEs and improve the quality of jobs they offer. Box 4.2 discusses how introducing systems for credit scoring of SMEs and hometown investment trust funds can help promote good jobs for inclusive growth.

\section{Box 4.2: Credit Scoring of Small and Medium-Sized Enterprises and Hometown Investment Trust Funds}

Although small and medium-sized enterprises (SMEs) account for the majority of employment and play an increasing role in Asian countries' exports and gross domestic product, due to information asymmetry, they typically face greater difficulties in obtaining finance than large enterprises. This is because banks usually find it difficult to obtain information about SMEs sufficient to evaluate creditworthiness. Moreover, unless banks can obtain adequate collateral, which also tends to be less available from SMEs, they are typically less willing to lend to SMEs than to large firms.

Difficulty of small and medium-sized enterprise data collection. Obtaining quality financial data is a major obstacle in enabling credit ratings in many Asian countries. With the intention to help SMEs disclose their true financial data, Japan, Malaysia, the Republic of Korea, and Thailand established credit guarantee systems to assist smooth lending from banks to SMEs. Credit guarantees encourage banks to lend to SMEs by lowering default risk. Credit guarantee corporations help cover losses when SMEs go bankrupt. ${ }^{a}$

A credit guarantee corporation can collect data from SMEs when it provides them a guarantee for a bank loan. Japan was an early innovator with its credit guarantee scheme dating back to 1937 and the scheme becoming more complete with the 2001 establishment of the Credit Risk Database. The database gathers data on SMEs collected by a credit guarantee corporation and member banks and uses them to analyze SME creditworthiness and provide an estimated default loan ratio for each industrial sector. Banks can use the Credit Risk Database's credit risk estimates when they make loans to SMEs.

Financing for start-ups. Start-up businesses, lacking business records, have even more difficulty borrowing money from banks than do normal SMEs. To address this issue, in the early 2000s, the Hometown Investment Trust (HIT) fund was developed in Japan as an innovative financing vehicle. HIT funds focus on gathering financial support from local communities, among individuals who know and trust each other, and are ready to promote innovative ideas. The basic objective of the HIT structure is to connect local investors with projects in their own areas, where they had personal knowledge and interest. Investors choose their preferred projects and make investments through the internet. $^{b}$

In one example, musicians were able to use it to finance recordings. In a second application, wind and solar power projects raised money from individuals interested in promoting green energy in their residential areas. In a third case, a farmer who improved the taste of beef by innovating the production process wanted to raise funds to expand his business. An internet distributor advertised his new beef products by guaranteeing their high quality and ensuring fast delivery.

Encouraged by the rapid development of such businesses, some local banks in Japan have started to make use of the information provided by HIT funds and were able to support early start-ups until the ventures grew large enough to borrow from commercial banks.

Sources: a N. Yoshino, F. Taghizadeh-Hesary, P. Charoensivakorn, and B. Niraula. 2016. Small and Medium-Sized Enterprise (SME) Credit Risk Analysis Using Bank Lending Data: An Analysis of Thai SMEs. Journal of Comparative Asian Development. 15 (3). pp. 383-406.

b N. Yoshino and S. Kaji, eds. 2013. Hometown Investment Trust Funds. Tokyo: Springer. 


\section{4 | Supply Side: Employment and Skills Development}

Promoting SME development and structural transformation to diversify the economy and provide better access to global demand are important policies in support of good jobs for inclusive growth. However, policy makers also need to look at the supply side of the labor market. As global technological trends are increasing demand for skills, without adequate intervention on the supply side, CASC countries will face a skills shortage that will hold back economic growth and raise the skill premium, increasing inequality.

CASC countries have already significantly reformed their education systems compared to other regions, with relative strengths in areas such as adult literacy and primary and secondary education enrollment rates. Indicators of gender equality in education are usually good when compared with those of other countries at a similar level of development. However, in most CASC countries, national systems for skills development are facing remarkable challenges. Addressing such challenges is of the utmost importance to develop the level of human capital required for achieving inclusive growth and economic diversification.

In CASC countries, public investment in education has been falling since the dissolution of the Soviet Union and is generally inadequate to satisfy the pressing needs for skills development. One of the most critical issues concerns the structural shortage of qualified teachers, which creates a fundamental bottleneck in the education system in many countries. Moreover, very low teacher salaries remain the single-most important problem almost everywhere. A number of studies suggest that while relatively strong basic education provides a generally good foundation for the quality of teachers, CASC education systems fail to develop adequate knowledge and skills for young populations nearing the end of compulsoryschooling. Such findings are validated by the average low marks students from CASC countries receive from programs such as the Organisation for Economic Co-operation and Development's Programme for International Student Assessment or Trends in International Mathematics and Science Study.

Tertiary enrollment rates are low in CASC countries, particularly in Turkmenistan and Uzbekistan. Another challenge with tertiary education is the low share of students choosing subjects such as science and engineering, which are critical to developing knowledge-based economies that generate good and high-paid jobs. While gender disparity in enrollment is not a major issue, educational choices at the postsecondary level and labor market outcomes exhibit gendered patterns, with women overrepresented in humanities and social science programs and ending up in lower-paying jobs in the public sector.

Access to education is also marked by significant inequalities. While education represents a fundamental gateway to a higher quality of life for children, especially those from low-income groups, the high school dropout rates of children belonging to the most marginalized groups are a cause of concern in many CASC countries (ADB 2014a). 


\section{Technical and Vocational Education and Training}

Since independence from the Soviet Union, systems for technical and vocational education and training (TVET) have been largely ignored in all CASC countries, except in Uzbekistan. TVET systems are perceived as having generally low status; they tend to serve a disproportionate number of less able or disadvantaged students and remain unable to provide the quality skills demanded in the markets. They also receive limited funding from the budget of CASC countries (OECD 2011).

As a result, the total number of students enrolled in TVET programs-and their quality-remain relatively low across the CASC region. Opportunities are also limited for enrolling in programs of continuous vocational and educational training, which were offered during Soviet Union times, as a large number of training centers serving state-owned enterprises (SOEs) were eventually closed. Box 4.3 discusses the key challenges of TVET in Tajikistan, including gender inequality, and illustrates how international financial institutions, such as ADB, can help governments improve the TVET system in the region.

\section{Box 4.3: Increasing Gender-Sensitivity in Technical and Vocational Education and Training in Tajikistan}

Tajikistan has a young and rapidly increasing population. Recent years have seen an increase in the working-age population with a parallel decrease in gainfully employed people. The gender gap in labor force participation has also been widening. The country is facing the challenge of how to integrate the growing number of working-age people into the labor market and ensure that young people-the youth bulge-have access to educational and employment opportunities as they reach working age. Currently, high youth unemployment and a mismatch between the state education program and local labor market demand contribute to one of the highest labor outmigration rates in the world.

The technical and vocational education and training (TVET) system has the potential to prepare young people to enter the job market. But, in Tajikistan, TVET is largely supply-driven and outdated in its contents and course structures. Limited investment, and a widespread perception that education offered at the tertiary level and through the private system is of higher quality than vocational education, has led to decreasing enrollment in TVET, when compared with investment in high education.

Tajikistan is also facing gender inequality in access to TVET, especially for girls from poor or rural families and remote regions. National estimates suggest that in 2012, only 30\% of all TVET students and 38\% of faculty members were women. Moreover, considering only primary vocational education, the percentage of females enrolled fluctuated from $28.1 \%$ of all students in 2005 to $22.5 \%$ in 2014 , as shown in the figure.
Tajikistan-Male and Female Enrollment in Primary Vocational Education by Academic Year

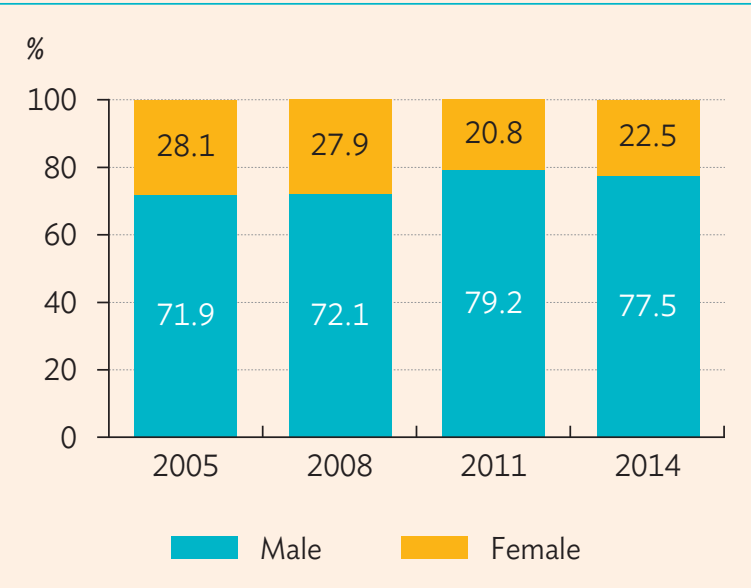

Source: Agency on Statistics under the President of the Republic of Tajikistan. https://www.stat.tj/en. 


\section{5 | Labor Market Institutions}

This study is distinctive in its analysis of labor market institutions that link the demand and supply sides of the labor market. Well-designed and -managed institutions play an important role in promoting the employability of the labor force, fostering labor mobility, providing market intermediation in placing skills where they are needed, and actively promoting inclusive access to the labor market.

Labor market institutions in CASC countries reflect pronounced legacies from the Soviet Union, European traditions and practices, and labor standards developed by the International Labour Organization and other international organizations. Labor practices from the Soviet Union era and those influenced by European countries were designed for well-developed and diversified economies capable of fully using human resources, where formal wage employment is the norm. As such, they are not well in tune with the demand and requirements of contemporary CASC countries, often displaying substantial discrepancy between the systems' aspirations and their abilities to deliver a high-quality and skilled labor force. Against generous provisions for social benefits, labor market institutions tend to be characterized by relatively poor issue coverage, ineffective legal enforcement, and often dysfunctional funding structures.

\section{Box 4.3: Continued}

According to Tajikistan's 2010 population census, $23.3 \%$ of all urban women of working age had some vocational training, compared with only $6.8 \%$ of rural women. ${ }^{a}$ There are also distinct gendered patterns in TVET course selection, with female trainees channeled toward fields considered acceptable and traditional for women (e.g., health-care assistance, teaching, office work, sewing, food preparation). Male students make up virtually the entire student body in courses on topics such as economics, management, construction, transport, agriculture, energy, engineering, mechanics, plumbing, and electrical works. Female-dominated occupations tend to be lower paying and, in areas marked by low investment and growth, contributing to women's economic dependence and poverty.

Several factors contribute to the low enrollment rates of Tajik females in TVET: (i) location of facilities, (ii) lack of appropriate student accommodation, (iii) lack of courses in nontraditional subjects for which women could find work, (iv) lack of job placement support, (v) gender disparities in instructors, (vi) high costs and limited family investment in girls' education, and (vii) widespread gender stereotypes about women's employment.

In response to these challenges, in 2016, the Asian Development Bank introduced a project aimed at strengthening TVET by supporting the Government of Tajikistan in developing a demand-driven, flexible system responsive to labor market needs. ${ }^{b}$ The project is focused on improving the overall system, promoting inclusivity, and removing barriers to young women. Activities include modernizing the curriculum and introducing standards, while also developing gender-sensitive learning materials; upgrading the housing facilities for students and making them accessible to girls; developing teacher competencies (with targets for training female teachers); providing students with opportunities to gain practical skills through internships; and using social marketing campaigns to increase female enrollment in nontraditional areas. The project also provides benefits for women, such as the provision of stipends for girls from poor families, internship placements with private firms, and priority placement in dormitories. It is estimated that more than 2,000 women and girls will benefit from this project.

Sources: a ADB. 2013. Strengthening Private Sector Participation in Technical and Vocational Education and Training (TVET) - Initial Poverty and Social Analysis. https://www.adb.org/sites/default/files/project-document/80010/ 46535-001-ipsa.pdf.

b ADB. 2016c. Project Brief: Tajikistan Strengthening Technical and Vocational Education and Training. https://www.adb.org/publications/taj-strengthening-tvet-project-brief. 


\section{Employment-Friendliness}

Institutions operating in the labor market need to facilitate job creation and safeguard qualitative aspects of good jobs. For employment protection, labor legislation in CASC countries can balance protecting workers with formal jobs while avoiding disincentives to hiring and formalizing jobs. Legislation tends to be generally less protective in CASC countries than those in Europe and other parts of Asia, yet more comprehensive than in many other developing countries around the world.

The presence of a generally large tax wedge on labor is, however, a deterrent to formal job creation. ${ }^{30}$ In 2016 , the combined contributions of employers and employees to social insurance funds ranged widely from $16 \%$ of gross wages in Kazakhstan to 25\% in Azerbaijan, the Kyrgyz Republic, and Tajikistan, to over 30\% in Uzbekistan. In Armenia, social contribution levies are de facto regressive, creating strong disincentives to the creation of formal jobs, especially for unskilled labor. Finally, in Georgia, which lacks a social insurance fund, employers are directly responsible for paying benefits such as maternity and sick leave, thus creating disincentives to hiring young women and/or workers with a medical history.

\section{Inclusiveness}

Employment legislation and labor market institutions are of limited value when the entire labor force is not covered or law enforcement is weak. The actual outreach and coverage in CASC countries tend to be limited to jobs in the formal employment system or a privileged minority of the labor force. The many self-employed and informally hired wage-workers, including those with the most precarious foothold on the labor market, remain outside the reach of labor market institutions (and policies) without the protection and benefits they aim to provide. Non-inclusive institutions, legislation, and policies arguably are a primary weakness of labor markets in the CASC countries. Governments need to make major effort to formalize self-employment and find innovative ways to extend the effective coverage of labor market regulations, institutions, and policies to include the entire labor force.

\section{Labor Mobility}

Despite economic transformation, calls for efficient labor markets, and the premium on occupational and geographic mobility of labor, labor market institutions remain marginal in promoting labor mobility in the CASC region. In a few instances, the absence of active labor market policies (ALMPs) has been ideologically motivated, but it appears, in most instances, to result from a lack of funding and tradition which, in turn, has translated into weak institutional capacity building.

The vast numbers of migrant foreign workers outside the reach and protection of job market institutions in both their source and host countries are an important dimension of labor mobility, and one that links with inclusiveness. Ample empirical evidence suggests that migrant workers from CASC countries are often deprived of their basic rights, subject to discrimination, and exploited. Working conditions of migrant workers often fall far short of the minimum legal requirements, and workers are granted few, if any, social benefits.

30 The labor wedge tax is the difference between the actual cost of labor to the employer and the employees' take-home pay. 


\section{Funding Mechanisms}

The funding mechanisms of employment-related social benefits, insurance, and ALMPs in the CASC region tend to be weak and somewhat dysfunctional. The small number of formally employed workers relative to the total labor force implies that the contribution basis for social insurance funds are small, resulting in underfunding and placing upward pressure on contribution rates. The tax wedge on labor, resulting from social contributions, disincentivizes creation of formal jobs, perpetuating a vicious circle. In most countries, social contributions are pooled in a unified fund used for paying pensions, maternity and sick leave, unemployment benefits, and also the costs for ALMPs.

\section{Flexicurity}

The enhanced dynamism of labor markets exposed to structural economic transformation calls for a shift from protecting jobs to protecting workers engaged in the formal and informal systems, where institutions are managed to combine flexibility for labor markets with reliable and predictable systems for social security. Such an approach, with roots in Denmark and other European countries, is referred to as "flexicurity."

The concept of flexicurity identifies a strong role for ALMPs that support individual workers with retraining, job-matching, and similar initiatives helping shape an efficient and flexible labor market at the aggregate level. Underpinning such an approach is a shift in the burden of financing job security from the employer to the public purse and from protecting jobs to protecting workers. As part of flexicurity, for instance, employment protection's legislation can be liberalized and labor costs for employers reduced without compromising job security, by introducing legislation that grants basic income security for workers together with ALMPs that help job-seekers qualify for accessing new jobs. Similarly, shifting funding of paid maternity leave from employers to the public purse can reduce disincentives to hire young women without compromising their economic security.

\section{6 | Structural Reforms}

While market institutions need strengthening in employment friendliness, inclusiveness, labor mobility, funding mechanisms, and flexicurity, structural reforms promoting labor market policies to achieve good jobs for inclusive growth should be focused on three interrelated areas:

(i) increasing the role of ALMPs that target the entire labor force and promote a shift away from the traditional focus on job protection, social benefits, and passive labor market policies designed for a privileged minority of workers operating in the formal employment system;

(ii) moving toward more inclusive social benefits and protection schemes while reforming funding mechanisms of labor market policies; and

(iii) developing strong mechanisms for improving labor market information and analysis that integrate employment and labor market issues with creation of human resources. 


\section{Active Labor Market Policies}

The introduction of ALMPs in CASC countries is an important step for addressing ongoing issues such as the pressing need to (i) resolve widespread problems of low employability and lack of employable skills; (ii) provide a premium on labor mobility; and (iii) improve the utilization of the countries' labor resources, as evidenced by widespread informality, labor migration, and unemployment and underemployment.

To exploit the full potential of ALMPs, interventions tailor-made to the specific conditions and challenges in each country are needed with flexible overtime, and closely coordinated with strategies for human resource development and with economic and industrial policies. The need for highly sensitive ALMPs to local situations precludes detailed recommendations for the CASC region as a whole.

\section{Inclusive Social Benefits and Protection}

Structural reforms are needed to improve the funding mechanisms of employment-related social benefits and ALMPs in most CASC countries with structural weaknesses. First, policy makers need to reassess the relative distribution of funding from contributory sources (mainly social insurance funds) and the public purse. Review is also needed of the criteria and mechanisms for drawing on social funds and the overall level of benefits.

A shift in focus from protecting jobs to protecting workers will inevitably require relative shifts in funding from social insurance funds to the general budget. At present, public expenditures on ALMPs in CASC countries tend to be very low: none of the countries in the region is spending more than $0.1 \%$ of GDP on such interventions. ${ }^{31} \mathrm{~A}$ paradigm shift is required for policies aiming at promoting employability and labor mobility as well as focused on creating inclusive and flexible labor markets as important public goods-and funded accordingly.

Strong arguments justify the need to set up separate funding mechanisms for different types of benefits and costs, or at least for earmarking funds for specific purposes within the frame of unified social funds. Moreover, funds destined for pensions, paid maternity and sick leave, and unemployment insurance should be separated from ALMPs (the latter being funded entirely from the government budget). The conditionalities and benefit levels of different schemes should also be reviewed to better balance the countries' ambitions and funding ability.

The system of employment-related contributions for social protection benefits used in almost all CASC countries is inevitably deepening the divide between the minority of workers operating in the formal system through wage jobs and the majority of the labor force engaged in informal employment. The de facto segregation of the labor force into one group enjoying labor rights, legal protection, social benefits, and security, and another group deprived of these rights and benefits is incompatible with the promotion of good jobs for inclusive growth.

31 In contrast, countries in the European Union spend approximately $0.4 \%-0.5 \%$ of their GDP on ALMPs. 
Eliminating such a divide requires formalization of informal employment and broader coverage of the legislative and regulatory framework, while detaching basic social protection and benefits from the workers' status in the labor market. Thus, the development of a publicly funded floor for universal social protection that covers the entire population irrespective of labor market status is arguably an essential dimension for achieving inclusiveness. ${ }^{32}$ To be sure, such a floor for basic social protection can be developed incrementally, first offering limited benefits that are increased as fiscal resources grow.

Universal social protection fosters inclusive access to good jobs and to labor mobility, primarily by reducing vulnerability. In the absence of social protection schemes, workers who can benefit from only small economic margins cannot afford to take even small, calculated risks associated with changing jobs or seizing economic opportunities, as the occupations available for most of the working poor and those employed in the informal sector seldom coincide with the most dynamic sectors of the economy. Labor mobility is essential to escape poverty and dead-end jobs: it is thus a sine qua non for inclusive economic development.

The importance of social protection and insurance schemes for reducing vulnerability and creating more equal opportunities for mobility is obvious and straightforward, with risk mitigation a main objective of social insurance. However, the effectiveness by which social protection reduces vulnerability depends not only on the magnitude of support, but largely also on its design. Schemes for social protection must be predictable and perceived to be so by its recipients. Universal schemes that automatically trigger support under specific well-defined circumstances and which leave little room for discretionary decisions are most effective as they minimize uncertainty and the risk that qualifying recipients are denied support.

\section{Information Systems}

Promoting good jobs for inclusive growth requires that strategies for human resource, employment, and economic development are designed and implemented in close coordination with each other. Structural reforms are needed to strengthen the capacity of labor market institutions to collect quality data and analyze the trends occurring in their own macroeconomic, employment, and labor market conditions, as well as their demographic structures and human resource composition.

Policy makers need to understand and factor in the employment dimensions of economic development policies. Those with immediate responsibility for ALMPs and other employment-related issues should also understand the underlying economic dynamics. Similarly, labor market institutions need strong capacity to undertake labor market and occupational projections, and identify emerging skills shortages, as a basis for TVET planning and for designing ALMPs more generally.

32 Universal social protection floors are nationally defined and supported by the International Labour Organization (www.ilo.org or www.socialprotection.org). They include four basic social security guarantees: (i) basic income security for children; (ii) basic income security for people in active age unable to earn sufficient income, particularly in cases of sickness, unemployment, maternity, and disability; (iii) basic income security for older people; and (iv) access to essential health care. 


\section{POLICY OPTIONS}

\section{by Duncan Campbell, Giovanni Capannelli, Ravi Kanbur,} Alessandro Pio, and Per Ronnås

he broad structure of policy options promoting good jobs for inclusive growth flows from a need to address the key challenges in the countries in Central Asia and the South Caucasus (CASC) identified in earlier chapters. In keeping with the analytical structure of this study, the causal factors shaping policy measures are classified as from the demand or supply side, or within institutions that govern the labor market's ability to mediate between demand and supply. In practice, however, interventions often overlap and interact with each other, with policies that directly impact the demand side having indirect effect on the supply side, and vice versa. The central diagnostic and specific policy interventions flowing from the analytical framework this study adopts must be seen through the prism of the CASC region's distinctive features and the inherent opportunities they create (Table 5.1).

\section{Table 5.1: Challenges and Opportunities for Good Jobs for Inclusive Growth in Central Asia and the South Caucasus}

\begin{tabular}{lll} 
Challenges & & \\
High labor share of low-productivity agriculture & $\rightarrow$ & Labor productivity can largely improve \\
\hline High rate of self-employment and informality & $\rightarrow$ & More formal economy can expand tax revenues \\
\hline High rate of cross-border labor migration & $\rightarrow$ & Remittances can promote skills development \\
\hline High degree of spatial inequality within countries & $\rightarrow \quad$ Regional development can spur demand for labor \\
\hline Low market penetration of non-resource exports & $\rightarrow \quad$ Nontraditional exports can rapidly expand \\
\hline
\end{tabular}

Source: Authors.

In market economies, when employment and jobs are identified as central to achieving inclusive economic growth, employment opportunities and workers' incomes are determined by the matching of demand with supply in the labor market. Opportunities are created by shifting jobs away from the agriculture sector as labor productivity improves and reducing economic informality, which expands budget revenues due to higher tax payments. Sustained international migration can, in turn, present a unique opportunity for skills development as remittances are invested in expanding human capital. Pronounced spatial inequality within countries makes it necessary to promote connectivity through infrastructure investment, which can absorb excess labor supply. Moreover, progress on diversifying economies into the non-resource sectors can promote exports and generate new demand for labor and help create good jobs.

Given the CASC region's distinct challenges and opportunities, this chapter discusses a set of policy options for expanding the labor market's demand, strengthening its supply side, and enhancing its institutions and governance. The transmission mechanism of policy options inevitably reflects the implications of the large informal sector in CASC economies, as informality affects policy and structural reform's effectiveness in enhancing the supply and demand sides, as well as labor market institutions. 


\section{1 | Policy Framework}

Empirical results from the analysis of CASC countries' specific situations suggest a clear need to invest in education and skills training to match the increasing demand for skilled workers as technology changes, which is crucial to controlling the inequality arising out of the higher wage premiums paid for skilled labor. Investing in infrastructure and in public services to address the non-income dimensions of inequality, in education and health, is a second prong of the supply side of economic policy.

However, high-skilled labor and better infrastructure will not deliver inclusive economic growth if there is no demand for that labor. As long as global and local forces keep demand for unskilled labor low, policy makers will need to grapple with the inclusivity of growth. In the current global environment, to generate good jobs for inclusive growth, an economic system must respond as technology shifts in the medium term away from demand for basic labor and toward demand for skilled labor. The system must also make informality manageable and use it to buffer internal and external shocks.

The level and structure of the demand for labor-partly caused by geography, historical factors, and economic policies - is a major reason for unemployment, underemployment, and informal arrangements within and outside labor markets. Policy measures and structural reforms introduced to shift countries away from obsolete growth drivers toward new business models that can deliver long-term, sustained, and inclusive growth will considerably affect demand for labor. Without recognizing and addressing these issues, supply-oriented labor market interventions and development policies will only have limited effect.

Labor market institutions, which lie between the forces of supply and demand, are crucial to enabling or inhibiting matching mechanisms. The presence, structure, and capacity of institutions also affect the extent and shape of informality in employment. Policies determine the nature of these institutions for good or ill, and through them, prospects for inclusive growth. Institutional issues are sometimes classified on the supply side, although they clearly affect the demand side as well. Table 5.2 lists policy options by whether they enhance the demand side, improve the supply, or strengthen institutional aspects.

\section{2 | Demand-Side Policies}

Because production technology enhancements increase demand for skills, if labor supply fails to keep up, it will undermine growth and its inclusiveness. Of course, interventions such as infrastructure investment that improve connectivity may have an impact on the supply side of the job market as they foster the mobility of labor. To be sure, such investment policies can also stimulate labor demand. Usually, supply-side policies include those that improve factor productivity in general, not only labor, but also land and capital, although this report focuses on labor market policies. 
Table 5.2: Good Jobs for Inclusive Growth in Central Asia and the South Caucasus: A Scheme for Policy Classification

ENHANCING LABOR DEMAND

\section{PROMOTING ECONOMIC DIVERSIFICATION}

Expanding production of basic goods and high value-added, nontraditional exports

Improving conditions for expanding private investment

Strengthening infrastructure development and connectivity

Engaging employers in private sector-led economic growth programs

\section{STRENGTHENING PRIVATE SECTOR DEVELOPMENT}

Improving competition and the business climate

Fostering development of small and medium-sized enterprises

FOSTERING REGIONAL ECONOMIC COOPERATION

Implementing regional economic cooperation arrangements

\section{IMPROVING LABOR SUPPLY}

\section{DEVELOPING HUMAN CAPITAL}

Improving quality of, and inclusive access to, education

Strengthening skills development

Enhancing public health schemes and improving access to other public services

PROMOTING FLEXICURITY (flexible contractual arrangements)

Introducing active labor market policies

Reforming the sources and mechanisms for funding social benefits

Creating solid systems for labor market information and analysis

\section{STRENGTHENING SOCIAL PROTECTION}

Raising minimum salary

Improving pension systems

Ensuring sustainability of social protection schemes

\section{STRENGTHENING INSTITUTIONAL ASPECTS}

\section{FOSTERING INCLUSIVE LABOR MARKET INTERMEDIATION}

Improving job matching and employability

Eliminating labor market segmentation and discriminatory practices

\section{FORMALIZING EMPLOYMENT CONDITIONS}

Strengthening use of employment contracts, wage employment, and self-employment

Extending the effective coverage of labor market regulations

\section{IMPROVING GOVERNANCE AND REDUCING CORRUPTION}

Introducing one-stop shops

Increasing basic salaries of public servants

Adopting integrated public service delivery systems

Source: Authors. 
As previous chapters note, abundant oil and gas resources have been a mixed blessing for countries such as Azerbaijan, Kazakhstan, and Turkmenistan. In these countries, large export earnings have induced the formation of high private incomes and public expenditure that were channeled toward public investment, provision of low-cost social services, and income support. At the same time, however, strong exchange rates until 2014-2015 have undermined long-term macroeconomic sustainability, reducing export potential and hampering development of other productive sectors.

Financial literacy and access to capital continue to be major constraints, particularly for small and mediumsized enterprises (SMEs) and firms in more remote regions. Overall, CASC entrepreneurship remains largely underdeveloped, and it is often channeled toward the informal sector as a result of regulations and the desire to go undetected by public officials. Policies that promote factor mobility toward uses that guarantee the higher returns of production factors should be encouraged to raise productivity in the whole economy.

A diagnostic representation of approaches in support of raising factor productivity for land, labor, and capital is provided in Table 5.3.

Table 5.3: Raising Factor Productivity: Policy Diagnostic Framework

\begin{tabular}{|c|c|c|c|}
\hline Issues & Implications & Policy Response & Strategy \\
\hline \multicolumn{4}{|l|}{ LAND } \\
\hline $\begin{array}{l}\text { Abundant } \\
\text { availability of } \\
\text { land, but relatively } \\
\text { low agricultural } \\
\text { productivity }\end{array}$ & $\begin{array}{l}\text { - Income remains low } \\
\text { in a large share of the } \\
\text { rural population }\end{array}$ & $\begin{array}{l}\text { Diversify agriculture into } \\
\text { higher-value crops } \\
\text { - Increase rural incomes } \\
\text { through agro-processing } \\
\text { and off-farm employment } \\
\text { - } \text { Review current pricing } \\
\text { and marketing policies } \\
\text { for cotton, wheat, and } \\
\text { other crops }\end{array}$ & $\begin{array}{l}\text { - Expand irrigation schemes } \\
\text { - Develop rural roads and } \\
\text { electrification } \\
\text { - } \quad \text { Invest in cold chains and } \\
\text { agriculture warehouses } \\
\text { - Strengthen logistics and } \\
\text { transportation } \\
\text { - Develop agriculture } \\
\text { extension services }\end{array}$ \\
\hline \multicolumn{4}{|l|}{ LABOR } \\
\hline $\begin{array}{l}\text { Abundant } \\
\text { availability } \\
\text { of labor, but } \\
\text { relatively low } \\
\text { skill level }\end{array}$ & $\begin{array}{l}\text { - Incomes of unskilled } \\
\text { workers remain low } \\
\text { Labor supply does not } \\
\text { match the increasing } \\
\text { sophistication of labor } \\
\text { demand }\end{array}$ & $\begin{array}{l}\text { - } \text { Raise and tailor labor supply } \\
\text { skill level to demand } \\
\text { - } \quad \text { Improve skills of migrant } \\
\text { workers } \\
\text { - Review technical and } \\
\text { vocational education and } \\
\text { training curricula } \\
\text { - Strengthen employers and } \\
\text { trainers' linkages }\end{array}$ & $\begin{array}{l}\text { - Strengthen tertiary } \\
\text { education } \\
\text { Expand and improve } \\
\text { vocational and technical } \\
\text { training curricula and } \\
\text { facilities }\end{array}$ \\
\hline \multicolumn{4}{|l|}{ CAPITAL } \\
\hline $\begin{array}{l}\text { - Capital for private } \\
\text { investment is not } \\
\text { easily available } \\
\text { - Public investment } \\
\text { is not always } \\
\text { put to the most } \\
\text { productive use }\end{array}$ & $\begin{array}{l}\text { Business and employment } \\
\text { opportunities are wasted } \\
\text { - } \quad \text { Productivity remains } \\
\text { below its full potential } \\
\text { - } \quad \text { Budget resources are not } \\
\text { used at their optimal level }\end{array}$ & $\begin{array}{l}\text { - Facilitate access to credit } \\
\text { for small and medium-sized } \\
\text { enterprises } \\
\text { - Attract foreign direct } \\
\text { investment } \\
\text { - Rank alternative public } \\
\text { capital expenditure options }\end{array}$ & $\begin{array}{l}\text { - } \text { Develop the private sector } \\
\text { Enhance public } \\
\text { infrastructure } \\
\text { - Strengthen public-private } \\
\text { - } \text { Introduce comparative } \\
\text { scrutiny of investment } \\
\text { projects }\end{array}$ \\
\hline
\end{tabular}


The scheme can be developed in far greater detail with different perspectives in mind. It identifies key strategies and policy measures based on the issues and economic implications. In addition to focusing on factor productivity, a policy diagnostic framework can also be used to identify policies and strategies for addressing the challenges (and opportunities) presented in Table 5.1. This can be done in relation to the small domestic markets in the CASC region and the need to expand production toward nontraditional exports. For example, when policy focuses just on expanding the domestic market or encouraging global integration to expand markets for nontraditional exports, a range of interventions could be further fleshed out on a country-by-country basis (Table 5.4).

Table 5.4: Addressing Small and Poorly Diversified Domestic Markets: Policy Diagnostic Framework

\begin{tabular}{|c|c|c|c|}
\hline Issues & Implications & Policy Response & Strategy \\
\hline \multirow[t]{4}{*}{$\begin{array}{l}\text { - Small domestic } \\
\text { markets for } \\
\text { goods and } \\
\text { services } \\
\text { - Insufficient } \\
\text { economic } \\
\text { diversification } \\
\text { - Limited } \\
\text { development } \\
\text { of the private } \\
\text { sector }\end{array}$} & $\begin{array}{l}\text { High gross domestic } \\
\text { product concentration } \\
\text { in the extractive } \\
\text { sector (Azerbaijan, } \\
\text { Kazakhstan, } \\
\text { Turkmenistan) }\end{array}$ & $\begin{array}{l}\text { Mitigate the impact of } \\
\text { commodity price swings } \\
\text { Redistribute revenues } \\
\text { to labor force employed } \\
\text { in the non-resource } \\
\text { sectors through transfers, } \\
\text { higher salaries, and } \\
\text { public investment } \\
\text { Develop downstream } \\
\text { industries to hydrocarbons } \\
\text { (petrochemical, fertilizers, } \\
\text { plastic) }\end{array}$ & $\begin{array}{l}\text { - Establish development } \\
\text { and stabilization fund } \\
\text { - Set appropriate domestic } \\
\text { prices for processed } \\
\text { hydrocarbon products } \\
\text { - Allow private investment } \\
\text { in the sector or operate } \\
\text { state-owned enterprises } \\
\text { commercially } \\
\text { - Lend a share of fund } \\
\text { balance at market rates } \\
\text { Use proceeds to } \\
\text { stimulate other sectors }\end{array}$ \\
\hline & $\begin{array}{l}\text { - High concentration } \\
\text { of employment } \\
\text { in agriculture and } \\
\text { services }\end{array}$ & 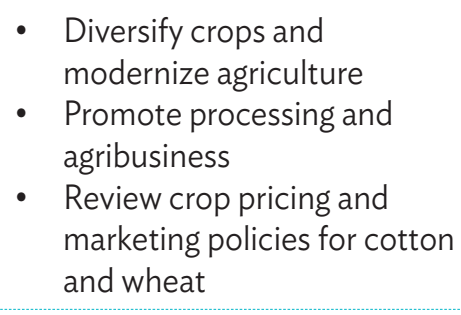 & $\begin{array}{l}\text { - Invest in irrigation, rural } \\
\text { roads, and electrification } \\
\text { - Introduce new } \\
\text { technology and promote } \\
\text { digital agriculture }\end{array}$ \\
\hline & $\begin{array}{l}\text { - Limited diversification } \\
\text { of the manufacturing } \\
\text { sector }\end{array}$ & $\begin{array}{l}\text { Review regulation and } \\
\text { policies on small and } \\
\text { medium-sized enterprises } \\
\text { - Eliminate discretionary } \\
\text { application of regulations } \\
\text { and the resulting corruption } \\
\text { - Provide skill-specific } \\
\text { (re)training courses and } \\
\text { business training for } \\
\text { entrepreneurs }\end{array}$ & $\begin{array}{l}\text { - Facilitate access to credit } \\
\text { for start-ups } \\
\text { - } \text { Promote financial literacy } \\
\text { Create training facilities } \\
\text { for entrepreneurs, and } \\
\text { small and medium-sized } \\
\text { enterprises }\end{array}$ \\
\hline & $\begin{array}{l}\text { Volume of } \\
\text { demand too low } \\
\text { (too small markets) } \\
\text { to allow for } \\
\text { economies of scale }\end{array}$ & $\begin{array}{l}\text { - Increase production of } \\
\text { tradable goods } \\
\text { - Facilitate private sector } \\
\text { participation in academic } \\
\text { research }\end{array}$ & $\begin{array}{l}\text { - Provide support to } \\
\text { innovation, and research } \\
\text { and development } \\
\text { - Create business } \\
\text { incubators }\end{array}$ \\
\hline
\end{tabular}


The centerpiece of a demand-side strategy promoting good jobs for inclusive growth comes from the race between the increase in labor productivity and the expansion in the number of jobs. Holding total output constant, higher labor productivity implies fewer jobs and it is associated with greater inequality and less inclusiveness. However, as holding back the march of labor productivity is not desirable for long-term economic growth, the only possible response is increasing the demand for labor through rising output. Output can be expanded through selling to domestic or export markets by increasing the quantity and enhancing the quality of production.

\section{Economic Diversification}

Although much can be done by improving infrastructure connectivity, expanding domestic markets for goods and services is, ultimately, a limited strategy for CASC countries due to their small populations. Thus, the major thrust has to be diversifying economies and expanding businesses to export goods and services. As discussed, potential is big in agribusiness, or in a wide range of manufacturing production, as well as in logistics, tourism, and other services. Box 5.1 presents the Rodina LLP case and its success in Kazakhstan's agriculture sector.

Demand-side policies must focus on processing agriculture products, non-resource-based manufacturing, and services. This holds true not only for those CASC countries without a strong natural resource base, but also for those which can exploit resource endowments since, ultimately, it is economic diversification which will provide long-term inclusive growth with good jobs. Government strategies to increase production for growing domestic and export markets are complementary and mutually enforcing. Thus, policy should focus on increasing competitiveness and expanding tradable goods, not just exports.

\section{Private Sector Development}

Demand-side policies focused on economic diversification can be classified into those targeting incentives in general and those designed in support of particular sectors or types of labor. Private sector development strategies generally fall into the first category. Improving the business climate would include initiatives such as reducing red tape, simplifying administrative procedures, controlling corruption, and introducing more effective dispute settlement mechanisms. Some of these, such as controlling corruption, fall under the heading of governance and institutions, as discussed in section 5.4.

Economic analysis suggests that monopolies restrict output. Increasing competition by reducing monopoly power, privatizing state-owned enterprises (SOEs), and ending special concessions for privileged and connected enterprises are all elements of a strategy aimed at increasing labor demand. Fostering SME development through improved access to finance, managerial and technical skills, and information flows are also important for demand-side policies. While entrepreneurship has long been recognized as a fundamental institution of economic development, it has only recently begun to receive attention as a conduit for inclusive growth. Box 5.2 discusses Georgia's recent support for entrepreneurship. 


\section{Box 5.1: Promoting Agricultural Development and Inclusive Growth in Kazakhstan}

In 2015, agriculture contributed only a 5\% share of Kazakhstan's gross domestic product. However, the sector maintains high social significance and, in the same year, it employed about $20 \%$ of the total labor force, with $43 \%$ of the country's population rural and a smallholder farm sector producing $75 \%$ of gross agricultural output. ${ }^{2}$

Expansion of agricultural production can contribute considerably to economic diversification. In 2016, the government introduced an ambitious national program (2016-2021) promoting the development of the sector, aiming to become a key player in world agricultural markets to exploit the country's considerable export potential in beef, wheat, and dairy. However, as studies note, Kazakhstan faces serious bottlenecks in developing the agriculture sector. These include low productivity, limited access to finance for farmers, underdeveloped basic infrastructure such as irrigation and rural roads, land tenure restrictions, lack of extension services and veterinary services, poor quality of the knowledge base for agriculture resource assessment, as well as the vast distance to markets. ${ }^{b}$ Despite such shortcomings, agricultural enterprises, such as Rodina LLP, have expanded production and increased productivity, and can be used as examples for inclusive growth.

Rodina LLP, a state farm 70 kilometers from Astana, was privatized in 1994 and became a limited liability partnership in 2005. The company was selected in 2007 as one of the country's three pilot "breakthrough projects" and started receiving financial support from the agri-food sector's national holding company KazAgro. ${ }^{c}$ The loan was used to purchase 700 head of dairy cattle as well as machinery and high-tech equipment for milk production, allowing Rodina LLP to become a major producer of dairy products. Eventually, the company diversified into processing, storing, and marketing of grain and elite seed, entering as well the production of meat, fruit, and vegetables.

In 2017, the company employed 520 people and its annual value of production was estimated to be KZT5.2 billion (approximately $\$ 16$ million), 40\% consisting of dairy production. In the same year, the company was estimated to have much higher factor productivity than the industry average. In dairy production, it had the capacity to process up to 50,000 liters of milk per day (18,000 tons per year), with a median cow milk yield estimated at 7,300 kilograms per year, a significantly higher figure than the 2,100 kilograms per year for the country's average agricultural enterprises. ${ }^{d}$

Rodina LLP is emblematic of how government policy, in coordination with corporate strategy, can promote the demand side of the labor market. The main factors allowing the company to prosper and create good jobs in the agriculture sector include

- integration of smallholder producers under a single leadership;

- diversification of production, from milk processing, cattle breeding, grain, as well as provision of agriculture services such as storage, research, and extension;

- continuous production modernization and use of the latest technologies;

- creation of infrastructure (the company invested in developing rural roads and it installed wind power turbines with a capacity of 750 kilowatts, which provide more than $50 \%$ of the farms' needs); and

- high corporate social responsibility, including respectable remuneration, good and safe working conditions for employees, as well as financial support (housing for its employees, cost of maintenance, central water supply and heating, and kindergarten facilities for employees and free school meals for their children).

Sources: a Committee on Statistics of the Republic of Kazakhstan. 2016. Gross Domestic Product by the Production Method for 2016. Astana. http://stat.gov.kz/faces/wcnav_externalld/homeNationalAccountIntegrated?_ afrLoop=950604426939239\#\%40\%3F_afrLoop\%3D950604426939239\%26_adf.ctrl-state\%3Dfmpl0fmt1_106.

b Asian Development Bank. 2018. Kazakhstan: Country Operations Business Plan 2019-2021. Manila; and Organisation for Economic Co-operation and Development (OECD). 2013. OECD Review of Agricultural Policies: Kazakhstan 2013. Paris: OECD.

c G. Mabieva. 2008. Zerno ostaetsya v strane (Grain stays in the country). Respublikanskiy delovoy ezhenedel'nik. 15 (237), 17.04. p. 1.

d M. Petrick and D. Oshakbaev. 2018. Kazakhstan's Agricultural Development Constraints: Evidence from the Wheat, Beef and Dairy Sectors. In A. Schmitz and W. H. Meyers, eds. Transition to Agricultural Market Economies. The Future of Kazakhstan, Russia, and Ukraine. Wallingford, UK: CABI. 


\section{Box 5.2: Produce in Georgia: Promoting Good Jobs through Entrepreneurship}

The government has operated the state program "Produce in Georgia" since 2014 to develop and support entrepreneurship, encourage creation of new enterprises, and increase export potential. The program provides support through the following measures:

- interest rate cofinancing on loans for the first 24 months of operation (the state finances up to $10 \%$ of the interest rate on loans in national currency and $8 \%$ on loans in US dollars);

- partial collateral guarantee for the first 3-4 years of operation up to $50 \%$ of the total loan (including an upper limit of $€ 1$ million);

- infrastructure support through the provision of state property at symbolic price; and

- consulting support, including due diligence of export markets, business matching, installation of technology, introduction of innovation, skills development, and quality management.

Entrepreneurs are eligible for program support if the following conditions are met:

- At least $80 \%$ of the loan amount is toward purchase of property, plant, and equipment.

- Production is oriented toward either industrial manufacturing or agro-processing.

- Enterprises start production within 24 months of the loan issuance date.

As of December 2016, the program was estimated to have created 11,000 new jobs by supporting 235 projects, corresponding to a total investment of GEL522 million (approximately $\$ 200$ million), of which about $50 \%$ (GEL265 million) was financed through loans from commercial banks.

Two project examples illustrate how the program works. They show how state support can effectively contribute to the success of entrepreneurship and the creation of good jobs.

Georgian Products. Two Georgian brothers in Germany came up with the idea of returning home to start a new business aimed at substituting imports with locally produced raw materials. Following a careful market analysis, the two entrepreneurs established a pet furniture manufacturing facility in Tbilisi, the capital. The state program provided a $\$ 500,000$ loan (approximately GEL1.35 million) at a 3\% concessional interest rate, allowing the new company to compete locally and in export markets. "Georgian Products" has been export-oriented since its inception, targeting the European market. After an initial focus on a few products, in 2017, the company manufactured 17 product lines, employing 220 workers.

Venus Partnership. Venus is a café-bar in the city of Gori operated in partnership by three proprietors. Before receiving support from the "Produce in Georgia" program, the company was functioning poorly, its assets were obsolete, and its revenues limited. However, taking advantage of a GEL15,000 (about $\$ 5,500$ ) loan provided under the state program, its owners were able to completely renovate the kitchen and the interior equipment. The small business more than doubled, with six additional workers hired. Currently, the café-bar is operating successfully as a favorite meeting place for tourists and locals.

Source: Authors, based on Ministry of Economy and Sustainable Development of Georgia, Entrepreneurship Development Agency, 2017.

Government policies can also be crafted to stimulate SME development and expand their contribution to GDP, and support the SME role in employment creation. While policies focused on SMEs can also target the creation of good jobs for inclusive growth, large firms are typically better positioned to promote good jobs, as they tend to pay higher salaries, introduce more advanced innovations, and provide safer working conditions than SMEs. 
In SME-focused measures, tax and other fiscal incentives can be used to foster productive investment, while targeted industrial policies can become effective in enhancing employment conditions and promoting private sector development, including for SMEs. Box 5.3 looks at Turkmenistan's success in promoting SME development and job creation through a focused program.

\section{Box 5.3: State Support for Creating Good Jobs in Small and Medium-Sized Enterprises in Turkmenistan}

Since 2012, the Government of Turkmenistan has fostered development of small and medium-sized enterprises (SMEs) to tackle inadequate job creation by supporting import substitution and export promotion in the nonresource sectors. Its measures raised the number of individual entrepreneurs by $5.2 \%$ and legal entities registered with private ownership by 33\%, from January 2012 to January 2016.

The adoption of the 2005 Tax Code of Turkmenistan with its subsequent 2015 amendment resulted in the simplification of tax reporting and payments for SMEs and individual entrepreneurs, which was set at a fixed rate of $2 \%$ for all revenues. The business community welcomed the initiative, which helped expand employment in SMEs and individual enterprises. The policy aimed to familiarize the population with entrepreneurial activities, expand investment, foster innovation, and help SMEs gain access to international markets. The following privileges were granted for SMEs:

- simplification of registration and reporting procedures for private entrepreneurs;

- preferential rate $(50 \%)$ in the state registration fee, including state duty and registration;

- annual fixed amounts of state procurements (agro-industrial sector and consumer services);

- import of goods, free of duties, for individual entrepreneurs (with some limitations);

- special programs of SME financing and access to credit in priority sectors;

- support for SMEs and individual entrepreneurs in training, retraining, and capacity building;

- provision of concessional lending for acquisition of fixed assets; and

- support in marketing functions and clients' identification.

Such measures supported development of the non-state sector, fostered market infrastructure, and introduced important changes in people's economic mentality and behavior. Eventually, the labor market in Turkmenistan was strengthened through the development of employment outside the state sector, self-employment, and, most importantly, by stimulating private entrepreneurial activity. Based on official statistics, individual entrepreneurs increased from $21.9 \%$ of the total employed population in 2010 to $26.2 \%$ in 2015 , while the share of the private sector in non-hydrocarbon production increased almost 1.5 times, making up over $65 \%$ of the economy in 2016.

Source: Authors, based on State Committee of Turkmenistan on Statistics. Various years.

In addition to policies to expand production of export-oriented goods and services and those fostering private sector investment, entrepreneurship, and SMEs, CASC countries can also promote good jobs for inclusive growth through policies to strengthen infrastructure and connectivity, including investment for improving secondary towns, intermediate cities, and regional development, as well as focused measures to enhance public-private partnerships in infrastructure development. While directly addressing spatial inequalities, such interventions can also stimulate demand for labor by expanding the size of domestic markets and helping remote populations gain access to global markets. 
To be sure, policies targeting infrastructure development and spatial connectivity are not specific to any sector. CASC governments may consider introducing well-crafted measures targeting the development of specific sectors, although international experience shows mixed results in using such policies in economic efficiency. Specifically, what CASC governments should systematically avoid is the introduction of subsidies for politically favored groups or individuals, which would distort market incentives.

Another set of policies relates to engaging employers in private-sector-led economic growth programs, which are typically implemented by multinational enterprises as they fulfill initiatives for corporate social responsibility. Such policies-including targeting production of basic goods as well as high value-added, nontraditional exports - can be given teeth through tax and other incentives for productive investments in particular nontraditional export industries and employment provisions in industrial policies. A foreign company, through its local affiliated company in the Kyrgyz Republic, is one example (Box 5.4).

\section{Regional Economic Cooperation}

As experience from initiatives around the world shows, regional economic cooperation can effectively stimulate demand for goods and services and for labor (ADB 2010). Structured by norms, rules, and shared strategies, regional cooperation and institutional arrangements affect national and regional development. The effectiveness of regional cooperation agreements relies on institutional power in individual countries to face external challenges such as changes in political leadership in member states and in government priorities (Capannelli and Kawai 2014).

Since independence from the Soviet Union, most CASC countries have focused on building their national economies and defining domestic agendas. Yet, successful implementation of initiatives for regional economic cooperation can provide tremendous stimulus to the demand side of the labor market. For example, the definition of common standards for food safety or the promotion of joint programs to promote regional tourism can generate substantial demand for labor in participating countries. Three CASC countries (Armenia, Kazakhstan, and the Kyrgyz Republic) are members of the Eurasian Economic Union (established in 2014) and have plans to strengthen their economic integration in trade, investment, and other areas. The European Union, the Association of Southeast Asian Nations, and other regional organizations and groupings may offer relevant examples that can inspire CASC countries to use regional cooperation to stimulate the demand side of the labor market.

An interesting program is the regional Central Asia Regional Economic Cooperation which, started in 2001, gathers seven of the eight CASC countries (Armenia is not a member), alongside Afghanistan, Mongolia, Pakistan, and the People's Republic of China. Initially focused on transport, energy, trade policy, and trade facilitation, in 2017, the regional grouping adopted its 2030 strategy, expanding its remit of activities to agriculture, water, health, education, tourism, human capital development, and financial cooperation (ADB 2017). 


\section{Box 5.4: Corporate Social Responsibility Development in the Kyrgyz Republic}

The multinational company, Centerra Gold, operates the Kumtor Gold Mine in the Kyrgyz Republic through its subsidiary Kumtor Gold Company which, as part of its initiatives promoting corporate social responsibility, has been adopting programs targeting long-term value creation. In 2013 , it launched the $\$ 900,000$ program, Karagat,$+{ }^{a}$ to reduce rural labor migration by promoting diversification of local production and expansion of market opportunities for berry and fruit growers. The program focuses on

- establishing nurseries for high-quality varieties of fruits and berries,

- promoting drip irrigation in areas suffering from water shortages,

- providing farmers with innovative technologies for greenhouse production,

- building cold storage facilities for fruits, and

- organizing training at local vocational schools for farmers on high-technology methods for cultivation of berries and vegetables.

The program supports establishment of farmer groups on cultivation processing, storage, packaging, and marketing. Participating farms produce seedlings, fresh and dried fruits and berries, juices, jams, and greenhouse vegetables. The program's accomplishments from 2013 through 2016 include the following:

- constructed greenhouses at four vocational schools and seven social institutions;

- trained more than 1,000 farmers in greenhouse cultivation of vegetables and herbs and trained more than 1,500 farmers in drip irrigation and fruit and berry cultivation techniques;

- installed 58 demonstration plots with drip irrigation for new varieties of berries and fruits;

- distributed 33,000 seedlings of high-yielding varieties of berries among farmers and reproduced 50,000 seedlings in six nurseries, with sale of seedlings to farmers;

- imported and planted more than 5,000 seedlings of altai black currant for testing; and

- established 20 collection points for fruits and berries, 8 with direct links to markets in Kazakhstan and the Russian Federation.

An important component of the Karagat+ is the annual Karagat Fest, including a fruits and berries fair, competitions, parades, and master-classes. Usually more than 1,000 representatives of companies take part alongside investors. It also promotes development of marketing channels. The Karagat Fest has been acknowledged several times as one of the best tourism projects in the country. The program has had a positive impact on the welfare of self-employed farmers and on local employment through services, and the creation of associated jobs such as

- nursery professionals and workers to serve the demand for seedlings;

- trainers and agro-technicians to provide extension services for farmers;

- engineers, construction workers, and suppliers to serve demand for nurseries and greenhouses; and

- professionals (phytosanitary specialists, consultants, lawyers, etc.) to support produce exports.

The Karagat Fest generates additional demand for local event organizers, tourism operators, hotels, and transportation and catering service providers. Thus, Karagat+ has significantly influenced local attitudes about production and marketing in the region.

a Karagat means black currant in the Kyrgyz language.

Source: Authors, based on Centerra Gold. 2013. 


\section{3 | Supply-Side Policies}

Supply-side policies, in broad terms, are those that increase human capital and reduce inequality among individuals and across salient groups. Such policies also include interventions aimed at increasing labor market flexicurity-introducing flexible arrangements on wages and transfers-and strengthening social protection, especially for groups considered high risk or exposed to vulnerability, such as the unemployed, people with structurally low incomes, and those with disabilities.

\section{Human Capital Development}

Section 4.4 focused on education and skills development and discussed major trends in CASC countries in human capital development. It introduced examples of policy options, from those targeting general improvements in the educational system, to specific actions aimed at strengthening technical and vocational education and training (TVET). Policies that improve educational quality and ensure inclusive access include (i) promoting skills development for job creation; (ii) increasing tertiary enrollment rates, especially in schools focused on science and engineering; (iii) eliminating gender bias in education; (iv) enhancing investment and active private sector participation in the education sector; and ( $v$ ) promoting financial literacy-a proven major bottleneck to development of SMEs and the private sector more generally.

In particular, policies for strengthening labor force skills include those expanding the number of teachers, their salaries, and qualifications; adopting contractual frameworks to enhance apprenticeship; facilitating entrepreneurship; incentivizing innovation; and introducing campaigns to attract students to TVET.

Matching education and skills development with labor demand is crucial to achieving inclusive growth and sustainable development. Policy makers need to ensure that workers have the knowledge, applied skills, and attitudes to find work, keep their employment, and create new ideas through which firms can prosper (Brennan 2014). Shifting the policy focus to "right skilling" the labor force is also needed in response to rising youth unemployment across the world. One approach to addressing youth unemployment uses flexible education and training systems with efficient skills recognition processes implemented and run through TVET systems (Maclean, Jagannathan, and Sarvi 2013). Box 5.5 discusses the Government of Uzbekistan's use of TVET programs to promote inclusive growth and sustainable development.

As policy makers from CASC countries formulate and implement human capital development measures, they should consider prioritizing three interrelated factors. First, integrate policies on education and skills with measures targeting the development of entrepreneurship and SMEs, as well as those that promote research and innovation. ${ }^{33}$ Second, introduce accurate selection criteria for public investments, including giving high priority to those increasing the number and qualifications of teachers and TVET instructors. ${ }^{34}$ Third, increase tertiary enrollment rates in science and engineering and ensuring that 21st century skills are integrated into all programs at schools and universities. In the above interventions, special attention should be paid to gender, youth, and spatial dimensions of inequities in human capital formation.

33 For example, by establishing multilevel governance and coordination mechanisms among different ministries, public bodies, and relevant stakeholders, at vertical and horizontal levels.

34 In parallel, policy makers should create effective mechanisms for introducing public-private partnership models to finance education and skills development. 


\section{Box 5.5: Technical and Vocational Education and Training in Uzbekistan}

Uzbekistan adopted the National Programme of Personnel Training in 1997 to provide the labor force the skills to succeed in a market economy. Under it, after completing secondary education, people aged 15-18 are required to choose between attending academic lyceums or professional colleges. Lyceums focus on academic subjects as they target young people aiming to enter higher education, while professional colleges target those who want to join the labor market with specific technical and professional skills, thus specializing in technical and vocational training. To be sure, graduates from professional colleges are not excluded from joining the higher education track as curricula usually cover many subjects taught in academic lyceums. ${ }^{2}$

Since the program's introduction, the government has invested heavily in building new professional colleges and academic lyceums. The table below shows the number of professional colleges increased 4.7 times and academic lyceums 3 times between the academic years 2000-2001 and 2012-2013.

\section{Uzbekistan's Progress in Secondary Education}

\begin{tabular}{|c|c|c|c|c|}
\hline Professional Colleges & 2000-2001 & 2005-2006 & 2010-2011 & 2012-2013 \\
\hline Number of professional colleges & 241 & 878 & 1,396 & 1,408 \\
\hline Number of students ('000) & 59.5 & 853.3 & $1,514.8$ & $1,573.9$ \\
\hline Number of teachers ('000) & 9.2 & 55.6 & 106.0 & 105.2 \\
\hline Teachers with higher education ('000) & 8.4 & 50.4 & 95.4 & 98.1 \\
\hline Student-teacher ratio & 6.5 & 15.3 & 14.3 & 15.0 \\
\hline Ratio of students to teachers with higher education & 7.1 & 16.9 & 15.9 & 16.1 \\
\hline \multicolumn{5}{|l|}{ Academic Lyceums } \\
\hline Number of academic lyceums & 46 & 77 & 143 & 143 \\
\hline Number of students ( $\left.x^{\prime} 000\right)$ & 9.8 & 37.3 & 108.3 & 112.0 \\
\hline Number of teachers ( $\left.x^{\prime} 000\right)$ & 1.8 & 4.4 & 9.3 & 9.3 \\
\hline Teachers with higher education ( $x^{\prime} 000$ ) & 1.8 & 4.4 & 9.1 & 9.2 \\
\hline Student-teacher ratio & 5.5 & 8.4 & 11.7 & 12.1 \\
\hline Ratio of students to teachers with higher education & 5.6 & 8.5 & 11.9 & 12.2 \\
\hline
\end{tabular}

a Government of Uzbekistan. 2013. Education Sector Plan of the Republic of Uzbekistan for 2013-2017 Interim PRSP Document. Tashkent.

The program also developed human capital, as professional college enrollment rates surged from $32 \%$ of secondary school graduates in 1990 to $97 \%$ in 2010 . For a country of about 32 million people-43\% under 25 -this is significant. In 2014, more than 500,000 people graduated from professional colleges.

Despite such impressive progress in developing the technical and vocational education and training (TVET) system, specifically in infrastructure development, further improvements in educational quality and governance are needed. According to a 2014 World Bank report based on a survey of 232 enterprises, only $57 \%$ of firms are satisfied with the skills staff acquired through TVET, versus $79 \%$ for university graduates. Anecdotal evidence also suggests that, given the inflexibility of centrally regulated curricula and lack of private sector participation, the TVET system remains unable to match the supply of skills with demand. Reforms are needed to increase system flexibility to respond to the increasing sophistication of the country's labor market demand.

Sources: European Training Foundation (ETF). 2015. Torino Process 2014 Uzbekistan. Turin: ETF. https://www.etf.europa. eu/sites/default/files/m/E784EF78775A591BC1257F3A0057BCC8_TRP\%202014\%20Uzbekistan_EN.pdf; Government of Uzbekistan. 2013. Education Sector Plan of the Republic of Uzbekistan for 2013-2017 Interim PRSP Document. Tashkent; World Bank. 2014. Uzbekistan Modernizing Tertiary Education. World Bank Report No. 88606-UZ. Washington, DC: World Bank. 


\section{Flexible Contractual Arrangements}

Supply-side labor market challenges in CASC countries argue strongly for moving toward flexicurity, or a system that combines flexible contractual arrangements with income and social security for individuals. Flexicurity contemplates a strong role for active labor market policies (ALMPs) that support (re)training and job-matching, and helping form an efficient and flexible labor market at the aggregate level.

Underpinning this approach is a fundamental shift from protecting jobs to protecting workers and of the burden of financing job security from employers to the public purse. Flexicurity systems require focused intervention with particular attention to (i) introducing ALMPs, (ii) reforming the sources and mechanisms for funding social benefits, and (iii) creating strong systems for labor market information and analysis. Notably, labor force age composition has major implications for ALMP design aimed at improving employability through retraining and related policies on skills development. As most CASC countries have reached "demographic maturity," it becomes increasingly important to introduce policies targeting lifelong learning and retraining of adults without jobs (or in dead-end jobs) but often with considerable work experience.

Introducing active labor market policies. Employment systems in CASC countries are characterized by underutilization of internal labor resources, problems of low employability or lack of employable skills, and a premium on labor mobility. CASC economies also feature widespread informal employment systems; considerable underemployment; and, in cases such as Armenia, the Kyrgyz Republic, and Tajikistan, extensive labor migration abroad.

Given the fundamental poverty-employment nexus, examining the role of labor market institutions and labor market and social policies for development is critical in identifying good jobs for inclusive growth. ALMPs include programs that enhance labor supply through training, increase labor demand through public works or subsidies, and improve labor market functioning through employment services. Generally, training and retraining programs account for a significant share of expenditures for ALMPs, ranging from $40 \%$ to $60 \%$ in most countries (Betcherman, Dar, and Olivas 2004). Training and retraining for the unemployed aims to provide job seekers with marketable skills that can increase their chances of getting a well-paid job. Box 5.6 presents the recent experience with ALMPs in Armenia.

Since ALMPs need to be highly sensitive to local situations, detailed recommendations for the CASC region as a whole cannot be included in this report. However, a few considerations may be put forward. First, large regional differences and generally weak economic development outside the capitals and main cities in CASC countries imply the need for combining ALMPs with regional and local economic development strategies and programs, including support to SME as a complement to entrepreneurship, management training, and other forms of ALMPs. Second, given the high labor mobility in the CASC region, focused ALMPs can be crafted to facilitate reintegration of migrant workers in their home countries. The reintegration of returning migrants into domestic labor markets poses particular challenges in terms of skills mismatch and lack of employability. However, it can also create development opportunities as repatriating workers bring capital and enhanced skills which, if appropriately channeled, can expand local investment and entrepreneurship. As migrant workers often come from rural areas, affected CASC countries may benefit from targeted approaches focused on less developed regions and secondary towns. 


\section{Box 5.6: Active Labor Market Policies in Armenia}

The Government of Armenia started a transition from passive to active labor market policies (ALMPs) in 2014, before which total expenditures for ALMPs remained very small. ${ }^{a}$ Most expenditures on labor market policies were directed toward an unemployment benefit program, which was discontinued at the end of December 2013, as it was found that it created disincentives for job search and acceptance of job offers by the unemployed. However, only part of the funds saved by the elimination of unemployment benefits has been used for ALMPs. The share of ALMP spending on total state budget remains low (table).

\section{Active Labor Market Policy Spending in Armenia (2010-2015)}

\begin{tabular}{|c|c|c|c|c|c|c|}
\hline & 2010 & 2011 & 2012 & 2013 & 2014 & 2015 \\
\hline $\begin{array}{l}\text { Share of ALMP expenditures in State Employment } \\
\text { Program spending (\%) }\end{array}$ & 13.0 & 6.4 & 32.0 & 36.0 & 52.0 & 94.0 \\
\hline Share of ALMP expenditures in total state budget (\%) & 0.07 & 0.03 & 0.12 & 0.10 & 0.07 & 0.10 \\
\hline \multicolumn{7}{|l|}{ Coverage indicators } \\
\hline Number of beneficiaries of all programs & 36,076 & 28,396 & 15,131 & 15,234 & 10,509 & .. \\
\hline Matching rate (jobs found/job seeker, \%) & 12.1 & 13.2 & 15.9 & 19.4 & 15.8 & $\ldots$ \\
\hline
\end{tabular}

$\ldots$ = data not available, ALMP = active labor market policy.

Source: Annual Budget reports, State Employment Agency (based on reported actual spending).

As of 2015, 12 major employment programs had been implemented by the State Employment Agency, the main body responsible for ALMPs in Armenia. Generally, the types of disadvantaged job seekers that training programs target are mainly those with high risk of losing their jobs or low probability of finding a job, such as persons with disabilities, individuals entering the labor market for the first time, women with children under 3 years, political refugees, the long-term unemployed, and people with socially disadvantaged family background as determined by the law and regulations.

Programs introduced in 2016 include (i) professional training for people unemployed and employed at risk of losing jobs, where participants receive scholarships throughout training; (ii) assistance to disadvantaged labor market participants by co-paying a share of wages in the case of employment or by providing the cost of indemnification for disabled people; (iii) internship and/or on-the-job training for first-time labor market entrants for unemployed people; and (iv) offer of seasonal agricultural work.

In 2016, Armenia also introduced a program assessment framework to estimate efficiency of recently adopted ALMPs. Further progress is needed, however, by introducing appropriate financial and nonfinancial indicators that would facilitate calculation of the effective cost per participant of individual policy measures and eventually evaluating the efficiency of policy interventions.

a Information on active labor market policy spending and general spending on employment programs is derived from annual reports on implementation of state budget, available at www.minfin.am.

Sources: Ministry of Labour and Social Affairs, Republic of Armenia; State Employment Agency of Armenia; World Bank. 
Several studies indicate that migrant workers usually face problems when they return home, especially in economic reintegration (Battistella 2004). Migrants become unemployed upon return often because jobs are unavailable. Unskilled workers generally face more difficulty finding jobs and experience higher occupational change than skilled workers. Often, finding a job for returnees involves a change of occupation, especially for those previously employed in agriculture. Skills acquired abroad are not necessarily helpful for reintegration. Migrant workers with degrees or diplomas often find jobs that do not allow them to develop skills in their professions. Moreover, even though many migrants want to establish businesses upon their return, in practice only a few are able to do so, as most returnees lack the necessary managerial skills, have insufficient finances, or cannot find attractive investment opportunities in the region of return (Abella 1986). Box 5.7 discusses policies the Government of Tajikistan has initiated to deal with its influx of returning migrants since 2014.

Reforming the sources and mechanisms for funding social benefits. To structurally transfer the burden of job security financing from the public to the private purse, policy makers need to address weaknesses in CASC countries' funding sources and mechanisms for provision of employment-related social benefits. In this respect, ALMPs are needed to review (i) the criteria and level of provision of social benefits; (ii) the rules and mechanisms used for drawing on social insurance funds; and (iii) the relative distribution of funding from contributory sources such as social insurance funds, and noncontributory sources such as the government budget and other public funds.

Creating strong systems for labor market information and analysis. Promoting good jobs for inclusive growth requires the capacity of policy makers to bring together strategies, plans, and interventions for enhancing human capital, employment, and economic development. As the design and implementation of such strategies and plans must be done in close coordination with different institutions and actors, it is important to create strong systems for labor market information and analysis. The capacity to integrate economic systems' variables with those of demographic and human resources is, indeed, a fundamental prerequisite to analyze the structure and employment conditions of the labor market. In many CASC countries, the need for upgrading the capacity to undertake labor market analysis and occupational projections is particularly urgent, also to improve TVET planning.

The lack of data and statistics is part of the problem, but probably not the major challenge related to the creation of strong systems for labor market information. Most CASC countries have well-functioning, and often also well-funded statistical bureaus, together with other institutional structures that produce quality data and statistics on employment and related issues at regular intervals. Rather, the principal challenge and task lies with strengthening the institutional capacity for producing high-quality analysis and dissemination of findings within and outside government agencies. In this regard, CASC countries would greatly benefit from creating observatories on economic and employment conditions with the capacity to provide analytical substance and knowledge for policy design and implementation to address economic growth, employment, and human resource development in an integrated manner. 


\section{Box 5.7: Reintegration Policies for Labor Migrants in Tajikistan}

Based on data released by the Ministry of Labor, Migration and Employment of the Population of Tajikistan in 2013, almost 800,000 migrant workers left the country to find jobs abroad. In the following years, however, this number steadily declined, reaching less than 500,000 in 2016, as a result of the external shocks that hit Central Asian countries (figure and Chapter 2).

Tajikistan's Labor Migration Trend, 2010-2016

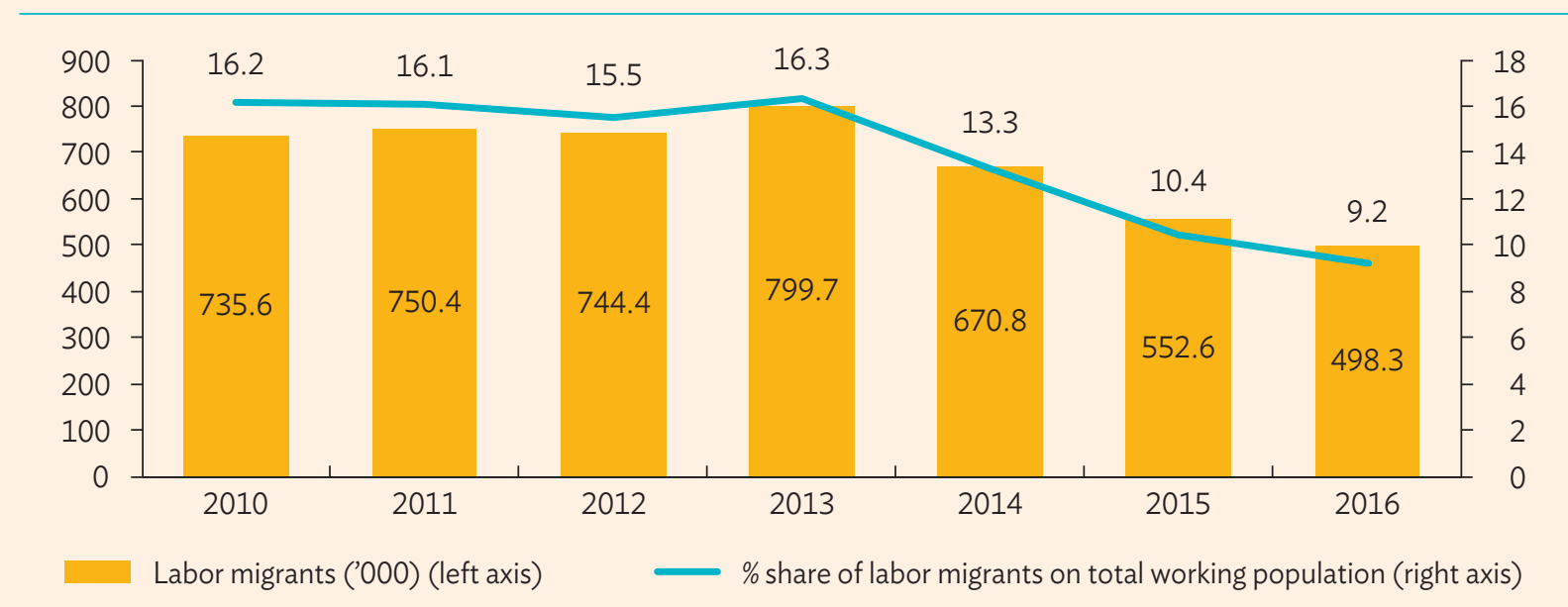

Source: Ministry of Labor, Migration and Employment of the Population of Tajikistan.

The main destination countries of Tajik workers, such as the Russian Federation and Kazakhstan, experienced economic instability, and the Russian Federation rigidly implemented labor legislation to prevent an excessive influx of foreign workers, especially the less skilled ones. In 2016 alone, official statistics suggest that 284,000 migrant workers returned, and faced several major problems:

- lack of information systems to facilitate job matching in the public and private sectors;

- limited capacity of productive employment in rural areas, where most labor migrants originated and were intending to return;

- lack of centralized data on returned migrants and counselling services for returnees;

- limited access to unemployment benefits, as working outside the country for more than 18 months disqualified returnees from applying for such benefits;

- no standardized practice for the formalization and certification of skills obtained as a result of nonformal education by migrants during their work abroad; and

- limited access to lifelong learning opportunities for adults.

In response to the challenges faced by returning migrants, in November 2015, the Government of Tajikistan introduced the State Program on Employment Promotion for 2016-2017 as part of anti-crisis measures aimed at promoting employment for more than 300,000 returning migrants, ensuring social guarantees, and regulating the labor market. Such a timely initiative included measures to promote job creation, strengthen labor market intermediation, develop professional labor services, provide psychological and social support to returning migrants, promote women's and youth employment, provide state social guarantees for those unemployed, and foster entrepreneurship. Specific interventions facilitated start-ups through tax rebates, fast-tracked registration of new enterprises, and subsidized interest rates. Other effective actions focused on providing short-term vocational training courses (including retraining and skill upgrading) for professions in demand domestically and abroad. 


\section{Social Protection Schemes}

As discussed in section 3.3, the extensive systems and generous schemes for social protection in CASC countries have served well to keep a check on inequality. However, assessment of measures and interventions adopted by different countries in the region typically raises questions about criteria adopted for targeting recipients of social protection schemes and their long-term sustainability with related budgetary implications.

The analysis in section 3.3 suggested that in CASC countries, on average, the poor receive less social protection benefits than the nonpoor. To be sure, the region's share of average social security benefits for the poor is about $1.6 \%$, or less than half that for the nonpoor (3.7\%). Such a result can be traced to the dominance of social insurance schemes, which are often tied to employment and whose beneficiaries are not considered to be poor. Moreover, the overall social benefits received by women are smaller than those received by men, because women are usually more poorly represented in the private sector's formal employment, are employed in lower-paid occupations, and are likely to receive fewer social insurance benefits than men.

Addressing the formal bias in social protection remains high on the agenda of CASC countries. Key issues include raising the minimum salary, improving pensions systems, and ensuring long-term sustainability of overall social protection schemes.

Data show that the combined contributions of employers and employees to social insurance funds add significantly to the cost of formal jobs: the ratios to gross wages range from approximately 15\% in Kazakhstan to 25\% in Azerbaijan, the Kyrgyz Republic, and Tajikistan, and to over 30\% in Uzbekistan. In Armenia, social contribution levies are regressive, creating strong disincentives to the formalization of jobs and the creation of formal jobs for unskilled labor. In Georgia, in the absence of a social insurance fund, employers are directly responsible for paying benefits such as paid maternity and sick leave, which arguably creates disincentives to hire young women and people with a medical history.

The impacts of social protection will have to be managed carefully by policy makers who wish to achieve inclusive growth while promoting the creation of good jobs. They can be considered part of a broader set of considerations under the supply-side rubric, which aims to ease labor mobility across sectors. The relatively large size and low productivity of agriculture labor in CASC countries have been highlighted in Chapters 2, 3 , and 4 . There are demand-side factors explaining the large share of employment in the agriculture sector that need to be addressed through policies such as those aimed at tapping into the world markets for nontraditional exports and promoting greater global integration. But supply-side reasons also exist, ranging from cultural attachment to rural areas, to the cultural inability to adapt to formal employment, or lack of connectivity between remote rural areas and urban manufacturing centers. Thus, promoting the development of infrastructure for strengthening national and regional connectivity appears once again as a key policy area, this time on the supply side of the equation. 


\section{4 | Institutions and Governance}

The institutions which govern the labor market are only part of an ecosystem of agencies, structures, and practices otherwise known under the collective title of "governance." Country-specific discussions cannot avoid considering the governance system under which policy recommendations are being formulated. To be sure, the proposed recommendations on the demand side, the supply side, or labor market institutions are all conditional on a well-functioning governance system.

Widely used data sources, such as the Worldwide Governance Indicators, suggest that CASC countries still face significant need for governance and institutional reform, even in comparison with other countries at similar levels of GDP per capita. Experts have highlighted governance and weak institutions as a major problem across the region, with significant implications for long-term economic and political sustainability.

Policies promoting good governance, fighting corruption, and shaping sound institutions that are welldesigned and effective in achieving their mandates have been frequently highlighted as increasingly important drivers of economic progress and development in CASC countries. At the same time, however, analytical and empirical work have repeatedly stressed the importance of identifying solutions from within each country system. When governance reforms saw their conceptualization originating from outside the target country's institutional system through the adoption of external programs, their outcomes, including their political impact, have been, at best, only partially successful (Grävingholt 2011).

\section{Labor Market Intermediation}

Labor market institutions play a fundamental role in matching the demand and supply of labor at different levels of skills requirement, in ensuring the labor force is fully employed, fostering the inclusivity of labor market regulations and practices, eliminating market segmentation and discrimination, and fostering labor force mobility. In CASC countries, market institutions are often unable to play their intermediary role between demand and supply of labor as efficiently as they should. Legal enforcement tends to be weak, and funding structures are often poorly linked with the schemes they are supposed to finance.

While detailed policy recommendations can only be crafted at the country level, in general, governments in CASC countries should address the above issues by improving the capacity of labor market institutions to perform their intermediation function between demand and supply. They should focus on promoting the labor force employability for good jobs, while actively promoting an inclusive system able to actively promote occupational and geographical mobility. To ensure long-term sustainability of domestic labor market systems, institutions should also adopt structurally sound funding sources and mechanisms.

\section{Governance and Corruption}

Corruption is certainly one of the most intractable governance challenges across the CASC region. Most CASC countries were in the lower quartile of the 2015 Transparency International's Corruption Perceptions Index, which included a total of 167 countries, with Turkmenistan (154), Uzbekistan (153), Tajikistan (136), the 
Kyrgyz Republic (124), and Kazakhstan (123) all experiencing severe challenges in overcoming corruption. Georgia (48) is the region's leader, followed by Armenia (95) and, further behind, Azerbaijan (119). There is growing consensus about the impact of corruption on inclusive growth, reflected in the inclusion of control of corruption in ADB's inclusive growth indicators. Everyday corruption often hits the poorest and most marginalized groups hardest. High-level corruption often involves either direct embezzlement of budgetary resources, thereby reducing funds available for education, health, and infrastructure, or tax avoidance, leading to the same reduction in government income (ADB 2015).

Increasing the basic salary of public servants is a standard policy approach which often delivers excellent results, provided there is enough fiscal space in the government budget to afford the related expenses. In CASC countries, given the historical legacy of the former Soviet Union system and the extensive role played by the public administration as a major absorber of the labor force, introducing structural reforms aimed at substantially increasing the basic salary of public servants may be challenging. Thus, the objective of policy reforms should not only focus on increasing basic salaries of public servants but also on a drastic streamlining of the public administration as a whole.

Another related area for reform, which often proves effective in combating corruption, is the adoption of integrated public service delivery systems. For example, various models of "customer service points," or "one-stop shops," can provide ways for the population to access public services conveniently and avoid the multiple and opaque transactions that often give rise to corruption. With one-stop shops, reformers aspire to reinforce the connection between public officials and communities, leading to a stronger, more accountable, and inclusive democracy.

One aim of one-stop-shop models is to make services feel seamless for users by providing a single-entry point for government services through modern applications of information and communication technology. Such models also aim for a customer-focused and responsive style of service delivery and easy accessibility (Askim et al. 2011). Another feature is their scope for achieving greater efficiency in public administration. By making public services accessible within one setting, the use of public service delivery systems reduces transaction costs and duplication from the perspective of citizens, providers, and governments, ultimately improving governance. Box 5.8 discusses Azerbaijan's success in increasing the transparency of public administration and the efficiency in the delivery of public services by introducing an innovative approach to public service delivery, which fights corruption through transparent processes and online payments for services (Jafarov 2013).

\section{Reducing Informality}

Promoting good jobs for inclusive growth presumes the introduction of focused policies to eliminate, or at least drastically reduce, the presence of informal employment. As discussed in previous chapters, one of the distinctive features of the CASC region is the presence of large informal economies, resulting in a disproportionate share of the labor force classified as self-employed and concentrated in agriculture, or working in informal and unregulated occupations were jobs are typically associated with lower salaries, security, social protection, and productivity, when compared with formal employment. 


\section{Box 5.8: Azerbaijan's System to Improve Government Effectiveness}

The Azerbaijan Service and Assessment Network (ASAN), established in 2012, gathers under one single agency about 30 services originally provided by 10 different state entities, including (i) birth/death registration; (ii) issuance and renewal of certificates on civil status acts; (iii) registration of divorce, and adoption and paternity determination; (iv) notary services; (v) renewal of identity cards/driving licenses; and (vi) issuance of reference notes on information about land cadastre.

ASAN's objective is to make government services more accessible using modern technology. In 2016, it successfully concluded more than 5 million transactions, of which more than 10\% were made using the system's mobile centers. Moreover, in January 2017, ASAN began to issue e-visas, valid for 30 days' stay, to nationals of 81 countries visiting Azerbaijan. Overall, the system has been offering an excellent example of one-stop shop. In 2015, it was awarded the United Nations Prize in the field of public service delivery.

ASAN can be considered a pocket of efficiency within Azerbaijan's state bureaucracy and has been instrumental for promoting reforms to raise public sector efficiency and transparency, contributing to improving the country's governance system. It has significantly increased public confidence in state bodies and triggered a radical change in public perception of state administration. While it has been unable to improve Azerbaijan's low score on the World Bank's governance indicators on the perception of corruption, regulatory quality, and rule of law, between 2011 and 2016, it has been quite instrumental in contributing to a marked improvement in the public perception of government effectiveness.

Sources: State Agency for Public Service and Social Innovations of the Republic of Azerbaijan; and authors.

In formulating policies that aim to reduce labor market informality, CASC governments should consider the underlying factors which, given the scarcity of formal jobs, cause informality to rise, such as the reduction in the tax burden, transaction costs, and entry barriers resulting in lower prices of goods and services. At the same time, however, they should realize the high costs of labor market informality associated not only with the inherent fiscal inequality, and lack of social security and protection of workers' rights, but also with problems related to employing and retaining skilled workers and providing quality certification of produced goods and services.

Policy makers should, therefore, support the gradual formalization of the labor market by introducing appropriate measures to strengthen the use of employment contracts and wage employment, while extending the effective coverage of labor market regulations, including on self-employment. To this extent, CASC governments should consider adoption of well-structured policies for flexicurity that combine labor market flexibility with a solid social security system. 


\section{5 | Policy Choices and Priorities}

The basic approach to policy formulation for creating good jobs for inclusive growth is to simultaneously create supply of skilled labor where there is excess demand, and demand for basic labor where there is excess supply, and to build labor market institutions able to mediate between the supply and demand sides of the labor market. At a very general level,

- demand-side strategies would strengthen private sector development and diversification into nontraditional sectors of production for which demand exists internally and externally;

- supply-side strategies would identify and build up skills in high demand, and promote security within a frame of labor market flexibility; and

- strategies for institutions' strengthening would improve labor market intermediation and more generally improve governance and reduce corruption.

Such broad framework can assist in a systematic and logical assessment of policy options. But how should CASC governments select and prioritize labor market policies? It goes without saying that selection and prioritization will depend on country-specific circumstances, and political economy considerations will also be important. But what is the underlying economic logic helping policy makers in their decisions?

Tautologically, the highest priority should be given to those policies that provide the highest payoff, i.e., measures to increase labor supply in case of excess demand, and actions which increase demand in the case of excess supply. Appropriate data and information are needed to assess the basic setting in each country and prioritize measures that would increase the supply or demand of labor. To this extent, it is important to use indicators that help identify which skills are in greatest demand, such as the rate of average wage increase, or the time from graduation to first job and seniority level of first job, or where there exists most labor which could work at higher levels of productivity, if only there was demand.

A systematic application of such a "binding constraints" approach to the supply and demand sides of good jobs for inclusive growth at the country level will illuminate not only priorities but also information needed to identify priorities (Hausmann, Rodrik, and Velasco 2006). In such context, it should be clear that institutional reforms that help match supply and demand and improve policy implementation by addressing governance and corruption will always emerge as a high priority in any CASC country. 


\section{CHAPTER}

\section{A ROLE FOR \\ DEVELOPMENT INSTITUTIONS}

by Alessandro Pio

$T^{h}$

his chapter discusses the role international financial institutions (IFIs) and other major development institutions can play in supporting the creation of good jobs for inclusive growth in countries in Central Asia and the South Caucasus (CASC). After describing the typical planning and programming process used by IFIs in supporting member countries achieve their national development strategies, the analysis shifts to a review of how a strong knowledge basis and international best practice can inform operational decisions and policy dialogue.

The choice and design of projects and interventions, and the financing modality used, are detailed using concrete examples of Asian Development Bank (ADB) operations to assess how IFls can help strengthen capacity in CASC governments to generate good jobs for inclusive growth.

All eight CASC countries joined the World Bank and International Monetary Fund in 1992-1993, shortly after independence, the European Bank for Reconstruction and Development in 1992, and ADB between 1994 and 2007. ${ }^{35}$ During 2010-2014, they received a combined annual average of close to $\$ 2.9$ billion from multilateral sources, or $0.8 \%$ of combined gross national income and less than $2 \%$ of total gross capital formation (Figure 6.1, OECD 2016a)..$^{36}$

The figure shows that the amounts of external development financing are relatively modest compared to the overall size of the CASC economies. How can such small amounts of funding help support ambitious inclusive growth and job creation strategies? The answer lies not so much in the total amounts as in the IFls' ability to contribute to the design of growth and employment policies, support their implementation, provide complementary investment, as well as leverage and catalyze additional external and domestic resources. IFls have engaged extensively in each of these areas through studies, projects, and policy advice. As such, their relationship to CASC governments does not need to be invented. It must simply be reenergized and sharply focused on inclusive growth and job creation, starting with a solid knowledge foundation, selectively planning the sector focus of country programs and strategies, carefully designing and implementing individual projects, increasingly leveraging private sector resources, and promoting regional integration and cooperation to expand market size.

35 Kazakhstan and the Kyrgyz Republic joined ADB in 1994, Uzbekistan in 1995, Tajikistan in 1998, Azerbaijan in 1999, Turkmenistan in 2000 , Armenia in 2005, and Georgia in 2007.

36 Multilateral flows include those from European Union institutions. The weight of multilateral official development assistance inflows ranged from $0.2 \%$ of gross national income for Turkmenistan to $3.7 \%$ for the Kyrgyz Republic. By comparison, average annual net private sector inflows to the eight countries amounted to $\$ 1.5$ billion, mostly to Kazakhstan and Turkmenistan. 


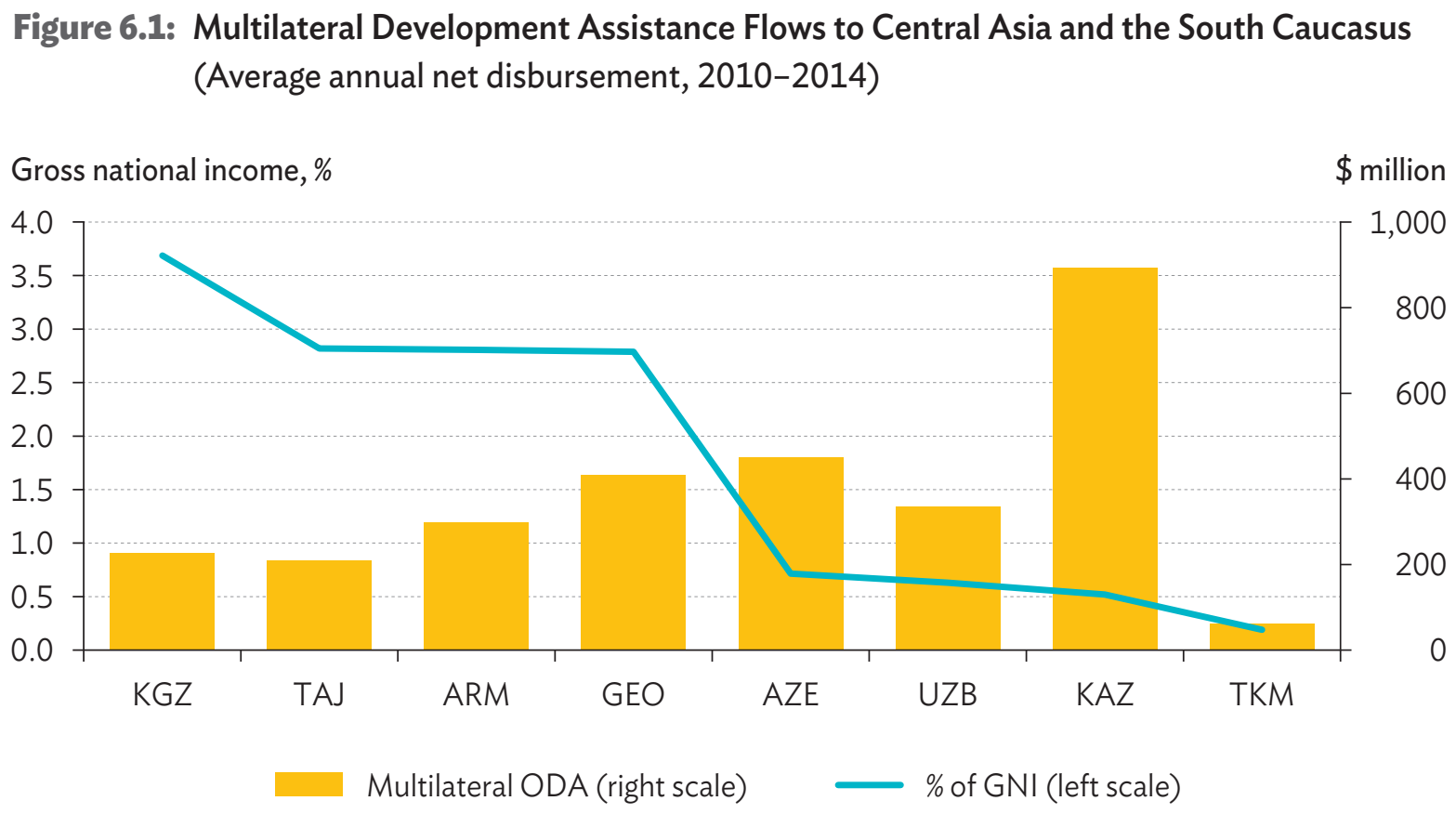

\begin{tabular}{lcc} 
& Multilateral ODA (\$ million) & $\%$ of GNI \\
South Caucasus & $1,157.5$ & $1.31 \%$ \\
\hline Central Asia & $1,726.8$ & $0.64 \%$ \\
\hline CASC Region & $2,884.2$ & $0.80 \%$ \\
\hline
\end{tabular}

$\mathrm{ARM}=$ Armenia, $\mathrm{AZE}=$ Azerbaijan, $\mathrm{CASC}=$ Central Asia and the South Caucasus, $\mathrm{GEO}=$ Georgia, $\mathrm{GNI}=$ gross national income, KAZ = Kazakhstan, KGZ = Kyrgyz Republic, ODA = official development assistance, TAJ = Tajikistan, TKM = Turkmenistan, UZB = Uzbekistan.

Source: Organisation for Economic Co-operation and Development. 2016. Geographical Distribution of Financial Flows to Developing Countries. Paris.

\section{1 | Applying the Study Framework to International Development Assistance}

Earlier chapters emphasized that for livelihoods, workers in CASC countries rely heavily on wage or salary income-either formal or informal-as well as on transfers. ${ }^{37}$ It is, thus, not surprising that the key policy agendas that IFls should support to improve inclusive growth and create good jobs in the region include (i) increasing labor productivity; (ii) ensuring workers reap the benefits of that productivity; and (iii) filling gaps in income distribution mechanisms by reaching those who are temporarily, or permanently, unable to work, through targeted and sustainable transfer programs.

37 For the many workers employed in the agriculture sector (from $24 \%$ of the labor force in Kazakhstan to 53\% in Tajikistan), a good share of this income may be in kind, as a result of subsistence production, which is deeply intertwined with landownership or specific land-use arrangements. 
Economic theory offers solutions to how such a process can be structured, implemented, and monitored. Growth models based on standard production functions suggest that one production factor (i.e., labor) faces diminishing returns if other factors (i.e., capital and land) are fixed. ${ }^{38}$ Thus, a first way to boost labor productivity is to increase the quantity of other productive factors through investment-in plants and machinery, as well as in infrastructure. While decisions on what kind of productive investment is likely to generate the highest economic returns are best left to the private sector, IFI resources can be mobilized to help create the conditions for funding such investment by facilitating, for example, entrepreneurs' access to financial markets. IFIs can also substantially assist governments in designing and financing public infrastructure: investment in transport or power systems can enhance agricultural productivity and manufacturing inputs by lowering logistics costs and making use of machinery and power tools possible. Investment in information and communication infrastructure can also increase service sector productivity and allow development of nonconventional marketing channels.

A second way to improve labor productivity is by fostering technical progress. About $40 \%$ of the CASC region's GDP growth rate is accounted for by technical progress, suggesting that countries should be choosing investment options which improve the quality of other productive factors by raising their technological level (Fuenfzig 2016). ${ }^{39}$ However, this does not always mean using sophisticated techniques, especially in sectors that suffer from low productivity-such as agriculture. What matters the most is matching the appropriate level of technology to the country's development level and factor endowment. For example, shifting from extensive cereal production to intensive vegetable cultivation in cold climates often simply requires modest irrigation, construction of greenhouses, and training of farmers in the requirements of the new crops-yet the gains in value of productivity can be substantial. Promoting technological progress can also be applied to institutions. For example, introducing more efficient ways of providing public services, increasing competitiveness of bids for public works through e-procurement, or electronic transferring of public funds to recipients can increase transparency and the efficiency of delivery. IFls can contribute knowledge of international best practices to ensure the introduction of appropriate technologies in the projects they finance.

A third way to increase labor productivity is to augment workers' human capital through investment in education and health. New growth theory emphasizes that an increase in human capital reduces the speed at which diminishing returns set in (Lucas, Jr. 1988). ${ }^{40}$ Since human capital is typically embedded in the workers, just like technical progress is embedded in the capital goods used to apply new technologies, increasing education and health investment is a key strategy to improve labor productivity.

38 This is the case with a Cobb-Douglas production function $Y=A L^{1-\alpha} K^{\alpha}$, where $Y$ is output, $A$ is total factor productivity or a residual representing explaining technical progress, $L$ is labor, $K$ is capital, and $(1-\alpha)$ and $\alpha$ are, respectively, the share of labor and capital in real output (Solow 1956).

39 The unweighted average contribution of total factor productivity to the growth rate was estimated at $43 \%$, ranging from $25 \%$ in the Kyrgyz Republic to $57 \%$ in Tajikistan.

40 Followed by other scholars who developed endogenous growth theory. While some theoretical models argued and demonstrated on paper that constant returns could be achieved, empirical estimates of these revised production functions show that with the introduction of human capital, returns are increased, but continue to be diminishing. 
The above three approaches will improve workers' income only under the assumption that production factors will be effectively remunerated based on productivity, the key tenet of freely functioning factor markets. Under such an assumption, higher workers' productivity will translate into higher returns on the labor and human capital assets they possess. Thus, it is important for policy makers to ensure the presence of competitive labor markets and remove rent-seeking opportunities or obstacles to labor mobility that would prevent workers from receiving the benefits of their enhanced productivity.

IFls can also assist CASC governments in the analysis and application of international best practices. They can help conduct focused studies; engage in capacity-building programs for government staff and other local stakeholders; and promote policy dialogue to introduce projects, programs, and agendas forming a partnership for development that fits country-specific circumstances.

\section{2 | Responding to the Region's Distinctive Features}

This report has identified five unique aspects of CASC countries that affect their ability to promote good jobs for inclusive growth. IFls' support should take such features into full consideration and adopt a mix of demand-side and supply-side interventions, combined with institutional innovation:

(i) Agriculture sector. Increase productivity and boosting rural incomes through diversification into high value-added crops and livestock, agro-processing, mechanization, and digitalization.

(ii) Informality and self-employment. Remove fiscal and other barriers that encourage informal employment, improve productivity of small and medium-sized enterprises through investment in education, skills development, infrastructure development, and increase access to finance.

(iii) Spatial inequalities. Invest in the improvement of the delivery of basic services (health, education, water supply, sanitation, power distribution) and equalize non-income disparities while creating good jobs, support agro-processing development, and improve connectivity to international markets.

(iv) International labor migration. Make more employment opportunities available domestically and better prepare migrants to look after their personal and financial security while abroad.

(v) Small domestic market. Overcome transport barriers to international trade through improved regional infrastructure and border crossing arrangements, improve incomes in rural and secondary urban areas to increase domestic demand, insource external demand through the expansion of tourism and other services, and utilize the potential of economic agreements to expand international trade.

IFIs are well equipped to assist CASC countries, not only through financing, but also through knowledge, by supporting the rigorous analysis needed to design appropriate policies. IFIs can also play a unique role in developing a demand side for labor. Domestically, they can focus on interventions to improve income distribution, increase demand, and shift it toward domestically produced goods. ${ }^{41}$ Internationally, IFls can

41 Since lower-income groups tend to consume a higher share of their income compared to other groups, and their consumption tends to be focused on food, clothing, shelter, and transportation, an increase in lower-income groups' share of total national income results in increased demand for domestic products, given the relatively low sophistication of the goods and services they consume. 
strengthen regional connectivity and promote closer integration with the global economy. Better physical and institutional connectivity can expand domestic markets and generate economies of scale. Economic integration can put producers in touch with external demand and further expand their market potential.

\section{3 | Sharpening Tools}

Most IFIs-including ADB-apply a systematic approach to the assistance they provide to their member countries. The analysis of a country's development needs and constraints leads to the preparation of a strategy, usually covering a period of 3-5 years and aligned with national plans. The strategy and subsequent programming exercises identify priority support sectors and specific projects. Interventions are typically designed, financed, and monitored to ensure successful implementation with due attention to social and environmental safeguards.

\section{Analytical and Knowledge Base}

The creation of good jobs for inclusive growth requires a combination of investment, capacity-building programs, and policy reforms. National governments have three good reasons to source from IFIs for ensuring that public policy design is inclusive and based on applicable best practices. First, experience suggests that policies have a higher chance of success if they are designed with the involvement of all relevant stakeholders. IFls can act as a convening platform for such consultations with the private sector and civil society to establish processes that produce robust and practical recommendations. Second, by operating in a variety of countries, IFls are well placed to bring international expertise to address specific issues. Third, the international character and technical inclination of IFIs make them a useful custodian of rigorous analytical approaches. Their support can be tapped to test and evaluate the soundness of current or planned government policies.

CASC countries have implemented a variety of programs to foster job creation. In 2015, Uzbekistan reduced the employers' Unified Social Payments that fund the pension system from 25\% of payroll to 15\% for micro and small enterprises, and farms. ${ }^{42}$ In 2011, Kazakhstan adopted an Employment Roadmap 2020 and, in 2013, started funding a related program based on (i) direct employment generation through infrastructure and communal services; (ii) support for entrepreneurship at the village level through credit, technical advice, and physical infrastructure and equipment; and (iii) training and relocation support for workers, to encourage labor mobility. The lessons from such programs should be carefully analyzed to improve future interventions. IFls can provide an impartial platform and technical support to ensure that the impact of past interventions is taken into proper account and proposed policies are rigorously analyzed based on international best practices.

42 A United Nations Development Programme-supported study provides analytical backing for this decision (Yuldashev, Rahimov, and Muhitdinov 2015). 


\section{Country Strategy Preparation and Sector Selection}

Figure 6.2 shows ADB's total operations to CASC countries during 1994-2015, including loans, grants, and technical assistance projects. Infrastructure sectors, such as transport and energy, cover more than $50 \%$ of the total portfolio in monetary terms, with finance, industry, trade, and public sector management reaching about one-fourth of the total, and the remainder accounted for by sectors such as urban development, water supply and sanitation, agriculture and rural development, health, and education. ${ }^{43}$

\section{Figure 6.2: Composition of ADB's Portfolio in Central Asia and the South Caucasus}

(Cumulative loans, grants, technical assistance, \$ million and number of projects, 1994-2015)

\$ million

TOTAL: \$18.24 billion

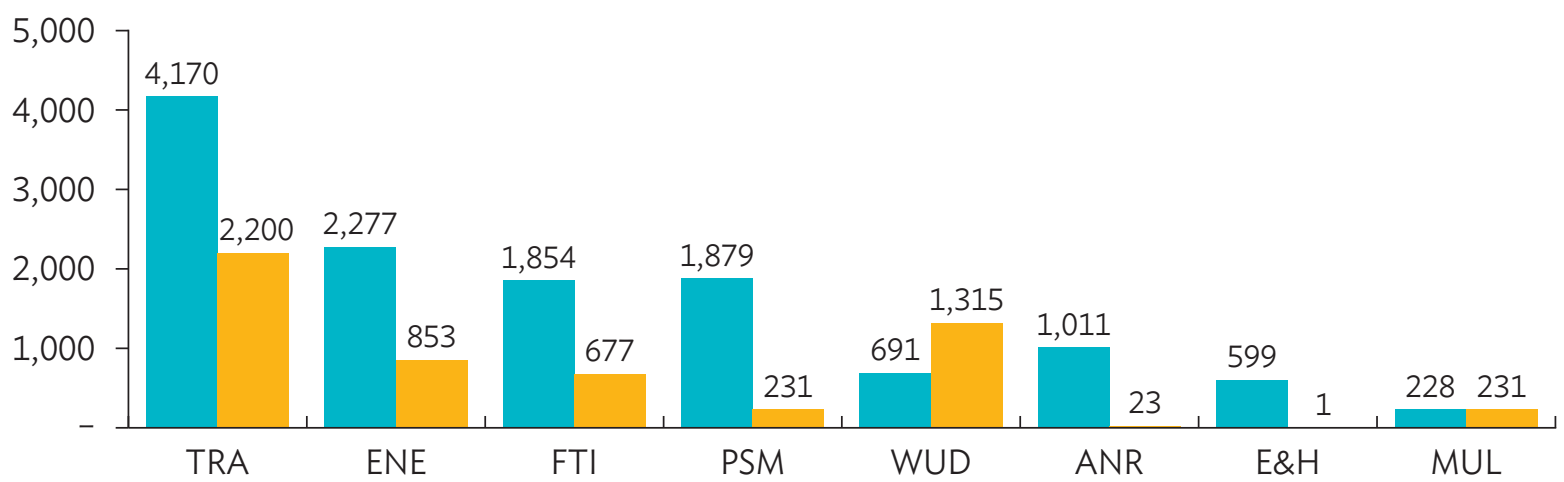

Number of Projects

TOTAL: 714 Projects

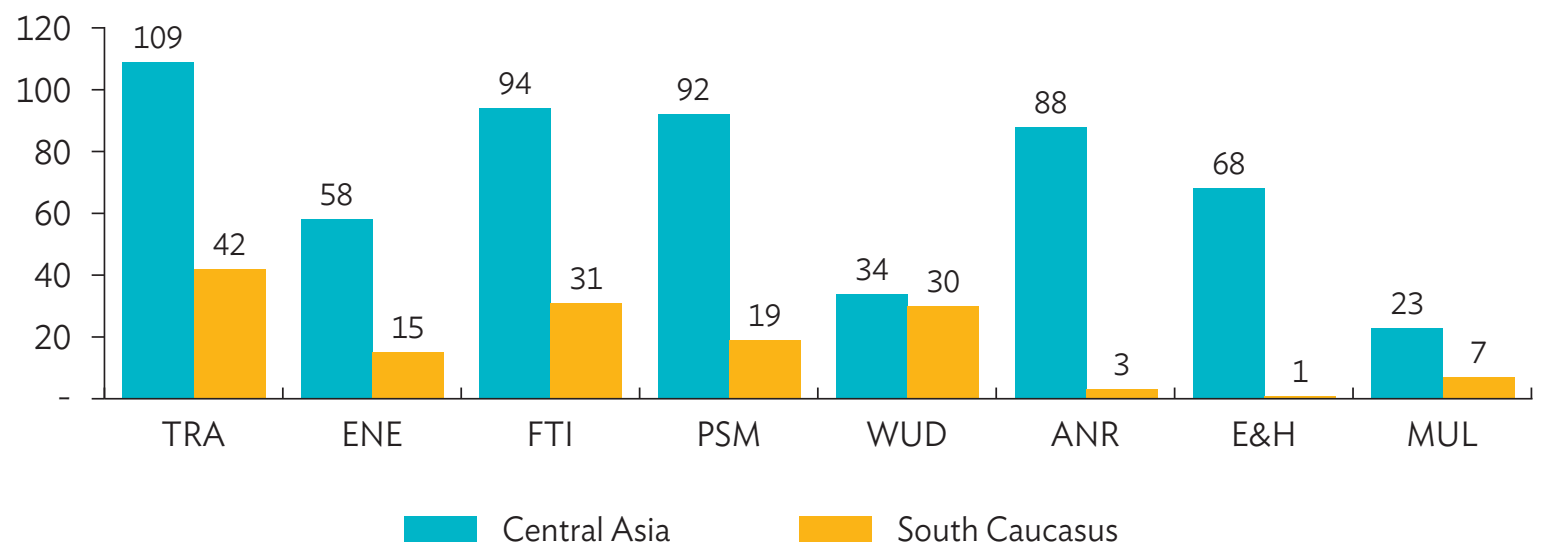

ANR = agriculture and natural resources; ENE = energy; E\&H = education and health; FTI = finance, trade, and industry; MUL = multisector; PSM = public sector management; TRA = transport; WUD = water and urban development.

Source: Asian Development Bank data elaborated by authors.

43 As an extreme case, $99 \%$ of the Turkmenistan portfolio during $2000-2015$ was focused on the transport sector. 
As discussed in previous chapters, the promotion of good jobs requires a special emphasis on investing in the development of human capital-particularly education, skills development, and health. Private sector development, which is focused on expanding the activities of small and medium-sized enterprises, should be accompanied by supporting infrastructure ensuring connectivity and access to job opportunities. Given the relatively high share of the workforce and population engaged in low-productivity agriculture, more emphasis by CASC governments and ADB on this sector through intensification, diversification, and modernization of agricultural production seems warranted.

In addition to strategy content, CASC governments and IFIs should pay close attention to processes. Significant consultation and dialogue with governments and other local stakeholders takes place during country strategy preparation. Through genuine involvement, the analytical framework can help identify operations linked to national priorities and programs. While the focus of country programming is on the investment component, proper attention needs to be paid to the preparation of knowledge plans and activities, policy development, and other forms of capacity-building support that IFIs can provide.

When implementing macroeconomic policies, governments can benefit from IFIs' long-term perspectives, to ensure that in addition to a short-term cyclical response, interventions are geared to inducing longlasting changes that will make economies more productive and more likely to generate employment. A typical response to stimulate growth and employment at times of recession is to finance public works through budgetary expansion. ADB and other IFIs have often assisted CASC governments in developing asset inventory and management plans for roads, bridges, power lines, water supply, and other public infrastructure, as well as "least-cost" expansion plans for infrastructure.

\section{4 | Choice and Design in Projects and Interventions}

IFIs can largely contribute to CASC countries' investment planning and implementation by bringing project identification and design based on problem-tree analysis, including the assessment of key issues and constraints, and the use of a results framework that identifies specific and measurable outcomes. Such a systematic approach brings discipline to project design and allows a clear risk identification. For example, most reforms in the education system are likely to be an uphill effort if their success relies solely on the motivation of teachers in countries where the average salaries in the education sector are a fraction of wages in the rest of the economy. ${ }^{44}$ The success of reform in education depends, therefore, on wider decisions on the relative remuneration and productivity of teachers and other civil servants that go beyond sector-specific boundaries. Such systemic considerations are among the benefits that IFls can bring to help governments meet external conditions for implementing successful projects.

44 Background country papers prepared for this report suggest that in 2015 , salaries in the education sector were only about $64 \%$ of the average salary in Georgia and 70\%-90\% of average salary in Azerbaijan (Babych, Mzhavanadze, and Beenstock 2016; Jafarov 2016). 
Project design and implementation affect inclusiveness and job creation. In the transport sector, for example, should regional corridors, national highways, or rural roads be prioritized? Which type of intervention has the most pronounced impact on the economy? And what are the spillovers on the rest of the transport sector and the country's economic activity and employment? It goes without saying that the answer depends on the specific conditions present in each country and the time of the analysis. Such questions must be thoroughly considered as they largely affect IFIs' portfolio allocation with different developmental impact at the country level on job creation and inclusive growth.

Another important consideration concerns the technology applied in projects. With due consideration for costing, can project design include labor-intensive and cost-effective construction technologies at the same time? Will small run-of-the-river hydroelectric projects lend themselves better to maintenance by trained local technicians? As a rule of thumb, indirect employment effects are likely to be more significant but, at the same time, more difficult to estimate than effects directly related to project realization, which are largely confined to the labor and expertise required during the construction phase, and tend to decline sharply following completion.

The design of procurement packages can also affect local incomes. Larger packages for more complex work are likely to attract the interest of international contractors, whereas smaller investment packages will probably be better suited to the local construction industry. For example, with an ADB's total country program of $\$ 2.3$ billion in Azerbaijan during 1999-2015, local suppliers and consultants were able to successfully compete for contracts worth $\$ 937$ million (ADB 2016a).

Finally, project design is important not only to fill financing gaps, but to also build capacity, or pilot test innovative solutions with a potentially high employment and inclusiveness impact. When projects address issues such as informal employment and other practices steeped in the local culture, involving domestic counterparts in project design is of the utmost importance to ensure understanding of the local context. For example, conditional cash transfers seem to achieve dramatic results in motivating participation in higher education for disadvantaged rural youth in Georgia at a modest cost. Empirical research shows that a monthly stipend of $\$ 100$ increases the chances of university enrollment by $6.3 \%$. In another case, the promise of a scholarship tied to specific behaviors (good academic performance, not smoking, and not getting married) raised college enrollment rates in a rural village to $100 \%$ in 3 years.

The choice of instruments can further leverage the impact of external financing. Results-based lending, a type of investment which supports government programs linking disbursements to the achievement of results and institutional improvements, can strengthen local design and implementing capacity (Box 6.1). 


\section{Box 6.1: Using Results-Based Lending to Strengthen National Systems}

The Asian Development Bank (ADB) introduced Results-Based Lending (RBL) in 2013, a year after the World Bank launched an analogous instrument called Program for Results. These lending methods are based on the same principle: following an assessment of country fiduciary and safeguard systems, international financial institutions (IFIs) are able to finance a time, or geographical, share of a well-defined national program. Instead of supervising procurement and disbursing against contracts for the acquisition of inputs, IFls focus on the result chain of such projects and the institutional strengthening that may be required for the recipient country to successfully implement the program through existing institutions and mechanisms. Disbursements are scheduled against the achievement of program outputs or outcomes which are agreed at the time of program design as indicators linked to disbursement.

During a 3-year pilot stage, $A D B$ successfully applied the RBL modality to operations for education and skills development in India, the People's Republic of China, the Philippines, and Sri Lanka; urban health in India; power grid strengthening in Indonesia; and transport infrastructure in Solomon Islands.

The World Bank reviewed the instrument in 2015 and ADB in 2016. Feedback from national authorities was positive, mainly because of the strong ownership, reduction in transaction costs, strengthening of national institutions, and financial leverage. IFIs found the RBL modality was about as staff-intensive as regular projects, but shifted the emphasis of design and implementation supervision from procedural controls to policy, technology, and institutional issues that need addressing to achieve program results, and nearly halved time from approval to first disbursement.

Source: Authors, based on ADB. 2016b. Midterm Review of Results-based Lending for Programs. Manila.

In designing fiscal and monetary policy measures, the significant size of informal or self-employment must be taken into account. Transfers can be redesigned to better target the needed assistance, remove the incentive to engage in informal economic activity, and encourage labor force participation. Monetary policy must also evaluate the extent to which interest rates in the formal banking system are able to affect investment and economic activity, since the frequent presence of a significant parallel (informal and/or dollarized) financial system will largely weaken transmission channels between financial and real markets. In such a case, support for microfinance or dedicated credit lines may be necessary and has, in fact, been used fairly extensively in CASC countries since the early 2000s.

\section{5 | Regional Cooperation and Integration}

Countries with small domestic markets and significant natural barriers to long distance transportation have strong incentives to integrate their economies, particularly when their industrial structures complement each other. Economic integration can help improve efficiency and achieve economies of scale. International labor migration among CASC countries and the Russian Federation is an example of how integration, facilitated by a common language and, in the case of Armenia, Kazakhstan, and the Kyrgyz Republic, also by the formation of the Eurasian Economic Union, is already happening since 2014. 
As IFls are multilateral, they are well-suited to promote regional approaches. Integration of transport, power transmission, or telecommunication networks, and the corresponding soft components that make the integration successful by allowing smooth flow of people, goods, and power across borders, requires an honest broker sufficiently trusted and independent to help forge mutually beneficial agreements.

$A D B$ has provided secretariat services to the Central Asia Regional Economic Cooperation (CAREC) program since its inception in 2001. By the end of 2017, a total of $\$ 31.6$ billion had been invested through 185 CAREC-related projects by a variety of multilateral, bilateral, and domestic sources. CAREC focus so far has been on strengthening the interconnection (hard and soft) of transport, energy, and trade (Figure 6.3).

\section{Figure 6.3: Evolution of ADB's Regional Cooperation Projects in CAREC Countries}

(Volume of approved CAREC-related projects by sector: cumulative since 2001)

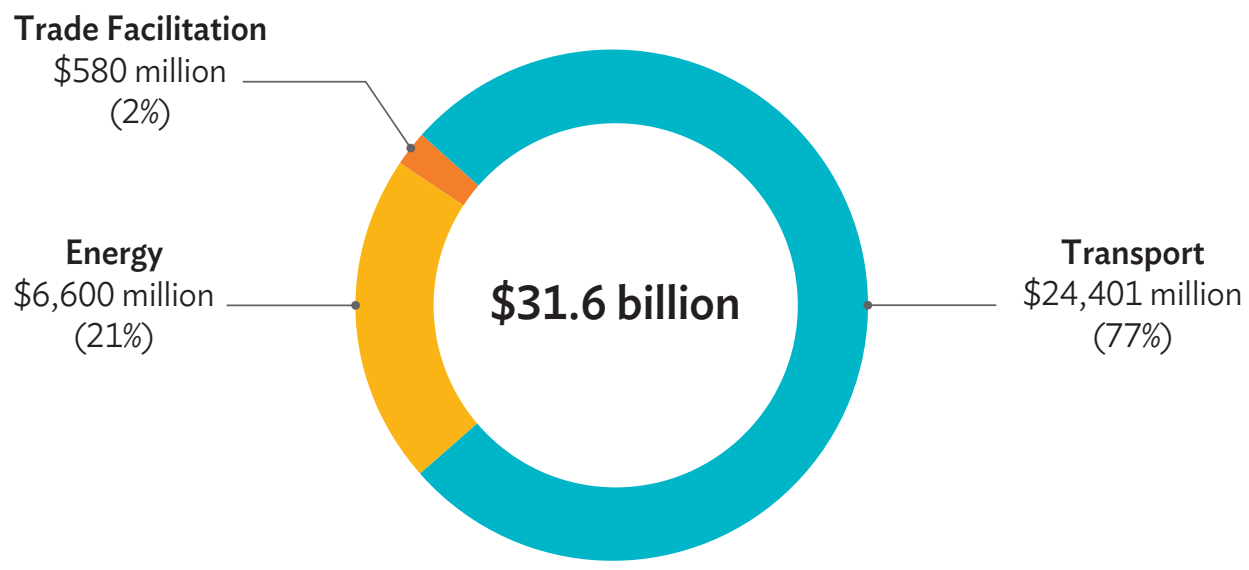

CAREC $=$ Central Asia Regional Economic Cooperation .

Source: Central Asia Regional Economic Cooperation Program. http://www.carecprogram.org/?page_id=13630.

The local economic and employment impact of CAREC transport corridors (Figure 6.4) will only be elevated if the concept expands beyond providing transit services to trade among the People's Republic of China, Europe, the Russian Federation, South Asian countries, Iran, and Turkey. Such corridors can provide locational advantages to domestic and foreign companies that intend to produce for a larger regional market, and engage in transport-related services. ${ }^{45}$ Looking beyond national boundaries, the core of the Central Asian regionencompassing the cities of Almaty, Bishkek, Dushanbe, Tashkent, and the Sry Darya and Fergana valleysappears to be a promising intercountry area where economies of agglomeration can take place, if reinforced by well-connected infrastructure networks.

45 An example is provided by high-skill aircraft maintenance services connected to the development of Air Astana as a regional carrier in Almaty. 


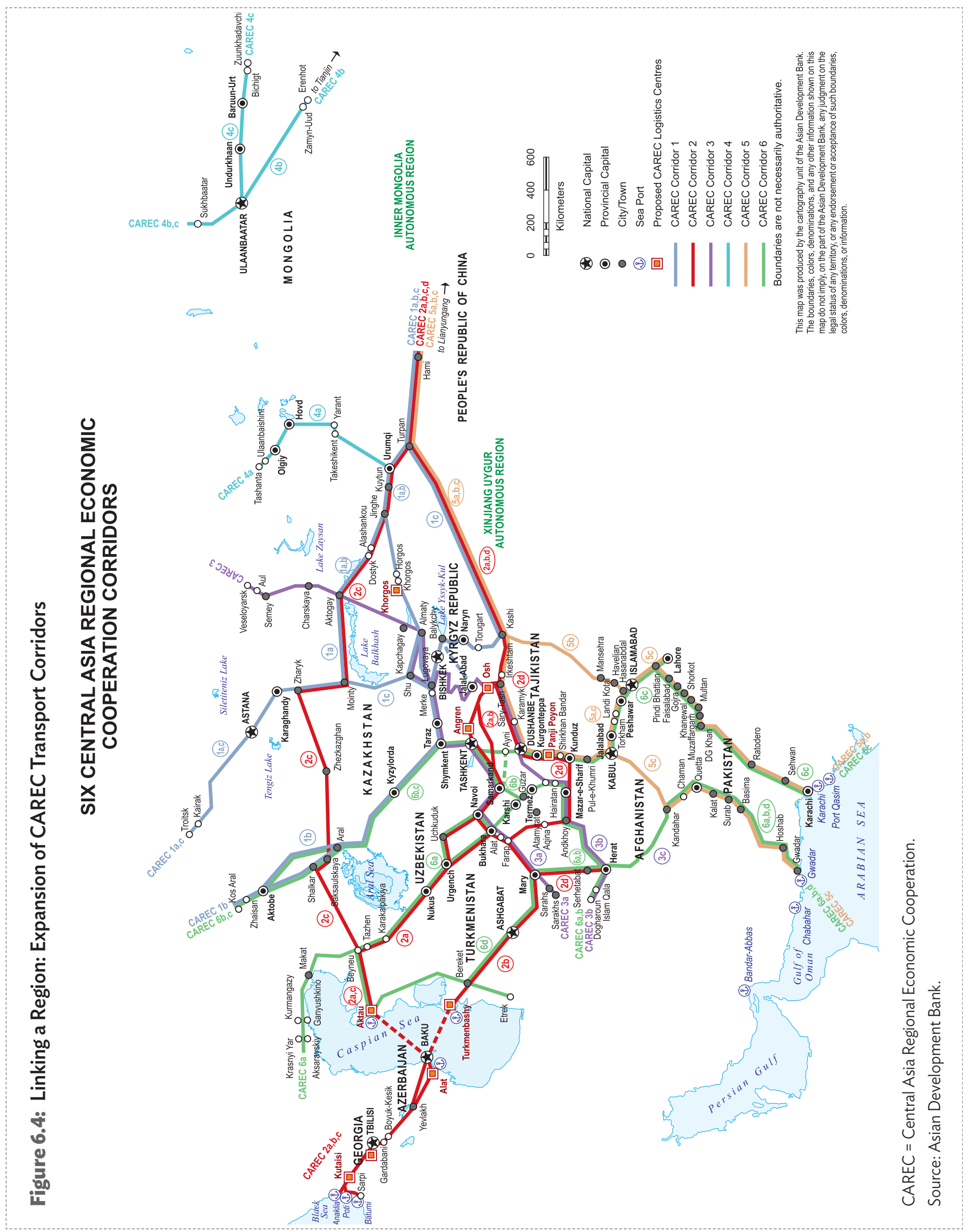




\section{6 | Conclusions}

Developing the potential for creating good jobs in the CASC region requires concerted national and regional effort. Policy adjustments, correction of incentives, and investment in physical and human capital are preconditions, but attention must be firmly placed on the domestic and foreign sources of additional demand. Higher productivity and incomes in agriculture, diversification of economic structure, greater international openness, and connectivity are of the utmost importance to create new markets. CASC governments have successfully overcome the formidable initial challenges of transition in the 1990s. The aftermath of the 2007-2008 global financial crisis, the external shocks of 2014, and long-term trends in the evolution of the global economy pose a new set of challenges.

It is time to forge a new set of responses that focus on maintaining social cohesion, expanding domestic demand, opening new markets, and promoting self-supporting improvements in CASC countries' living conditions by focusing on creating good jobs for inclusive growth. IFls can bring international best practice, analytical tools, financing, systematic and meticulous project design and implementation, and convening power to the table to help support economic transformation, eventually putting CASC countries on the path of rapid, sustainable, and shared economic prosperity. 


\section{REFERENCES}

Abdih, Y. and L. Medina. 2013. Measuring the Informal Economy in the Caucasus and Central Asia. IMF Working Paper. No. 13/137.

Abella, M. I. 1986. Epilogue: Impacts and Adjustments. In M. I. Abella and A. Yogesh, eds. Middle East Interlude: Asian Workers Abroad. A Comparative Study of Four Countries. Bangkok: United Nations Social and Cultural Organization.

Ali, I. and J. Zhuang. 2007. Inclusive Growth toward a Prosperous Asia: Policy Implications. ERD Working Paper Series. No. 97. Manila: ADB.

Anderson, K., G. Capannelli, E. Ginting, and K. Taniguchi, eds. 2018. Kazakhstan Accelerating Economic Diversification. Manila: ADB.

Arellano, M. and O. Bover. 1995. Another Look at the Instrumental Variable Estimation of ErrorComponents Models. Journal of Econometrics. 68 (1). pp. 29-51.

Asian Development Bank (ADB). 2006. Connecting Central Asia: A Road Map for Regional Cooperation. Manila.

_.2008a. Social Protection Index for Committed Poverty Reduction. Manila.

2008b. Strategy 2020: Working for an Asia and Pacific Free of Poverty. April. https://www.adb.org/ documents/strategy-2020-working-asia-and-pacific-free-poverty.

_2010. Institutions for Regional Integration: Toward an Asian Economic Community. Manila.

_. 2012a. Confronting Raising Inequality in Asia. Special Chapter. Asian Development Outlook. Manila.

_. 2012b. Infrastructure for Supporting Inclusive Growth and Poverty Reduction in Asia. Manila.

_2013. Strengthening Private Sector Participation in Technical and Vocational Education and Training (TVET) - Initial Poverty and Social Analysis. https://www.adb.org/sites/default/files/projectdocument/80010/46535-001-ipsa.pdf.

_2014a. ADB's Support for Inclusive Growth. Thematic Evaluation Study. Manila.

_. 2014b. "Framework of Inclusive Growth Indicators." Key Indicators for Asia and the Pacific Special Supplement. 4th ed. Manila.

_ 2015. "Special Chapter: A Smarter Future - Skills, Education, and Growth in Asia." Key Indicators for Asia and the Pacific 2015. Manila.

_2016a. Azerbaijan. Asian Development Bank Member Fact Sheet. Manila.

_. 2016b. Midterm Review of Results-based Lending for Programs. Manila.

-2016c. Project Brief: Tajikistan Strengthening Technical and Vocational Education and Training. https://www.adb.org/publications/taj-strengthening-tvet-project-brief. 
2017. CAREC 2030. Connecting the Region for Shared and Sustained Development. Manila.

_. 2018a. Kazakhstan: Country Operations Business Plan (2019-2021). Manila.

_2018b. Strategy 2030: Achieving a Prosperous, Inclusive, Resilient, and Sustainable Asia and the Pacific. July. https://www.adb.org/documents/strategy-2030-prosperous-inclusive-resilient-sustainableasia-pacific.

Askim, J., A. L. Fimreite, A. Moseley, and L. H. Pedersen. 2011. One-Stop Shops for Social Welfare: The Adaptation of an Organizational Form in Three Countries. Public Administration. 89 (4). pp. 1451-1468.

Battistella, G. 2004. Return Migration in the Philippines: Issues and Policies. In D. S. Massey and J. E. Taylor, eds. International Migration: Prospects and Policies in a Global Market. New York: Oxford University Press.

Betcherman, G., A. Dar, and K. Olivas. 2004. Impacts of Active Labor Market Programs: New Evidence from Evaluations with Particular Attention to Developing and Transition Countries. Social Protection Discussion Paper Series. No. 0402. Washington, DC: World Bank.

Blundell, R., and S. Bond. 1998. Initial Conditions and Moment Restrictions in Dynamic Panel Data Models. Journal of Econometrics. 87 (1998). pp. 115-143.

Bond, S. R., A. Hoeffler, and J. Temple. 2001. GMM Estimation of Empirical Growth Models. Discussion Paper Series. No. 3048. London: Centre for Economic Policy Research.

Brennan, P. 2014. Raising the Quality and Image of TVET: Lower-Level Training or Motor for Inclusive and Sustainable Growth? Prospect. 44 (2). pp. 183-195.

Capannelli, G., and M. Kawai, eds. 2014. The Political Economy of Asian Regionalism. New York: Springer.

Centerra Gold. 2013. Corporate Responsibility Report 2011, 2012. http://www.kumtor.kg/en/centerra-crreports/.

Central Bank of the Russian Federation. 2015. Results of Survey of Individuals Making/Receiving Cross-Border Remittances (2014 Data).

2018. www.cbr.ru/eng/search/?text=remittances.

Centralized Bank of Legal Information of the Republic of Tajikistan (Adliya). 2015. State Program to Promote Employment of the Population of the Republic of Tajikistan for 2016-2017. http://www.adlia.tj/show_ doc. fwx?rgn=125831.

Duban, E. 2015. Armenia Country Gender Assessment. Manila: ADB.

European Training Foundation (ETF). 2015. Torino Process 2014 Uzbekistan. Turin: ETF. http://www.etf.europa.eu/webatt.nsf/0/E784EF78775A591BC1257F3A0057BCC8/\$file/ TRP\%202014\%20Uzbekistan_en.pdf.

Feige, E. L., and I. Urban. 2008. Measuring Underground (Unobserved, Non-Observed, Unrecorded) Economies in Transition Countries: Can We Trust GDP? William Davidson Institute Working Paper. No. 913. March. 
Foster-McGregor, N., and B. Verspagen. 2016. The Role of Structural Change in the Economic Development of Asian Economies. Asian Development Review. 33 (2). pp. 74-93.

Ganiev, B. 2017. Growth Performance and Prospects of the Countries of Central Asia and the South Caucasus. Background paper prepared for the report. https://www.adb.org/projects/49045-001/ main\#project-documents.

Giuliano, P., and M. Ruiz-Arranz. 2009. Remittances, Financial Development and Growth. Journal of Development Economics. 90 (1). pp. 144-152.

Gollin, D., D. Lagakos, and M. E. Waugh. 2014. Agricultural Productivity Differences across Countries. The American Economic Review. 104. pp. 165-170. Nashville: American Economic Association.

Government of Georgia, Ministry of Economy and Sustainable Development, Entrepreneurship Development Agency. 2017. Government Program "Produce in Georgia". Tbilisi. http://www.economy.ge/en/our-projects.

Government of Kazakhstan, Ministry of National Economy, Committee on Statistics. https://www.stat.gov. kz/faces/wcnav_externalid/homeNumbersAgriculture?_afrLoop=91651923974102\#\%40\%3F_ afrLoop\%3D916519.

Government of Tajikistan State Statistics Agency. Various years. Women and Men of the Republic of Tajikistan. https://www.stat.tj/en.

Government of Tajikistan, Ministry of Labor, Migration and Employment. http://www.mehnat.tj/ mehnat/ru/.

Government of Uzbekistan. 2013. Education Sector Plan of the Republic of Uzbekistan for 2013-2017 Interim PRSP Document. Tashkent.

Grävingholt, J. 2011. The Political Economy of Governance Reforms in Central Asia. United States: SSRN.

Grieco, E. M. and M. Boyd. 2003. Women and Migration: Incorporating Gender into International Migration Theory. Migration Policy Institute. 1 March. https://www.migrationpolicy.org/article/women-andmigration-incorporating-gender-international-migration-theory.

Hausmann, R., D. Rodrik, and A. Velasco. 2006. Getting the Diagnosis Right. F\&D (Finance and Development). 43 (1). March. International Monetary Fund.

International Labour Organization (ILO). 2008. Can Low-Income Countries Afford Basic Social Security? Social Security Policy Briefings Paper 3. Geneva: Social Security Department, ILO.

—. 2014. World of Work 2014: Developing with Jobs. Geneva: ILO.

_. 2015. World Employment and Social Outlook: The Changing Nature of Jobs. Geneva: ILO.

_. 2016. Tajikistan - State Programme on Employment Promotion for 2016-2017, YouthPol eQuestionnaire. http://www.ilo.org/dyn/youthpol/en/f?p=30850:3000:0::NO::P3000_ COUNTRY_CODE:TJ. 
International Monetary Fund. 2013. Jobs and Growth: Analytical and Political Considerations for the Fund. Washington: International Monetary Fund.

Jafarov, K. 2013. Azerbaijan's One-Stop Public Service Shop Is Driving Up Efficiency. The Guardian. The Guardian News and Media Limited. 31 July. 08.00 BST.

Kanbur, R. 2014. Globalization and Inequality. Vol. 2B, in Handbook of Income Distribution, edited by A. Atkinson and F. Bourguignon, pp. 1845-1881. Elsevier B.V.

Karpestam, R. P. D. 2012. Dynamic Multiplier Effects of Remittances in Developing Countries. Journal of Economic Studies. 39 (5). pp. 512-536. Emerald Group Publishing.

Kireyev, A. and J. Chen. 2017. Inclusive Growth Framework. IMF Working Paper WP/17/127. International Monetary Fund. https://www.imf.org/ /media/Files/Publications/WP/2017/wp17127.ashx.

Kupets, O. 2014. Informal Employment in Moldova: Characteristics and Policy Measures. Policy Note World Bank. Washington, DC: World Bank.

Lucas, R. E., Jr. 1988. On the Mechanics of Economic Development. Journal of Monetary Economics. 22 (1). pp. 3-42.

Mabieva, G. 2008. Zerno ostaetsya v strane (Grain stays in the country), Respublikanskiy delovoy ezhenedel'nik. 15 (237), 17.04. p. 1.

Maclean, R., S. Jagannathan, and J. Sarvi. 2013. Skills Development Issues, Challenges, and Strategies in Asia and the Pacific. In R. Maclean, J. Shanti, and J. Sarvi, eds. Skills Development for Inclusive and Sustainable Growth in Developing Asia-Pacific. Netherlands: Springer.

McMillan, M., D. Rodrik, and I. Verduzco-Gallo. 2014. Globalization, Structural Change and Productivity Growth, With an Update on Africa. World Development. 63. pp. 11-32. United States: Elsevier Ltd.

Montenegro, C. E. and H. A. Patrinos. 2014. Comparable Estimates of Returns to Schooling Around the World. Policy Research Working Paper; WPS 7020. Washington, DC: World Bank Group. http://documents.worldbank.org/curated/en/830831468147839247/comprable-estimates-of -returns-to-schooling-around-the-world.

National Agency for the Promotion of Small and Medium-Sized Entrepreneurs (SME DNC). 2011. Women's Entrepreneurship Promotion. Chapter in National Strategy of Small and Medium Entrepreneurship Development. Small and Medium Entrepreneurship Development National Center. http://smednc.am/en/publications/.

Organisation for Economic Co-operation and Development (OECD). 2010. Competitiveness and Private Sector Development: Kazakhstan Sector for Competitiveness Strategy 2010. Paris: OECD.

2011. Divided We Stand: Why Inequality Keeps Rising. Paris: OECD.

_. 2013. OECD Review of Agricultural Policies: Kazakhstan 2013. Paris: OECD.

_. 2016a. Entrepreneurship at a Glance. http://www.oecd.org/std/business-stats/entrepreneurshipat-a-glance-22266941.htm.

_. 2016b. Geographical Distribution of Financial Flows to Developing Countries. Paris: OECD. 
Pedraza, S. 1991. Women and Migration: The Social Consequences of Gender. Annual Review of Sociology. 17 (1). pp. 303-325.

Petrick, M., and D. Oshakbaev. 2018. Kazakhstan's Agricultural Development Constraints: Evidence from the Wheat, Beef and Dairy Sectors. In A. Schmitz and W. H. Meyers, eds. Transition to Agricultural Market Economies. The Future of Kazakhstan, Russia, and Ukraine. Wallingford, UK: CABI.

Republican Union of Employers of Armenia. 2015. The main business obstacles in Armenia. SME situational comprehensive survey at macro and micro levels. Yerevan. http://www.employers.am/News. aspx? Newsld=60\&lang=eng.

Sarkisyan, A. and M. Shahmenendyan. 2014. Armenia: Promoting Gender Equality and Women's Empowerment (baseline assessment). Caucasus Research Resource Center.

Schneider, F., A. Buehn, and C. Montenegro. 2011. Shadow Economies All Over the World: New Estimates for 162 Countries from 1999 to 2007. Handbook on the Shadow Economy. Econ Papers. Edward Elgar Publishing.

Solow, R. 1956. A Contribution to the Theory of Economic Growth. Quarterly Journal of Economics. 70 (1). pp. 65-94.

State Committee of Turkmenistan on Statistics. Various Years. Turkmenistan National Accounts.

Transparency International. https://www.transparency.org/news/feature/corruption_perceptions_ index_2015\#table.

United Nations Development Programme (UNDP). 2008. National Human Development Report (2007/08) Education in Uzbekistan: Matching Supply and Demand. Tashkent, Uzbekistan.

—. Various years. National Human Development Report.

United States Central Intelligence Agency (CIA). The World Factbook. https://www.cia.gov/library/ publications/the-world-factbook/docs/profileguide.html (accessed 2 January 2017).

World Bank. 2001. Social Protection Sector Strategy: From Safety Net to Springboard. Washington, DC: World Bank.

_2006. Equity and Development. World Development Report 2006. Washington, DC: World Bank.

-2008. Global Economic Prospects 2009: Commodities at the Crossroad. Washington, DC: World Bank.

_ 2009. What Is Inclusive Growth? https://siteresources.worldbank.org/INTDEBTDEPT/ Resources/468980-1218567884549/WhatIsInclusiveGrowth20081230.pdf.

_2012a. Resilience, Equity and Opportunity. The World Bank's Social Protection and Labor Strategy 2012-2022. Washington, DC: The World Bank.

_. 2012b. Skills, Not Just Diplomas: The Path for Education Reforms in Eastern Europe and Central Asia. Washington, DC: World Bank.

_. 2012c. World Development Report 2012: Jobs. Washington, DC: World Bank. 
_. 2013a. Georgia Urbanization Review: Toward an Urban Sector Strategy. Washington, DC: World Bank.

_. 2013b. World Development Report 2013: Jobs. Washington, DC: World Bank.

_ 2014a. Leveraging Armenia's Social Protection System for the Activation of Vulnerable Groups: Technical Assistance. Policy Note. Washington, DC: World Bank.

_. 2014b. Republic of Armenia Public Expenditure Review Expanding the Fiscal Envelope. Report No. 93154. Washington, DC: World Bank.

—. 2014c. Uzbekistan Modernizing Tertiary Education. World Bank Report No. 88606-UZ. Washington, DC: World Bank.

—2015. Promoting Labor Market Participation and Social Inclusion in Europe's and Central Asia's Poorest Countries. Washington, DC: World Bank.

—. 2016. World Development Indicators 2016. Washington, DC: World Bank.

_ 2017. World Development Indicators 2017. Washington, DC: World Bank.

- Health Nutrition and Population Statistics: Population Estimates and Projections. http://databank. worldbank.org/data/ (accessed 2 January 2017).

—. World Bank Development Indicators. https://datacatalog.worldbank.org/dataset/ world-development-indicators (accessed 9 January 2017).

World Economic Forum. 2017. The Inclusive Growth and Development Report 2017. January. Geneva. https://www.weforum.org/reports/the-inclusive-growth-and-development-report-2017.

Yoshino, N. and S. Kaji, eds. 2013. Hometown Investment Trust Funds. Tokyo: Springer.

Yoshino, N., F. Taghizadeh-Hesary, P. Charoensivakorn, and B. Niraula. 2016. Small and Medium-Sized Enterprise (SME) Credit Risk Analysis Using Bank Lending Data: An Analysis of Thai SMEs. Journal of Comparative Asian Development. 15 (3). pp. 383-406.

Yuldashev, O., F. Rahimov, and Z. Muhitdinov. 2015. The Impact of Unified Social Payments on Employment and Enterprise Financial Performance in Uzbekistan. Report for UNDP Local Governance Support Project/Phase 2. New York.

Zaiceva, A. and K. F. Zimmermann. 2016. Migration and the Demographic Shift. In J. Piggott and A. Woodland, eds. Handbook of the Economics of Population Aging 1A. pp. 119-177. Amsterdam, The Netherlands: Elsevier.

Zettelmeyer, J. 1998. The Uzbek Growth Puzzle. IMF Working Paper. Washington, DC: International Monetary Fund.

Zhuang, J., R. Kanbur, and C. Rhee. 2014. Rising Inequality in Asia and Policy Implications. ADBI Working Paper Series 463. Tokyo, Japan: Asian Development Bank Institute. http://www.adbi.org/workingpaper/2014/02/21/6172.rising.inequality.asia.policy.implications/. 


\title{
EMPIRICAL GROWTH MODEL
}

\section{APPENDIX}

\author{
by Bahodir Ganiev
}

rowth projections for countries in Central Asia and the South Caucasus (CASC) for 2016-2030 were estimated under different reform scenarios. Among the explanatory variables, the model includes indicators of macroeconomic stability, institutional reforms, human capital, and the external environment, based on the following equation:

$$
\begin{aligned}
\Delta y_{i, t} & =\alpha+\beta_{1} y_{i, t-1}+\beta_{2} \text { fixcap }_{i, t}+\beta_{3} \Delta \text { pop }_{i, t}+\beta_{4} h_{i, t-1}+\beta_{5} \text { saverh }_{i, t}+\beta_{6} \Delta \text { cpi }_{i, t} \\
& +\beta_{7}\left(\Delta \text { cpi }_{i, t}\right)^{2}+\beta_{8} \text { sopenness }_{i, t}+\beta_{9} \Delta \text { inst }_{i, t}+\beta_{10} \text { remit }_{i, t}+\beta_{11} \text { remit }_{i, t} * \text { inst }_{i, t} \\
& +\beta_{12} \Delta \text { tot }_{i, t}+\gamma_{i}+\delta_{t}+\in_{i, t}
\end{aligned}
$$

where $i=$ country; $t=5$-year period; $\Delta x_{t}=$ change in the value of variable $x$ between periods $t-1$ and $t$; $y_{i, t}=$ natural logarithm of gross domestic product (GDP) per capita, based on purchasing power parity at constant 2011 international dollars, in country $i$ in the last year of period $t$; fixcap $p_{i, t}=$ natural logarithm of the average share of fixed capital formation in GDP at current prices in country $i$ in period $t$; $p_{0} p_{i, t}=\operatorname{logarithm}_{\text {m }}$ of total population in country $i$ in the last year of period $t ; h_{i, t}=$ logarithm of the human capital index (based on years of schooling and returns to education) in country $i$ in the last year of period $t$; averh $_{i, t}=$ average value of logarithm of the human capital index in country $i$ in period $t$; $c p i_{i, t}=$ value of the consumer price

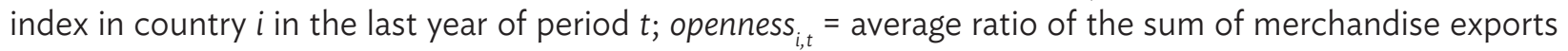
and imports to GDP in country $i$ the last year of period $t$; inst $t_{i, t}=$ rescaled average of the simple mean of the Worldwide Governance Indicators for control of corruption, government effectiveness, regulatory quality, and rule of law for country $i$ and period $t$; remit ${ }_{i, t}=$ average ratio of remittance inflows to GDP in country $i$ in period $t$; tot $t_{i, t}=$ natural logarithm of the average value of the index of the terms of trade of country $i$ in period $t ; \gamma_{i}=$ country-specific effect; $\delta_{t}=$ dummy variable for period $t$; and $\epsilon_{i, t}$ is an error term.

All the estimated coefficients of the equation, except the constant and the coefficient of the dummy variable for 2006-2010, are statistically significant at the 10\% level and their signs are consistent with the intuitions provided by economic theory (tables). 
Table A1: Growth Equation Estimation Results for Countries in Central Asia and the South Caucasus, 2016-2030

\begin{tabular}{|c|c|c|c|c|}
\hline & Coefficient & Corrected Std. Err. & z & $P>|z|$ \\
\hline Constant & $(.0944922)$ & .206824 & $(0.46)$ & 0.648 \\
\hline$y_{i, t-1}$ & $(.0732165)$ & $(.0202996)$ & $(3.61)$ & 0.000 \\
\hline fixcap $_{i, t}$ & .2291061 & .0388637 & 5.90 & 0.000 \\
\hline$\Delta p o p_{i, t}$ & $(.8893202)$ & .2778625 & $(3.20)$ & 0.001 \\
\hline$h_{i, t-1}$ & .1861853 & .1040301 & 1.79 & 0.073 \\
\hline$\Delta_{a v e r h}{ }_{i, t}$ & .9895094 & .4361645 & 2.27 & 0.023 \\
\hline$\Delta c p i_{i, t}$ & .1814443 & .0729642 & 2.49 & 0.013 \\
\hline$\left(\Delta c p i_{i, t}\right)^{2}$ & $(.1186811)$ & .037921 & -3.13 & 0.002 \\
\hline Dopenness ${ }_{i, t}$ & .1283099 & .052587 & 2.44 & 0.015 \\
\hline$\Delta$ inst $_{i, t}$ & .9379027 & .2407385 & 3.90 & 0.000 \\
\hline remit $_{i, t}$ & $(.0573265)$ & .0150773 & $(3.80)$ & 0.000 \\
\hline remit $_{i, t}{ }^{*}{ }^{i n s t} t_{i, t}$ & .0753645 & .027658 & 2.72 & 0.006 \\
\hline$\Delta$ tot $_{i, t}$ & .0813199 & .040255 & 2.02 & 0.043 \\
\hline dummy variable for 2001-2005 & .0327611 & .0108002 & 3.03 & 0.002 \\
\hline dummy variable for 2006-2010 & $(.0082387)$ & .0108917 & $(0.76)$ & 0.449 \\
\hline dummy variable for 2011-2015 & 0 & (omitted) & & \\
\hline Number of observations: & 383 & Number of instruments: & 142 & \\
\hline Number of countries: & 134 & Wald chi (18) & 231.51 & \\
\hline Number of observations per country: & & Prob > chi2 & 0.000 & \\
\hline Min 1, Max 3, Average: 2.86 & & & & \\
\hline
\end{tabular}

()$=$ negative.

The system generalized method of moments estimator was used in the estimation exercise, as it addresses the endogeneity problem inherent in empirical growth models and evidence suggests it produces good results in estimating such models (Arellano and Bover 1995; Bond, Hoeffler, and Temple 2001; Blundell and Bond 1998). The model included panel data on 134 countries for the seven 5-year periods during 1980-2015. Data for 5-year periods were used instead of annual data to eliminate bias-caused business cycle effects on economic growth. 


\section{Table A2: Key Assumptions Underlying Growth Scenarios}

\begin{tabular}{|c|c|c|}
\hline Indicator & Limited-Action Scenario & Full-Action Scenario \\
\hline Total population & \multicolumn{2}{|c|}{ Total population will grow at the rates projected by the United Nations in 2017.} \\
\hline Consumer price index & \multicolumn{2}{|c|}{$\begin{array}{l}\text { - The rate of inflation in 2016-2020 is equal to the estimates for these years made } \\
\text { by the International Monetary Fund (IMF) in October } 2017 \text {. } \\
\text { - The average annual rates of inflation in 2021-2025 and 2026-2030 will be } \\
\text { equal to the annual average of the IMF's forecasts for 2021-2022. }\end{array}$} \\
\hline $\begin{array}{l}\text { Gross fixed capital formation } \\
\text { as a percentage of gross } \\
\text { domestic product (GDP) }\end{array}$ & $\begin{array}{l}\text { The GDP share of gross fixed capital } \\
\text { formation has been calibrated } \\
\text { to ensure it is broadly consistent } \\
\text { with } 2016-2017 \text { trends and that } \\
2016-2020 \text { growth projections are } \\
\text { consistent with the IMF's projections } \\
\text { for those years. }\end{array}$ & $\begin{array}{l}\text { The share of gross fixed capital formation } \\
\text { in GDP will be 3-5 percentage points } \\
\text { higher than in limited-action scenario as } \\
\text { private sector investment will receive a } \\
\text { boost due to greater progress in building } \\
\text { human capital, implementing economic } \\
\text { and institutional reforms, and improving } \\
\text { transport and other infrastructure. }\end{array}$ \\
\hline Human capital index & $\begin{array}{l}\text { The value of the index will remain } \\
\text { unchanged during 2016-2030, with } \\
\text { improvements in access to education } \\
\text { being offset by the worsening quality } \\
\text { of education in most countries in } \\
\text { Central Asia and the South Caucasus } \\
\text { (CASC). }\end{array}$ & $\begin{array}{l}\text { The value of the index for Armenia, } \\
\text { Azerbaijan, the Kyrgyz Republic, } \\
\text { Tajikistan, and Turkmenistan will } \\
\text { gradually rise close to 3.59, which was } \\
\text { the value of the index for the Republic } \\
\text { of Korea in } 2014 \text {. } \\
\text { - The value of the index for Georgia and } \\
\text { Kazakhstan will gradually rise close to } \\
\text { 3.73, which was the value of the index } \\
\text { for the United Kingdom in } 2014 \text {. }\end{array}$ \\
\hline $\begin{array}{l}\text { Merchandise exports and } \\
\text { imports as a percentage } \\
\text { of GDP }\end{array}$ & $\begin{array}{l}\text { The period-average ratios of the sum } \\
\text { of merchandise exports and imports } \\
\text { to GDP in 2016-2020, 2021-2025, } \\
\text { and } 2026-2030 \text { will be equal to the } \\
2015 \text { ratio. }\end{array}$ & $\begin{array}{l}\text { Due to economic and institutional reforms } \\
\text { and improvements in connectivity in all } \\
\text { CASC countries, the ratio will gradually rise } \\
\text { to } 1.56 \text {, which is close to the } 2015 \text { ratio of } \\
\text { merchandise exports and imports to GDP } \\
\text { in Viet Nam. }\end{array}$ \\
\hline $\begin{array}{l}\text { The mean of the Worldwide } \\
\text { Governance Indicators for } \\
\text { (i) rule of law, (ii) control of } \\
\text { corruption, (iii) government } \\
\text { effectiveness, and } \\
\text { (iv) regulatory quality }\end{array}$ & $\begin{array}{l}\text { During 2016-2030, the value of the } \\
\text { indicator will change as much as it } \\
\text { changed during 2001-2015. }\end{array}$ & $\begin{array}{l}\text { Due to institutional and economic reforms, } \\
\text { the value of the indicator for Georgia will } \\
\text { reach } 0.84 \text {, which is close to the average } \\
\text { value of the indicator for the Benelux } \\
\text { countries in } 2014 \text {. For the other six CASC } \\
\text { countries (excluding Uzbekistan), the value } \\
\text { of the indicator will gradually rise to } 0.70 \text {, } \\
\text { which is close to the average value for the } \\
\text { Baltic countries in } 2014 \text {. }\end{array}$ \\
\hline $\begin{array}{l}\text { Ratio of remittance inflows } \\
\text { to GDP }\end{array}$ & \multicolumn{2}{|c|}{$\begin{array}{l}\text { The period-average ratios of remittance inflows to GDP in 2016-2020, 2021-2025, } \\
\text { and } 2026-2030 \text { will be equal to the ratio in } 2015 \text {. }\end{array}$} \\
\hline Terms of trade & \multicolumn{2}{|c|}{$\begin{array}{l}\text { The period-average values of the index of terms of trade in } 2016-2020,2021-2025 \text {, } \\
\text { and } 2026-2030 \text { will be equal to its value in } 2015 \text {. }\end{array}$} \\
\hline
\end{tabular}

Source: B. Ganiev. 2017. Growth Performance and Prospects of the Countries of Central Asia and the South Caucasus. Background paper prepared for the report. https://www.adb.org/projects/49045-001/main\#project-documents. 


\section{BACKGROUND PAPERS}

The report was informed by several country and thematic background papers, which can be downloaded from the following website: https://www.adb.org/projects/49045-001/main\#project-documents.

Background papers were finalized in 2017.

\section{Country Background Papers}

Inclusive Economic Development

\begin{tabular}{ll} 
Country & \multicolumn{1}{c}{ Author(s) } \\
Armenia & A. Grigoryan and V. Baghdasaryan \\
Azerbaijan & V. Gasimli and R. Rahmanov \\
Georgia & L. Labadze, M. Beenstock, N. Doghonadze, Y. Babych, and G. Mzhavanadze \\
Kazakhstan & S. Alpysbayeva \\
Kyrgyz Republic & L. Yugai, S. Ryskulova, A. Puzikova, I. Abdieh, and E. Karpovich \\
Tajikistan & F. Muminova and G. Rasulov \\
Turkmenistan & Y. Aronskiy and R. Mogilevskyi \\
Uzbekistan & U. Aliev
\end{tabular}

\section{Employment and Labor Market Policies}

$\begin{array}{ll}\text { Country } & \\ \text { Armenia } & \text { V. Baghdasaryan and A. Grigoryan } \\ \text { Azerbaijan } & \text { S. Hajiyev } \\ \text { Georgia } & \text { M. Beenstock, Y. Babych, M. Chitanava, and L. Labadze } \\ \text { Kazakhstan } & \text { B. Akmoldina } \\ \text { Kyrgyz Republic } & \text { I. Lukashova and R. Mogilevskyi } \\ \text { Tajikistan } & \text { F. Muminova } \\ \text { Turkmenistan } & \text { Y. Aronskiy } \\ \text { Uzbekistan } & \text { M. Ahunov }\end{array}$




\section{Enabling Conditions for Inclusive Growth}

$\begin{array}{ll}\text { Country } & \\ \text { Armenia } & \text { V. Ghushchyan and N. Ohanyan } \\ \text { Azerbaijan } & \text { S. Jafarov } \\ \text { Georgia } & \text { Y. Babych, G. Mzhavanadze, and M. Beenstock } \\ \text { Kazakhstan } & \text { B. Aidarkhanova } \\ \text { Kyrgyz Republic } & \text { Z. Kudabaev } \\ \text { Tajikistan } & \text { H. Kholiknazar and F. Muminova } \\ \text { Uzbekistan } & \text { B. Mirkasimov }\end{array}$

\section{Responding to External Shocks Hitting the Economy}

$\begin{array}{ll}\text { Country } & \\ \text { Armenia } & \text { A. Nurbekyan, A. Shirkhanyan, and M. Galstyan } \\ \text { Azerbaijan } & \text { H. Hasanov } \\ \text { Georgia } & \text { E. Bochorishvili } \\ \text { Kazakhstan } & \text { O. Khudaibergenov } \\ \text { Uzbekistan } & \text { R. Salahodjaev }\end{array}$

\section{Background Thematic Papers}

\section{Title}

The Evolution of Employment and Occupational Structures in the Countries of the South Caucasus and Central Asia

Labor Markets and Good Jobs in the South Caucasus and Central Asia

Improved Indicators for Income Inequality Using Asset Indexes and Dichotomous Variables:

The Case of Central and Western Asia

Confronting Gender Inequality in Central Asia and the South Caucasus: Issues and Policies

Gender and Employment in Central and West Asian (CWA) Countries

Education and Skills in Central and West Asia

Policy Options for Promoting Inclusive Growth through SME Development in Central and West Asia

Structural Transformation in Central and West Asia

\section{Author(s)}

D. Campbell and R. Efendiyev

D. Campbell and P. Ronnås

J. Deutsch, J. Silber, and G. Wan

E. Duban

R. Efendiyev

S. Elci

R. Francisco and J. Farinha

M. Fuenfzig 


\section{Title}

Remittances in Central Asia and the South Caucasus

Growth Performance and Prospects of the Countries of Central Asia and the South Caucasus

Spatial Inequality in Central and West Asian Countries and Policy Options for Balanced Regional Development

Promoting Inclusive Growth through Health Development in Central and West Asia

Recent Social Protection Indicator in Central and West Asia

Promoting Good Jobs for Inclusive Growth through Energy Projects in Central and West Asia

Economic Growth in Central and West Asia

Promoting Inclusive Growth through Private Sector Development Projects

Economic Corridors in Central and West Asia

Key Trends and Issues of Labor Migration in Central and West Asia

Evolution of Economic Institutions and Governance in Central Asia and South Caucasus

Multidimensional Poverty Analysis for Armenia

Promoting Good Jobs for Inclusive Growth through Agricultural and Natural Resource Projects in Central and West Asia

Job Market Institutions and Regulatory Frameworks in Central and West Asia

Good Jobs for Small and Medium-Sized Enterprises

Emergent Themes for Education and Skills Development for Inclusive Jobs in Central and West Asia

\section{Author(s)}

B. Ganiev

B. Ganiev and D. Yarcia

T. Gokan and S. Kumagai

G. Gotsadze and M. Counahan

S. W. Handayani

D. Hankinson and K. Mitsuhashi

K. Hong

S. Hovhannisyan and A. Torres

F. Irnasarov

F. Irnasarov

D. Lewis

P. Mukhopadhaya and A. Grigoryan

A. J. A. Quilloy and G. M. Bui

P. Ronnås

R. Vakulchuk

T. Weyman and C. Martinez 


\section{Good Jobs for Inclusive Growth in Central Asia and the South Caucasus Regional Report}

This study explores prospects for inclusive growth in the Central Asia and the South Caucasus region and highlights the central role played by the creation of good jobs. The study reviews economic performance in the region and discusses prospects through 2030, introducing two growth scenarios related to the adoption of structural reforms for creating good jobs and inclusive growth. It also highlights the importance of adopting a full policy reform scenario.

\section{About the Asian Development Bank}

ADB is committed to achieving a prosperous, inclusive, resilient, and sustainable Asia and the Pacific, while sustaining its efforts to eradicate extreme poverty. Established in 1966, it is owned by 67 members48 from the region. Its main instruments for helping its developing member countries are policy dialogue, loans, equity investments, guarantees, grants, and technical assistance. 